\title{
Wolf Listening:
}

Acoustemological Politics and Poetics of Isle Royale National Park

\author{
Erik Ian DeLuca
}

M.A., University of Virginia, 2011

M.M., Florida International University, 2009

B.S., University of North Florida, 2007

A Dissertation presented to the Graduate Faculty

of the University of Virginia in Candidacy for the Degree of Doctor of Philosophy

Department of Music

University of Virginia

May, 2016 
(C) 2016 Erik Ian DeLuca

All rights reserved 


\begin{abstract}
Listening to wolf howls as both material object and socially constructed metaphorinfinitely interpretable, ideologically malleable, and ultimately based on particular values, biases, and cultural ideas-highlights the contested relationship between nature and culture. The author conducted field research on Isle Royale National Park from 2011-15, from which he offers a narrative wherein citizen-scientists listening for the howl literally "lend their ears" to a wolf biologist who has led the longest continuous wildlife study in the world. This listening community and its web of meaning — an interwoven tangle of national park politics and policies, wilderness ideology, environmental ethics, and global climate change-will be introduced in this dissertation as a rethinking of environmental aesthetics, as art in the anthropocene. This dissertation discusses acoustic epistemologies (acoustemologies) and sonic environments in the political world of Isle Royale National Park as a form of music in everyday life. The theoretical framework of this dissertation, therefore, extends acoustic ecology—which is often intended to provide the scientific justification behind the preservation of nature - to include environmental history, and cultural theory_—which problematizes definitions of 'nature' and 'natural'—- to ultimately describe a nuanced form of participatory, situational environmental music that plays out in the everyday lives of those listening on this remote, roadless island in Lake Superior-a location where the nature/culture dialectic (as opposed to a dualism) is critically engaged.
\end{abstract}




\section{Contents}

Acknowledgement ............................................... 01

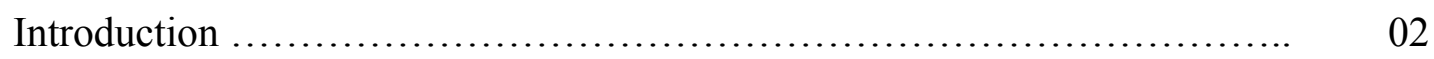

The Iconic Howl .............................................. 04

Quasi-object ................................................... 05

A Brief History of Isle Royale as a Wilderness National Park .............. 08

Notebook Entry: Noise in Silence $\ldots \ldots \ldots \ldots \ldots \ldots \ldots \ldots \ldots \ldots \ldots \ldots \ldots \ldots \ldots \ldots \ldots$

Natural Sound in Law............................................ 18

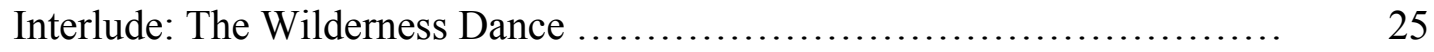

Citizen-Science in Sound .......................................... 27

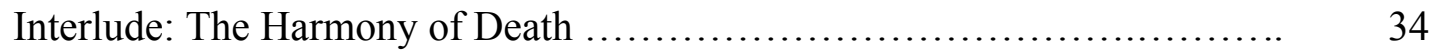

The Politicized Wolf ........................................... 36

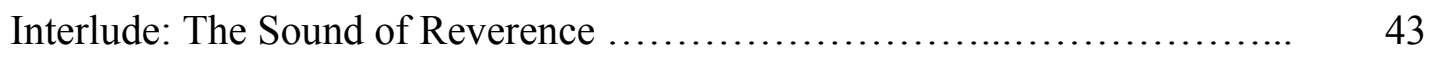

Discussing Natural Sound in Law .................................. 45

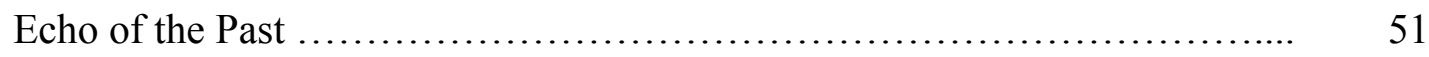

Interlude: The Yawn/Wolves as People ............................. 54

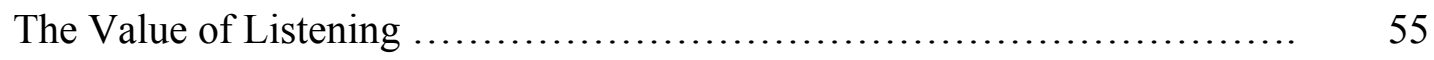

Transition: From Wilderness to Music ............................... 64

The Last Boat Out: to Empathy in Nature ........................... 69

Coda: Rethinking Environmentalism through Music .................... 79

Appendix A: Conversation with Kurt Fristrup........................ 82

Appendix B: Discussing Fieldworks and Representation.................. 89

Appendix C: Wolf Listeners: An Adventure Through Sound................ 94 
Appendix D: Portfolio of Musical Works.................................. 95

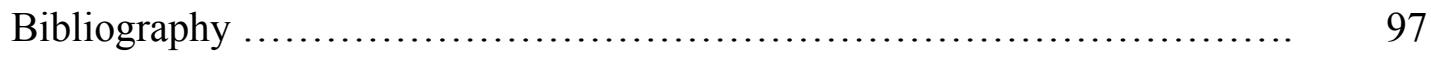




\section{Acknowledgement}

A few written words cannot express how important the people in the McIntire Department of Music at the University of Virginia were in my growth as a composer, sound artist, sound studies scholar, and most importantly, as a human being. One pillar that I feel binds this community is our ability to nurture the scholarship and art that we love. Personally, my dissertation committee chair, Matthew Burtner has supported my shifting interests during my time at UVa. My mentor, Michelle Kisliuk taught me about the importance of being a critically aware artist, scholar, and teacher. My mentor, Ted Coffey, among so many things, taught me the importance of my unique past as it plays out in the present, to the future. My outside reader, Jim Igoe, introduced me to a new batch of environmental history and cultural theory that made the theoretical framework of this dissertation more robust. Most of the undergraduate students that I taught at UVa and my fellow graduate students in both the Critical and Comparative Studies and Composition and Computer Technologies inspired and pushed me. I also owe much thanks to the department staff for making sure that I was organized. I am grateful of my Isle Royal friends for accepting me into their community: Rolf and Candy Peterson, the Gales, and all the Isle Royale National Park employees and park visitors that I conversed with on the trail. I am grateful for the financial support that I received to complete this project: Fickenscher-Pace Fellowship, OpenGrounds Art and Environmental Action Student Scholarship, Digital Humanities Scholars Lab Fellowship, Buckner Clay Fellowship, Arts Humanities and Social Science Summer Research Fellowship, Robert J. Huskey Travel Fellowship, GSAS and UVA's Society of Fellows Travel Grant, Double Hoo Grant, Raven Fellowship, and the National Park Service. Last but not least, I owe endless amounts of gratitude to my family for encouraging me to follow my passion in life-music. 


\section{Introduction}

But if we listen closely, we human beings can learn a great deal from the tales we tell of such a place. This silent rock, this nature about which we argue so much, is also among the most important things we have in common. That is why we care so much about it. It is, paradoxically, the uncommon ground we cannot help but share. ${ }^{1}$-William Cronon (environmental historian)

This dissertation, an ethnography of listening, has at its foundation my own past as a composer and fieldwork artist ${ }^{2}$ who made music which emerged from seven official Artist-inResidence positions in the National Park Service from 2010-2015. ${ }^{3}$ This body of work fell within the realm of landscape, environmental art that uses sound and other "natural" objects framed ${ }^{4}$ as artistic forms of environmental activism. Art historian Malcolm Andrews, in his book Landscape and Western Art, said:

Landscape in art, as conventionally conceived and executed, is a framed representation of a section of the natural world, a cropped view, selected and reduced so that it can be a portable memento of an arresting or pleasing visual experience of rural scenery. The implication is that landscape art doesn't happen in nature; landscape art is an abstraction from, and appropriation of, nature such that, once the process has issued in an art object, one might say (point to the land) 'there is the original', and (pointing to the painting or photograph) 'here is the artist's representation'. The distinction bestows a mystique on the 'original', a different kind of value on the artifact, and generates a tension of a dialectic between the two. The investigation of the point at which land become landscape raises questions about where the artistic engagement with the site begins and ends. [This] indoors-outdoors duality [determines] the constitution of landscape as that sense of something beyond our domesticating reach, [which has been] interpreted and engaged with landscape since the Renaissance. ${ }^{5}$

This pursuit - recording my ideas of nature and communicating them through music, a one-way communication or a secondary orality ${ }^{6}$ - lacks the kind of intersubjective relationships that I

found with Isle Royale National Park acoustic epistemologies (acoustemologies). Most

importantly, this music perpetuated the very contradictory nature/culture dualisms that it initially attempted to breakdown. This problem is concisely summarized in a notebook entry from 2011, written from the Daisy Farm campground on Isle Royale National Park:

\footnotetext{
${ }^{1}$ Cronon, "Introduction," (1995), 56.

2 see Appendix B: Discussing Fieldworks and Representation. This appendix is an edited conversation with fieldwork artist, Charles Stankievech. We traverse many issues related to artistic representation.

${ }^{3}$ see Appendix C: Portfolio of Musical Works

${ }^{4}$ Tia DeNora, Music in Everyday Life (Cambridge: Cambridge University Press, 2000), 27.

${ }^{5}$ Malcolm Andrews, Landscape and Western Art. (Oxford: Oxford University Press, 1999), 201-02.

${ }^{6}$ Le Guin, 194.
} 
The maintenance crew is trimming trees. This can't be natural. And if this isn't natural, and my intention with this piece of music is to bring awareness to nature, then what am I actually going to bring awareness to?

During this moment I suddenly realized that my artistic inspiration—wilderness, was not the solution to our "culture's problematic relationship with the nonhuman world" 7 because of the history from which it sprang. Environmental Historian William Cronon writes:

It is not a pristine sanctuary where the last remnant of an untouched, endangered, but still transcendent nature can for at least a little while longer be encountered without the contaminating taint of civilization... Instead, it is a product of that civilization, and could hardly be contaminated by the very stuff of which it is made. Wilderness hides its unnaturalness behind a mask that is all the more beguiling because it seems so natural. As we gaze into the mirror it holds up for us, we too easily imagine that what we behold is Nature when in fact we see the reflection of our own unexamined longings and desires. ${ }^{8}$

A critique of any kind of environmental music may be read as hostile, mocking, or even authoritarian to the general cause of environmentalism. ${ }^{9}$ Ultimately though, "right" and "wrong" ideas about how environmental music should exist in the world are relative to an individual's values. I value the idea that rethinking and reconstructing our relationship with the natural world through music today could produce a dialogue where questions about the nature/culture dualism are confronted. I am not arguing that environmental music is "bad"; I am actually advocating for it. Nature is a "contested terrain" where many visions rub against one another, "each claiming to be universal." ${ }^{10}$ A critical reflection of nature - in a context which includes an understanding of its autonomy — will make the important relationships between the human and the nonhuman more just and more accountable.

\footnotetext{
${ }^{7}$ Cronon, "The Trouble with Wilderness," (1995), 70.

${ }^{8}$ Cronon, "Introduction," (1995), 52.

${ }^{9}$ Gregory Bateson, Mind and Nature: A Necessary Unity (New York: Dutton, 1979) 26.

${ }^{10}$ Cronon, "Introduction," (1995), 52.
} 


\section{The Iconic Howl}

About 20 years ago I brought a Boy Scout troop up here. We were at the center of the island and we heard two wolf packs howling at each other, before they finally came together. For an hour we sat and listened to wolf calls. I see some of those scouts today — they are approaching middle age — and they still say, 'Do you remember that night we listened to wolves? ${ }^{, 11}$ - Isle Royale National Park Visitor

Humans have long had a special interest in wolves. ${ }^{12}$ Wolves are the subject of myth and legend, folklore and fairy tale. ${ }^{13}$ They have been both persecuted and protected. From birth wolves are socially vocal. They make short-range and long-range sounds that are both harmonic and noisy; they moan, whine, squeak, yelp, scream, snarl, bark, growl, and yawn. With each type of sound, wolves convey mood and meaning. A particularly illuminative example is the woof, which is used to communicate a need for defense: pups respond to adult woofs by returning to the den, whereas nearby adults are alerted to defend. ${ }^{14}$ But perhaps the sound most known by humans is the wolf howl. They howl as individuals and in pack choruses, which can be both harmonious and discordant. As characterized by wolf biologists Cheryl Asa and Fred Harrington, the howl evolved in response to the environment through which it traveled. A variety of climate factors - including temperature, humidity, precipitation, and noise - affect the fidelity and range of the howl while features of the landscape further scatter and attenuate the sound. Some of the most important causes of "signal distortion" influence primarily higher frequency sounds.

Consequently, the howl has evolved into a lower-pitched, harmonically simple, modulating (low, high, low) signal. This sound — which can travel up to ten miles — is the wolf's primary form of long-distance form of communication. ${ }^{15}$

\footnotetext{
${ }^{11}$ Isle Royale National Park visitor. Personal Interview. 2013.

${ }^{12}$ D. Mech, and L. Boitani, Wolves: Behavior, Ecology, and Conservation (Chicago: University of Chicago Press, 2003) 333.

${ }^{13}$ D. Mech, and L. Boitani, xvii.

${ }^{14}$ D. Mech, and L. Boitani, 74.

${ }^{15}$ D. Mech, and L. Boitani, 76.
} 


\section{Quasi-object (part natural, part cultural)}

"When you go somewhere be thankful for what you have and hope it's natural and real and it's not tinkered with and manipulated." — Seth DePasqual (Isle Royale National Park Cultural Resource Manager)

Wolves howl, and people listen. As characterized by Geographer Neil Smith, nature is as much a material object as it is a spiritual force - at once a gift of God and a product of its own evolution; it is both given and made, a totality and a series of parts. ${ }^{17}$ Likewise, the howling message of a wolf is both a material object and a socially-constructed metaphor that is infinitely interpretable and ideologically malleable based on the hearer's own values, biases, and cultural ideas. ${ }^{18}$ As anthropologist David Harvey explains, "the framework of interpreting nature is given in the metaphor rather than in the evidence." ${ }^{\prime 19}$ For example, the Oxford English Dictionary uses the words "mournful cry" to describe the howl-representing the sound as melancholic. ${ }^{20}$ However, wolves are not "crying," but rather howl to socially bond, to rally, or to mark territory. Western society's interpretation of the wolf howl is directly tied to "ways of seeing landscape," a sonification of nature which assigns meaning in a method similar to scenery or religious monuments. $^{21}$

Bifurcations of the landscape into the practical and the aesthetic can be traced back to $18^{\text {th }}$-century English landscape parks that emerged from a wealthy class of landowners. This division separated the observer from the land, implying both a sense of ownership and control. Geographer Roderick Neumann explains, "The great landscape parks of England were, in

\footnotetext{
${ }^{16}$ Seth DePasqual. Personal Interview. 2013.

${ }^{17}$ Neil Smith, Uneven Development: Nature, Capital, and the Production of Space (New York, NY: Blackwell, 1984) 11.

${ }^{18}$ Paul Cloke, Chris Philo, and David Sadler, Approaching Human Geography: An Introduction to Contemporary Theoretical Debates (New York: Guilford Press, 1991), 192.

${ }^{19}$ David Harvey, The Condition of Postmodernity: An Enquiry into the Origins of Cultural Change (Oxford England: Blackwell, 1990), 163.

${ }^{20}$ OED Online, howl (Oxford University Press, September 2015).

${ }^{21}$ Denis Cosgrove, Social Formation and Symbolic Landscape (Madison, Wis: University of Wisconsin Press, 1998), xiv.
} 
essence, idealized representations of nature, based on paintings." 22 The postmodernist approach to the landscape - that nature is something "other" than human culture — has been linked to Greek and Roman history where the human mind was viewed as something superior than any other in nature. ${ }^{23}$ After nature was placed "out there," individuals and groups continued to spend time trying to decide how, where, when, and what should be done with it.

Rather than trying to uncover the inherent nature of nature, so to speak, all one can do is represent it and accept that our representations are both politically-influenced and culturallybiased. William Cronon observes:

The work of literary scholars, anthropologists, cultural historians, and critical theorists over the past several decades has yielded abundant evidence that "nature" is not nearly so natural as it seems. Instead, it is a profoundly human construction. That is not to say the nonhuman world is somehow unreal or a mere figment of our imagination - far from it. But the way we describe and understand the world is so entangled with our own values and assumptions that the two can never be fully separated. ${ }^{24}$

The concept of "wilderness" - which is both a place and a mental state, a material and an idea, ultimately rooted in the frontier myth and the sublime - is a powerful example of the trouble with the nature/culture dualism. Cronon writes:

The removal of Indians to create an "uninhabited wilderness" reminds us just how invented, just how constructed, the American wilderness really is...there is nothing natural about the concept of wilderness. Indeed, one of the most striking proofs of the cultural invention of wilderness is its thoroughgoing erasure of the history from which it sprang. ${ }^{25}$

If there is one iconic place in the United States where individuals and the State attempt to define nature, it is in the National Park System (NPS):

\footnotetext{
${ }^{22}$ Roderick Neumann, Ways of Seeing Africa: Colonial Recasting of African Society and Landscape in Serengeti National Park (Cultural Geographies (formerly Ecumene). 2.2 (1995): 149-169), 152.

${ }^{23}$ Denis Cosgrove, and Stephen Daniels, The Iconography of Landscape: Essays on the Symbolic Representation, Design, and Use of Past Environments (Cambridge England: Cambridge University Press, 1988). Glacken, Clarence J. Traces on the Rhodian Shore: Nature and Culture in Western Thought from Ancient Times to the End of the Eighteenth Century (Berkeley: University of California Press, 1967).

${ }^{24}$ William Cronon, “Introduction: In Search of Nature," Uncommon Ground: Toward Reinventing Nature (New York: W.W. Norton \& Co, 1995) 25.

${ }^{25}$ William Cronon, "The Trouble with Wilderness; or, Getting Back to the Wrong Nature," Uncommon Ground: Toward Reinventing Nature (New York: W.W. Norton \& Co, 1995) 79.
} 
National parks would seem to be as much about the nature of national identity as about physical nature. If this is so, they should be able to tell us a lot about ourselves as Americans, a lot about the way we interact with each other and our environment. When seen in this light, parks become places where we "reinvent nature" in our own image, and hence good places to study the reflections of that image. ${ }^{26}$

And Isle Royale National Park — $99 \%$ of which is designated under the Wilderness Act of 1967 - is a place where the nature/culture dualism is audible. On this roadless island in the northern section of Lake Superior, wolves - who live on, around, and in-between the nature/culture schism-howl and people listen. ${ }^{27}$

\footnotetext{
${ }^{26}$ Kenneth Olwig, "Reinventing Common Nature: Yosemite and Mount Rushmore-A Meandering Tale of a Double Nature". In Uncommon Ground: Toward Reinventing Nature, William Cronan, ed., (New York: W.W. Norton and Company) 380.

${ }^{27}$ Wockner, 218.
} 


\section{A Brief History of Isle Royale as a Wilderness National Park}

Whatever the advantages of a particular landscape people always seem to reshape it according to their vision of what it should be. ${ }^{28}$ - William Cronon

As we float from the dock, the captain of the Ranger III - the largest piece of moving equipment owned and operated by the NPS — sounds the air horn, signaling the Portage Lake Lift Bridge operator ahead to make room for us to slither the rest of the way down the Keweenaw Peninsula. Ten miles from Houghton, Michigan and an hour later, we pass through the breakwall and two lighthouses. At the bow of the ship, all I can see are two colors, the abnormally calm turquoise water of Lake Superior, and — broken by the horizon — the endless deep blue of the sky. Gradually separating from the mainland, we follow the ferry route for sixty miles through the largest lake in the world. Sitting on the horizon ahead, a strip of land gets bigger and bigger before us, while, to the south, the Upper Peninsula becomes featureless and opaque in a scrim of fog. Staring north, we begin to make out features of the southern shore of the isolated 210square-mile island, closed off by the icy waters of Lake Superior. We have been on the water now for six hours; a fellow passenger on the Ranger III vessel plays "Amazing Grace” on the fiddle as the opening of Chippewa Harbor and Saginaw Point comes into view off the portside. The balsam fir, white spruce, paper birch, and aspen of the Boreal forest show their fall colors. As we pass through the breakwall at Middle Island Passage, with the old Edison Fishery on the left and the Rock Harbor lighthouse on the right, I can make out the defunct fire lookout on top of Mount Ojibwa - a craggy mountain that a billion years ago poked out from the midcontinent rift system. We travel another seven miles down the harbor, I grab my pack and as soon as we dock, I break for the trail. I'm back on Isle Royale, called Minong in the language of the Ojibwe tribe. I head west and begin walking the familiar trail to Daisy Farm, eight miles ahead.

28 William Cronon, Nature's Metropolis: Chicago and the Great West (New York: W.W. Norton, 1991) 55. 
My first trip to the island in 2011 had been as the park's Artist-in-Residence. When I disembarked the Ranger III that time, instead of walking west to Daisy Farm, I headed east. My chaperone Jack Gale and I ferried a little fifteen-foot skiff around Scoville Point to the cottage I was assigned to live in — which was built in 1905 by the Dassler family. That night, I walked the two miles back to the Rock Harbor center on the Stoll trail—almost stumbling into a moose and her calf - to attend a park program on the now 58-year-long Wolf-Moose Project. John Vuesetich, the project's co-leader, ended the presentation with a riff on Voltaire saying, "The more you know, the less you understand." Little did I know that this place, the Wolf-Moose Project, and this Voltairean truth would dominate my thoughts for the next five years.

In 1970, aspiring biologist Rolf Peterson went to Isle Royale as a graduate student to assist wildlife ecologist Durward Allen to continue the twelve-year study of wolves and moose on the island. 45 years later, Peterson has stayed on as the leader of that study, making it the longest continuous research project—almost six decades—of any predator-prey system in the world. For ecologists, as Peterson points out, "the island has been viewed as a natural system simple enough to be understood, even predictable to a degree, yet large enough to be instructive as a microcosm, or a smaller version of the world. ${ }^{29}$ Along with the rest of his team, Peterson seeks to understand the ecology of predation in this microcosm and what knowledge about our own relationship with nature might develop from that understanding. Central to this study are the wolves that arrived on Isle Royale for the first time around 1949, finding their way twenty miles across Lake Superior on an ice bridge from Ontario. As famed wolf biologist Dave Mech explains, “...the island was ideal for wolves. It supported a moose herd that for a half century

\footnotetext{
${ }^{29}$ Rolf Peterson. The Wolves of Isle Royale: A Broken Balance (Ann Arbor: University of Michigan Press, 2007) 18.
} 
had never felt a fang of a wolf. The right combination of wandering mainland wolves and a solid ice bridge to the island apparently only happened once."30

Jack Gale and his cousin Chris ferried me to Passage Island - the northeastern-most point of the archipelago, seven miles away from Scoville Point. As we docked on the island, I witnessed an intense family discussion about the cultural history of Isle Royale: Drawing on his own experience, Chris explained, “They [the Park Service] just don't understand the importance of the families that lived here before the park was established." ${ }^{, 31}$ In the early 1930s, Chris and Jack's great-grandfather Alfred and his daughter (their grandmother) Alfreda traveled to Isle Royale to stay with friends in Tobin Harbor. The following summer, Alfred bought Chicken Island, which was the former chicken pen for the hotel that used to sit on Minong Island. Today, Minong Island houses the Tobin Harbor mail dock where Tobin Harbor residents receive their mail. The commercial fisherman Art Mattson—a second-generation Finland Swede_-supervised teenage brothers John and Phil Gale, Alfreda's children who would later become Jack and Chris's fathers, on the construction of the cabin that still sits on the island today. Chris flew to the Island on a specialized J-3 Cub on Floats plane for the first time in 1948, when he was just three months old and he's been back to Gale Island every year since.

During my time on the island in 2011, the Gale brothers helped me to contemplate the invisible convoluted history of Isle Royale — a history defined in the early twentieth century by the establishment of the Wilderness Act, social and political movements that grew from the new automobile industry, logging, mining, and a resulting newfound environmental awareness. Historically, Isle Royale is defined by people like the Gales and the Native Americans who seasonally lived there since 6000 BCE. With the 1842 Treaty of LaPointe, the United States took

\footnotetext{
${ }^{30}$ Rolf Peterson. The Wolves of Isle Royale: A Broken Balance (Ann Arbor: University of Michigan Press, 2007$) 11$.

${ }^{31}$ Chris Gale. Personal Interview. 2011.
} 
control of the island from the Ojibwa, and by the early 1860s boats were taking tourists to the island for afternoon picnics. ${ }^{32}$ Soon after, the 1872 Yellowstone Act was passed to set apart the land lying near the headwaters of the Yellowstone River as the world's first national park to be enjoyed by people. The Transcendentalists, for example Ralph Waldo Emerson and Henry David Thoreau, wrote about these sublime landscapes with vivid descriptions that celebrated their "power." Their words took the physicality of the environments they were experiencing, and the emotions they evoked, and "transmuted it into an icon of the sublime: a symbol of God's presence on earth." Environmentalist, John Muir wrote descriptions of Yosemite that reflected none of the "anxiety," "terror," and "satanic temptation" that earlier writing conveyed. Instead, they depicted these landscapes as "sacred temples" and made them accessible through the Penny press. The idea of the sublime became domesticated..$^{33}$ In 1871, Muir published his first writing, "Yosemite Glaciers," in the New York Tribune:

In the waning days of this mountain ice, when the main river began to shallow and break like a summer cloud, its crests and domes rising higher and higher, and island rocks coming to light far out in the main current, then many a tributary died, and this one, cut off from its trunk, moved slowly back amid the gurgling and gushing of its bleeding rills, until, crouching in the shadows of this half-mile hollow, it lived a feeble separate life. Here its days come and go, and the hiding glacier lives and works.

Isle Royale's protected national park designation would follow Yellowstone soon after, but not without an aggressive public battle between loggers, the government, and islanders like the Gales.

By the 1920s, six resorts had established themselves on Isle Royale. The Industrial Revolution made the United States an increasingly urban country through major changes in agriculture, manufacturing, mining, transport, and technology. With this urban living, people began to look at nature through a different, more-romanticized lens. In her book Becoming

\footnotetext{
${ }^{32}$ Amalia Tholen Baldwin. Becoming Wilderness: Nature, History, and the Making of Isle Royale National Park (Houghton, Mich: Isle Royale \& Keweenaw Parks Association, 2011) 5-6.

${ }^{33}$ Cronon (1995), 75.
} 
Wilderness, author Amalia Baldwin points out that, "to many nature tourists, remote Isle Royale, with its moderate climate, clean air and water, abundance of fish, and unspoiled forests, offered the perfect getaway from their troubled city life." ${ }^{34}$ In other regions, the appeal of the outdoors was enhanced by the affordability of automobiles and new highway infrastructures. States began to capitalize on this newly sought after craving for an accessible, but still perceived as wild, nature, often marketing their parks as "virgin." 35 It is this craving for nature in an increasingly industrialized society that brought the Gales and so many others to Isle Royale.

However, after hearing of a pulpwood claim that would lead to the clear cutting of large sections of the same territory, Isle Royale cottagers like the Gales and resort owners became defensive of their island. The islanders argued that this clear cutting would potentially ruin the "virgin" character of the island forest — which at the time was unique in comparison to the logged-out Upper Peninsula. Albert Stoll, Detroit News' conservation editor, heard about this potential threat to Isle Royale and began visiting and writing regular articles advocating for the islanders - both in terms of the economic interests of the resort owners and the environmental values of the cottagers. As Baldwin points out, for Stoll and the islanders "saving Isle Royale in the 1920s meant saving a piece of Michigan's once-great forest. And the NPS, with its mission of 'preservation,' seemed just the agency to do it.",36

After the success of the Yellowstone Act, lawmakers were eager to ensure the protection of more "natural" and "historic" American land from industrialization and development through the creation of a government agency specifically to do just that. On August 25, 1916, President Woodrow Wilson signed the Organic Act into law, establishing the National Park Service (NPS) as an agency of the United States Department of Interior:

\footnotetext{
${ }^{34}$ Baldwin, 15.

35 Baldwin, 22.

${ }^{36}$ Baldwin, 23-24.
} 
The service thus established shall promote and regulate the use of the Federal areas known as national parks, monuments, and reservations hereinafter specified by such means and measures as conform to the fundamental purpose of the said parks, monuments, and reservations, which purpose is to conserve the scenery and the natural and historic objects and the wild life therein and to provide for the enjoyment of the same in such manner and by such means as will leave them unimpaired for the enjoyment of future generations. $^{37}$

Fifteen years later, as the national park experience took hold, people across the country were expressing their irritation in newspapers with the automobile congestion that plagued their new park infrastructure. In response, Isle Royale's untouched forest with no roads became something to praise and protect. Around the same time, Aldo Leopold—now famed environmental ethicist—started to define wild nature with a new word: "wilderness." With remarkable specificity, Leopold argued that wilderness is "a continuous stretch of country preserved in its natural state, open to lawful hunting and fishing, big enough to absorb a two-week pack trip, and kept devoid of roads, artificial trails, cottages, or other works of man."38 Through his work, Leopold helped to establish a movement that regarded the nation's protected areas as land that should be preserved and unchanged by humans. ${ }^{39}$

On March 3, 1931, President Herbert Hoover signed a bill that designated Isle Royale as a national park once the state of Michigan procured the land. Private parties like the Gales, however, owned most of Isle Royale. The Park Service has a long history of removing people that live within park boundaries by using the authority stated in the Yellowstone Act that "all persons who shall locate or settle upon or occupy the same, or any part thereof, except as hereinafter provided, shall be considered trespassers and removed therefrom.. ${ }^{, 40}$ As Baldwin elaborates, "The precedent had been set when the United States Army removed American Indians from the first national park, Yellowstone, and the Park Service continued the practice

\footnotetext{
${ }^{37}$ The National Park Service Organic Act (16 U.S.C. 12 3, and 4).

${ }^{38}$ Aldo Leopold. The Wilderness and Its Place in Forest Recreation Policy. (Journal of Forestry 19(7), 1921) 718721.

${ }^{39}$ Roderick Nash. Wilderness and the American Mind. (New Haven: Yale university press, 1973) 182-200.

${ }^{40}$ Baldwin, 25.
} 
after its initiation in 1916." ${ }^{\prime 1}$ On the east coast, families that had lived in Shenandoah and the Great Smoky Mountains for generations were removed from their homes until resistance to the Park Service forced a change in policy. On the basis of a new 1932 bill modifying the original 1931 establishment of the Isle Royale National Park, the Park Service gave Isle Royale homeowners the option of selling their property or donating it in exchange for a life-lease_-and, in some cases, a lease for their children as well. A majority of Islanders, including Alfreda Gale and her two sons, opted for a life-lease. In April of 1940, the park acquired the last property and Isle Royale officially became a national park— $99 \%$ of which is now designated "wilderness.",42

Wilderness, however, is no longer broadly specified by individual and local settings, but rather determined according to a nationwide mandate. In 1964, Congress enacted the Wilderness Act written by environmental activist Howard Zahniser, which provided a specific definition of "wilderness":

A wilderness, in contrast with those areas where man and his own works dominate the landscape, is hereby recognized as an area where the earth and its community of life are untrammeled by man, where man himself is a visitor who does not remain. An area of wilderness is further defined to mean in this Act an area of undeveloped Federal land retaining its primeval character and influence, without permanent improvements or human habitation, which is protected and managed so as to preserve its natural conditions and which (1) generally appears to have been affected primarily by the forces of nature, with the imprint of man's work substantially unnoticeable; (2) has outstanding opportunities for solitude or a primitive and unconfined type of recreation; (3) has at least five thousand acres of land or is of sufficient size as to make practicable its preservation and use in an unimpaired condition; and (4) may also contain ecological, geological, or other features of scientific, educational, scenic, or historical value. ${ }^{43}$

When "wilderness" was designated on Isle Royale, as Chris Gale pointed out, "someone actually sat down with a pencil and drew the line." ${ }^{\prime 4}$ On one side of this line exists people like the Gales who value the cultural history of Isle Royale; on the other side, exists organizations like PEER (Public Employees for Environment Responsibility) and Wilderness Watch who value "untouched" nature.

\footnotetext{
41 Baldwin, 25.

${ }^{42}$ In addition, Isle Royale was designated as an UNESCO World Network Biosphere Reserve in 1980.

${ }^{43}$ United States. Wilderness Act. United States Statutes at Large. 78. 1964.

${ }^{44}$ Chris Gale. Personal Interview. 2011.
} 
Gale Island is now owned by the National Park Service. In 2008, Chris's father Phil died. He was the last remaining member on the life-lease that his mother Alfreda signed. "The majority of life-lease holders have passed away and most of their cottages are being consumed by the forest, ${ }^{, 45}$ Chris related to me. In his book Isle Royale: a Photographic History, Chris's brother Tom said that "the cabin and community in Tobin Harbor that formed so much of the families' traditions and values will disappear with time, as will evidence of the once-vital summer communities on the island. ${ }^{, 46}$ Under the Wilderness Act, the NPS is allowing for an overtly natural landscape to consume the island. While the actions of Isle Royale National Park Service officials indicate that they do not strongly value observing the cultural history of the island prior to the establishment of the island's NPS status, they do value the culture that today walks along a network of man-made trails. Such a reshaping of the landscape in response to evolving values is not particularly novel. As explained by Cronon, "whatever the advantages of a particular landscape, people always seem to reshape it according to their vision of what it should be. ${ }^{, 47}$ Phyllis Green, the Superintendent of Isle Royale, once told Chris that she had "never talked to anybody that wanted to keep these structures [cabins] except you. ${ }^{.48}$ Chris replied by saying that he had "never talked to anybody that wanted to remove these structures except you." ${ }^{49}$ This interaction reveals the crux of the idea of "wilderness," defined by lines that illuminate the separation of people, places, and their values.

Under the façade of "nature" — so greatly celebrated by the Park Service—exists a complicated entanglement of environmental ethics. The cabin on Gale Island is one of the only

\footnotetext{
${ }^{45}$ Chris Gale. Personal Interview. 2011.

${ }^{46}$ Thomas P. Gale and Kendra L. Gale. Isle Royale: A Photographic History (Houghton, Mich: Isle Royale Natural History Association, 1995) 1-15.

${ }^{47}$ Cronon, (1991), 55.

${ }^{48}$ Chris Gale. Personal Interview. 2011.

${ }^{49}$ Chris Gale. Personal Interview. 2011.
} 
standing tributes to the people who planted the seed of Isle Royale becoming a national park. For now, the Gales have been granted special-use permits that allows them to continue using their family's cabin. Their permit is contingent upon the family maintaining VIP (volunteers in the park) status as chaperones for the Artist-in-Residence while the Cultural Resource Management Plan is conducted by the park's archeologist and Cultural Resource Manager, Seth DePasqual. This plan - a review that explores the conflict of human occupation in wilderness cultural resources - is not the only representation of change that is putting Isle Royale at the forefront of NPS policy making. The park's most iconic species — the wolf — is rapidly dwindling in numbers due to genetic instability, a dramatic change some attribute to global climate change and others to natural ecological cycles on the island. 


\section{Notebook Entry: Noise in Silence}

Denali National Park, Artist-in-Residence, Winter Solstice 2011

The soundscape concept is complicated: as a component of my 3-week residency in the park, I skied 10miles from the park headquarters to the Savage Cabin where I was scheduled to stay for 9-days. Halfway through the ski, I noticed a slight burning sensation on several points of my body, so I stopped to check myself. I pulled out my water bottle from a down koozie and found the entire liter to be frozen solid; the peanut butter sandwich in my pocket was also a frozen brick. My friend Carl, an experienced Alaskan guide and photographer who accompanied me on the trip at the park's request, appeared to me as a small dot at the top of the incline ahead. When I reached him he nervously muttered, "The weather has dropped from negative 15 to negative 40. "He was deeply concerned-an emotion I had never before seen from himand he immediately skied ahead to maintain his body heat. He vanished into the white and a wave of anxiety-induced heat passed through my body-death, frostbite, and exhaustion filled the sounds of my thoughts. Alone in the timeless frozen landscape, all I could do was ski faster to keep my body temperature stable. I focused on my breathing, the periodicity of my skis gliding across the slick snow, and the comforting thought of my lifeline, a SPOT (an emergency locator beacon) that the park service had lent me. When I paused for a rest, in between my breaths, I heard nothing. In these moments of nothingness, I thought: is thinking listening to yourself? If so, then listening to oneself is a component of the soundscape. 


\section{Natural Sound as Law}

This is a heavily engineered landscape as far as sound goes - we have quiet hours, there are places in the park where certain kinds of sounds are prohibited - like quite/no-wake zones_in much the same way that trails are managed for certain kinds of values. As much as it is a place that is wild, and for a lack of a better term natural, it is a place where decisions have been made about the things to manage, the things to allow, and not to allow. I can tell you after working here for five years that it's a complicated collection of rules... ${ }^{50}$ - Lucus Wescott (Isle Royale National Park Interpretive Ranger)

The soundscape is a conceptual term that describes an acoustic space that surrounds listeners. To introduce this concept, as treated by the NPS, lets depart from Isle Royale for a moment: during the summer of 2012, I was the Artist-in-Residence at Grand Canyon National Park. During this residency, I became especially interested in the listening methods of park employees and scientists. For example, on the murky banks of the Colorado River at Phantom Ranch lies a wastewater treatment facility. As part of a maintenance routine, Gerome, the facility's sole operator, walks the plant every morning with his eyes closed, coffee in handlistening. Gerome was taught to listen for deviation in sound. For example, cavitation-a condition where small bubbles of vapor form and explode against the impeller - causes a pinging-like sound, as if marbles are trapped in the pump. New plant operators often use stethoscopes to train their ears to be able to pick out those sounds that should not be presentscraping, chirping, whining, or bumping. This way of listening has a certain aesthetic quality that involves unwanted sounds — noise — which the NPS vigorously tries to eradicate in their composed soundscape. During the month I spent researching Gerome's listening methods at the wastewater treatment facility_ purposely located right by the noisy waters of the Colorado River so as to mask the facility's generator noise - the Senate was in the process of passing a bill. The bill counteracted Grand Canyon National Park's efforts to enhance what they call, "natural quiet" in the park. The official statement from U.S. Senators John McCain and Jon Kyl read:

\footnotetext{
${ }^{50}$ Lucus Wescott. Personal Interview. 2013.
} 
We are pleased with the overflights provision in the conference agreement. It requires air tour operators to install noise reduction equipment and finally settles a protracted debate over what constitutes 'quiet' at Grand Canyon National Park. This legislation also thwarts a recent Obama Administration proposal to ban up to 77 percent of the Park from air tours, which would have killed hundreds of tourism jobs. That plan was deeply flawed and would have severely diminished a unique sightseeing experience. Fortunately, this provision ensures that visitors who might otherwise be unable to explore the Grand Canyon, particularly the elderly, disabled, and our nation's wounded warriors, will be able to continue to enjoy the Canyon in one of the most unique ways possible. The stunning beauty of the Grand Canyon should be shared among everyone, not locked away for a small group of activists demanding absolute quiet, everywhere, at all hours. ${ }^{51}$

In addition to illustrating how people of wealth, power, and social status define our culture's construction of nature, this bill highlights the issues associated with defining the subjective experience of listening to sounds. In this statement—beyond issues related to age, disability, and class — sight is valued over sound, with the focus of the bill on the commodification of overflight sightseeing, rather than on Obama's proposal to ban up to 77 percent of air tours.

The NPS's observation of sound is a new constituent of their resource management that aims to conserve specifically-identified resources for the enjoyment of public visitors. Each park individually identifies the resources that they value, which can include "scenic natural areas, historic or cultural structures or sites, unique natural formations, bodies of water or wildlife and wildlife habitats. ${ }^{, 52}$ The protection of the soundscape in national parks has been growing in popularity since the word "soundscape" first appeared in the NPS management policies of 1988. The manual states that "the National Park Service will strive to preserve the natural quiet and the natural sounds associated with the physical and biological resources of the parks (for example, the sounds of the wind in the trees or of the waves breaking on the shore, the howl of the wolf, or

\footnotetext{
${ }^{51}$ John McCain and Jon Kyl, "Statement by Senators McCain and Kyl on Passage of Grand Canyon Overflights Provision," http://www.mccain.senate.gov/public/index.cfm/press-releases?ID=397d18be-9be2-2453-2549ca956ee5f758 (June 2012).

${ }^{52}$ Nicholas P. Miller, "US National Parks and Management of Park Soundscapes: A Review" (Applied Acoustics. 69, no. 2 2008) 77-92.
} 
the call of the loon)..." ${ }^{53}$ In the 2006 Management Policies, the National Park Service included a more detailed section called Soundscape Management:

\subsection{Soundscape Management}

Park natural soundscape resources encompass all the natural sounds that occur in parks...Natural sounds occur within and beyond the range of sounds that humans can perceive, and they can be transmitted through air, water, or solid materials... The Service will restore to the natural condition wherever possible those park soundscapes that have become degraded by unnatural sounds (noise), and will protect natural soundscapes from unacceptable impacts. Using appropriate management planning, superintendents will identify what levels and types of unnatural sound constitute acceptable impacts on park natural soundscapes...In and adjacent to parks, the Service will monitor human activities that generate noise that adversely affects park soundscapes, including noise caused by mechanical or electronic devices. The Service will take action to prevent or minimize all noise that through frequency, magnitude, or duration adversely affects the natural soundscape or other park resources or values, or that exceeds levels that have been identified through monitoring as being acceptable to or appropriate for visitor uses at the sites being monitored. ${ }^{54}$

Natural sounds, quietness, and more recently "cultural sounds" have been observed in law as an important park resource. These resources are as clear a subject for park management, as is any other park resource. ${ }^{55}$ But how does the National Park Service identify what a natural or cultural sound is? How do they "manage" and "preserve" them? How do they protect the soundscape from "unacceptable impacts"? What qualifies as an "unacceptable impact"?

Acoustic ecologist Nicholas Miller says that to answer these questions the National Park Service will need to determine the "true objective of natural sounds preservation," the ambition to "limit the audibility of inappropriate sounds." $" 57$ Explained in more concrete terms, the Gales on Isle Royale, for example, consider the boat motor as an appropriate sound that melds with the true fabric of their Isle Royale soundscape. The NPS, by contrast, limits the use of this machine sound because it is against what they value as natural quiet. The NPS is not merely protecting the environment, but reshaping the environment "according to their vision of

\footnotetext{
${ }^{53}$ United States (Management Policies, 1988) 34.

${ }^{54}$ United States. Management Policies, 2006. Washington, D.C.: U.S. Government Printing Office, 2006.

${ }^{55}$ Miller (2008), 77-92.

${ }^{56}$ Miller (2008), 79.

${ }^{57}$ Miller (2008), 79.
} 
what it should be" 58 _ by limiting "use" of specific kinds of human-made sounds like boat motors. The "use" of sounds in parks as a resource has not been supported with the type of scientific evidence that the NPS values because of a lack of historical precedent and methodology. Moving forward Miller suggests that the NPS needs to think about the type of evidence that is needed to justify decisions about appropriate levels of human-produced sound and how that noise might affect humans and wildlife in parks.

To support and define its approach to the soundscape the NPS relies on the soundscape theories of acoustic ecologist and composer R. Murray Schafer. ${ }^{59}$ For both Schafer and the NPS, noise abatement is valued in the protection of ecosystem health ${ }^{60}$ and, for the NPS, visitor experience. ${ }^{61}$ The Natural Sounds and Night Skies Division-located within the Department of Natural Resources — quantifies the soundscape by identifying sound sources and monitoring long-term their sound pressure level (SPL) and frequency. However, this long-term monitoring is highly variable and raises many potential questions which have remained unanswered: Where are measurements taken and why? How long to measure for? In what season? What instruments should be used?

While analyzing these quantitatively and selectively measured patterns can determine how loud a human-produced sound is relative to other sounds defined as "non-human,"62 the quantification of the soundscape — even that based on any amount of "rigorously collected and

\footnotetext{
${ }^{58}$ Cronon (1991), 55.

${ }^{59}$ R. Murray Schafer, “The Soundscape: Our Sonic Environment and the Tuning of the World," Rochester, VT: Destiny Books, 1994.

${ }^{60}$ For an annotated bibliography of research on the impacts of noise on wildlife, see www.nature.nps.gov/sound/assets/docs/Wildlife_AnnotatedBiblio_Aug2011.pdf.

${ }^{61}$ For an annotated bibliography of research on the impacts of noise on visitors and soundscapes, see www.nature.nps.gov/sound/assets/docs/VisitorExperience_Soundscapes_AnnotatedBiblio_17Aug10.pdf.

${ }^{62}$ Proctor P. Reid and Steve Olson. Protecting National Park Soundscapes. Washington, DC: The National Academies Press, 2013.
} 
analyzed data (called science)" ${ }^{\prime 63}$ — cannot represent the experience of all individual listeners to the soundscape in parks. In the words of anthropologist Gregory Bateson: "Experience of the exterior is always mediated by particular sense organs and neural pathways. To that extent, objects are my creation, and my experience of them is subjective, not objective." ${ }^{64}$ However, the forms of qualitative soundscape research supported by this statement, as Miller points out, are viewed as too subjective by the NPS, if not entirely arbitrary. The NPS, like Schafer, understands the soundscape as an objectification of sound - a thing out there waiting to be tuned into. ${ }^{65}$ Instead, the NPS should also research the soundscape with the understanding that it is, in the words of anthropologist Tim Ingold, speaking from a phenomenological approach to perception, "a phenomenon of experience - that is, of our immersion in, and commingling with, the world in which we find ourselves...We do not touch the wind, but touch in it." ${ }^{\text {66 }}$ Accordingly, the NPS needs to find a middle ground in their perception of hearing inside and outside the soundscape. The NPS should consider listeners as both apart from the world and immersed in it, to include a mixture of aesthetics and technologies of objectification and subjectification. In this way, we ultimately need to think — to listen-beyond the notion of the soundscape. ${ }^{67}$

Until the NPS finds a way to understand visitor experiences of listening at a more nuanced level, the quantification of sound as the sole measure of the park's soundscape will continue to lead to an overly-simplified conception of soundscape and environment built on unstable assumptions about the human experience. ${ }^{68}$ For example, Grand Canyon National Park

\footnotetext{
${ }^{63}$ Miller (2008), 79.

${ }^{64}$ Gregory Bateson, Mind and Nature: a Necessary Unity, (New York: Dutton, 1979) 31.

${ }^{65}$ Stefan Helmreich, 2010. "Listening Against Soundscapes". Anthropology News. 51, no. 9.

${ }^{66}$ Carlyle, Angus. Autumn Leaves: Sound and the Environment in Artistic Practice. Paris, France: Association Double-Entendre in association with CRISAP, 2007.

${ }^{67}$ Helmreich, 1.

${ }^{68}$ Gramann, J. H. (1999). "The Effect of Mechanical Noise and Natural Sound on Visitor Experiences in Units of the National Park Service." Social Science Research Review, 1 (1), 1-16. Harrison, R. T., Clark, R. N., \& Stankey, G. H. (1980). Predicting Impact of Noise on Recreationists San Dimas Forest Service, U.S. Department of
} 
officials say that natural quiet will have been achieved when 50 percent of the park is absent of aircraft noise for 75-100 percent of the day. Miller builds on this notion, stating that in parks "if human-produced sounds are audible for less than five percent of the time, it is likely that most people will judge such a soundscape as relatively pristine or natural." ${ }^{, 69}$ While the results from these types of metrics might be valid within a given NPS policy, they lack descriptive power for a whole range of qualitative experience in regards to the sound: for example, one's perception of the five percent of unwanted sound experienced and how those sounds might affect the remaining $95 \%$ of the "pristine" soundscape experienced. No amount of data will determine when human-made sounds in parks are appropriate or inappropriate because individuals' sensitivity to sounds in parks is subjective, varies form location to location, and can depend on specifics like a given person's location and therefore degree of "remoteness." For some, humanmade sounds detract from the solitude they seek; for others, such human-made sounds in parks are desirable to combat feelings of isolation and insecurity.

The NPS overlooks crucial information by mainly focusing on the impacts of specific kinds of human-made sounds in policymaking. Looking to the future, Miller points out that, "before spending efforts on measurement or modeling, prudence suggests that decision makers should first decide how they want the parks to sound."70 This decision-which should reflect the values of not only NPS policymakers, but also park visitors — is highly variable and would benefit from an understanding of the socioesthetic situation of a place. Performance studies scholar Michelle Kisliuk, in her work on performance with the BaAka people of the equatorial

Agriculture. Jensen, M., \& Thompson, H. (2004). Natural Sounds: An Endangered Species The George Wright Forum 21(1), 10-13. Pilcher, E. J., Newman, P., \& Manning, R. E. (2008). "Understanding and Managing Experiential Aspects of Soundscapes at Muir Woods National Monument." Environmental Management, 43(3), 425435.

${ }^{69}$ Miller (2008), 79.

${ }^{70}$ Miller (2008), 80. 
rainforest of Central African Republic, emphasizes "the elements of experience and interaction, leaving room for choice, irony, contradiction, and surprise." ${ }^{71}$ As expressed in Kisliuk's ethnography, understanding a place through socioesthetics allows the particulars of time and place, "the variability of social situations, the possibility of internal contradictions, and the immediate, multiplex consequences of power politics" to emerge. ${ }^{72}$ On Isle Royale, the socioesthetics of the soundscape - focusing particularly on the wolf howl-allows us to understand how individuals listen through their threshold of perception to construct webs of relational meaning.

\footnotetext{
${ }^{71}$ Michelle Kisliuk, Seize the dance!: BaAka musical life and the ethnography of performance (New York: Oxford University Press, 1998) 12.

${ }^{72}$ Kisluik, 12
} 


\section{Interlude: The Wilderness Dance}

National Geographic: The call of the wild in northern Michigan's Isle Royale National Park may be losing one of its voices: that of the gray wolf. ${ }^{73}$

Ecologist Candy Peterson gives a bi-weekly presentation for park visitors at the Daisy Farm campground - a central hub in the park that links up to the 40-mile long Greenstone Ridge Trail intersecting the island. At these talks, park visitors gather at the Daisy Farm boat dock overlooking Moskey Basin and Middle Island Passage to learn about the Wolf-Moose Project through Candy's poet/conservationist perspective, and participate in sing-alongs. During one of these presentations, as the wind blew showers of buzzing mosquitos, about 30 hikers and I sparked a conversation about how the NPS defines "wilderness." The following dialogue illuminates the highly contested nature/culture conundrum ${ }^{74}$ of managing nature and wilderness character with the park visitor's experience, desires, and socioeconomic contributions in mind.

I ask, "Does the park discuss the differences and similarities between maintaining a trail and maintaining a wolf population?"

"I don't know if anybody has asked them that," responds Candy. "There are certain areas that are excluded from wilderness - like this campground. But I don't know if the trail system is excluded from wilderness."

An older hiker with a long white beard responds, "The wilderness act allows trails. They don't allow manipulating nature. Like bringing wolves here."

“But isn’t cutting a trail manipulating nature?” I respond.

He quickly fired back, "Congress decided that under the Wilderness Act, that trails be allowed."

\footnotetext{
${ }^{73}$ Accessed from: http://news.nationalgeographic.com/news/2014/04/140427-wolves-isle-royale-animals-sciencenation/

${ }^{74}$ Gary L. Wockner, Policy Conundrums in the National Parks: Nature, Culture, and the Wolves of Isle Royale (Dissertation, 1997).
} 
Rolf Peterson, sitting in a fold up chair behind us interjects, "The extreme view adopted by Adolph Murray in 1936 actually says there shouldn't be any trails.”

The hiker rebuts, "But Congress said that there should and because this is a legally designated wilderness area trails are allowed."

Candy steps in, "There is wording in the Wilderness Act that would allow for the maintenance of natural processes and what we have here is an impaired wilderness because we don't have a top predator... we have an unhealthy wilderness here. The Wilderness Act says that natural processes need to be maintained and predation is a natural process that is needed."

Rolf clarifies, "But that is not in the Wilderness Act — that is in the National Park Service policies."

"Now does the Wilderness Act," asks Candy "trump the National Park legislation?"

"The Wilderness Act says that there is nothing in this act that would affect the protection afforded to a National Park already," replies Rolf.

"So what does that mean?" asks Candy.

"Paragraph 5," says Rolf, as all the hikers in the crowd laugh, "suggests that that National Park Organic Act trumps the Wilderness Act. But that's an interpretation.”

Another hikers interrupt, "Has anybody seen any wolves?"

Candy replies, "There have been a few sightings. But what we are really listening for is the high-pitched yips of pups which is a sign of reproduction. We haven't gotten any reports of that yet. But if you hear any howling out there be sure to report that to us or to rangers at either end of the island." 


\section{Citizen-Science in Sound}

At about two am we heard the distinct sound of a wolf. It was melodious and very pure toned...then the loons started their laughing call [...] it was so authentically wild. ${ }^{75}$-Isle Royale National Park Visitor

Bringing to mind the way in which Gerome listens to the wastewater treatment facility in the Grand Canyon, Rolf Peterson uses listening as a central component to his research methodology. He listens, for example, to radio telemetry beeps to track wolves. A small collar transmitter worn by a wolf emits radio waves that are picked up by a receiver. By listening to volume fluctuations of these beeps, Peterson can plot coordinates, triangulate, and determine very specific spatial information. I was invited back to Isle Royale National Park in 2013 with a NPS Social Science Permit—with co-investigator Rolf Peterson—-to research the listening practices of Peterson and his partner/wife Candy that involve park visitors and employees. A major objective of summertime footwork for the Wolf-Moose Project is to determine whether the wolves observed during winter overflight observations displaying courtship behavior have denned and had pups.

Wolf pups are usually birthed during the third week of April—63 days after mating — and they start making distinct sounds in July. ${ }^{76}$ The frequency of howls drops from an average of $1,100 \mathrm{~Hz}$ at two weeks of age to $350 \mathrm{~Hz}$ by six months of age. Until then, the higher pitch and shorter duration of the pup's howl—occurring within pack choruses_-provides metainformation which can reveal the age of a pup. ${ }^{77}$ This information helps to determine wolf reproduction on the island. Rolf explains further,

$[\ldots]$ wolves howl together when they're happy [...] they howl when they are busy feeding many pups and coordinating the activities of many pack members. Even if they [older wolves] come home empty handed their arrival is a big occasion and a greeting ceremony normally ensues...Pups are looking for any excuse to yip and howl. ${ }^{78}$

\footnotetext{
${ }^{75}$ Isle Royale National Park visitor. Personal Interview. 2013.

${ }^{76}$ Peterson (2007), 35.

${ }^{77}$ D. Mech, and L. Boitani, 70.

${ }^{78}$ Peterson (2007), 77.
} 
As field research scientists, the Petersons have become attuned to this sound, which they listen for each summer, which requires them to survey this roadless, off-the-grid island the island for this sound. But how do they do this? The famed wolf biologist Dave Mech, who worked on the island in the 1950s, played a 45RPM record of a howl via a battery-powered player to elicit response howling. More recently, wolf biologists are deploying "howl boxes"79 that generate artificial howls at programmable intervals which records the response. The Petersons used to actually howl through megaphones themselves to evoke responses, but they stopped because it was deemed to be unethical as it disturbed wolf behavior. Instead of projecting their own voices into the environment as pseudo wolves, they now rely on "hearing aids"- a community of human listeners roaming the island. ${ }^{80}$

In early August 2013, I made it to Mott, the park's administrative headquarters on the island, where Rolf picked me up. We zipped through Rock Harbor and Moskey Basin to the Bangsund cabin. Originally built by fishermen in the 1930s, the Bangsund cabin has served as the summer headquarters of the Wolf-Moose Project since 1960. The park service has allowed the Petersons to "squat" in this cabin between April and October for 47 years. When we arrived at the Bangsund cabin, fifteen Moosewatch volunteers had just emerged from a week bushwhacking in the field. The "field banquet" was well underway with a line for showers, a hot feast, and a sing-along to tunes like "Bone Bone Ain't it Great to do Moosewatch," from Candy's original songbook. The Petersons started Moosewatch in 1988 under the Earthwatch program - a citizen-science expedition where volunteers spend a week on Isle Royale searching for moose bones. The result is the world's largest collection, over 4,000 moose bones collected

\footnotetext{
${ }^{79}$ Rolf Peterson. Personal Interview. 2013.

${ }^{80}$ This particular listening community functions in many ways as the inverse of the "human megaphones" made popular at recent political protests.
} 
largely by the citizen scientists, displayed in the back of the Bangsund cabin. Each bone tells a story: cause of death, age at time of death, year of death, and the condition of the moose at the time death.

Citizen-science is "scientific work undertaken by members of the general public" that leads to both data collection and public education. ${ }^{81}$ Candy Peterson is proud of the ways in which she and her husband involve people in their research because collecting data of all types validates individual experience and empowers the citizen-scientist. "This experience in the woods," Candy explains, "reassures them of how amazingly well people can work together on a project and how a natural place like this can bring out the best of us." ${ }^{\circ 2}$ She explains, "Rainbows, moose sightings, trail food, and storms knit individuals together. The generosity, self-denial, sensitivity, tolerance, and forgiveness practiced by these volunteers are prescriptions for our planet's ills." ${ }^{83}$ Beyond the Moosewatch community, the Petersons have cultivated a second citizen-science network that serves as their "hearing aid." The Petersons tap into the park visitor and employees' listening experience for clues about wolf reproduction. They ask, "Was it really just one wolf howl? What pitch did you hear? Was it like a coyote? Where was it and what time of day?" The Petersons "keep their antennas [ears] open" 84 for any information that comes through this human sound surveillance. When a promising report emerges they go investigate. Candy explains, "12,000 visitors a year are out there-all over the place. We are not all over the place. We need them and their reports." $" 85$

\footnotetext{
${ }^{81}$ OED Online, citizen science (Oxford University Press, September 2015).

${ }^{82}$ Candy Peterson. Personal Interview. 2013.

${ }^{83}$ Carolyn C. Peterson. A View from the Wolf's Eye. (Houghton, Mich: Isle Royale Natural History Association, 2008) 49.

${ }^{84}$ Rolf Peterson. Personal Interview. 2013.

${ }^{85}$ Candy Peterson. Personal Interview. 2013.
} 
This citizen-science in sounds initiative is a successful form of data collection for several reasons. Unlike auditory observations in bird surveying — which requires listeners to recall many distinct bird songs and calls—-when identifying wolves through howling, listeners are attuned to a singular, iconic sound. Also, park visitors bond over the experience of listening to this sound, which further perpetuates its popularity on the island. One visitor noted that, "whenever you cross someone on the trail they ask where you are coming from and if you've seen or heard anything. ${ }^{, 86}$ One of the reasons why this trail bonding occurs is because Isle Royale-due to its relative isolation - is one of the least visited national parks. This results in visitors staying for longer periods of time, usually about five days, which is, on average, the longest average length of visitation of all national parks. In the most visited national park - the Great Smokey Mountains - visitors generally spend less then 7.5 hours and most never leave their vehicles. Lucas Westcott, the lead interpretive ranger at the Rock Harbor visitor center on Isle Royale, elaborates on this:

People who come here are here. There's no disconnection from the place. You can't get on your phone and connect with the outside world. You can't drive away. Also, this is a difficult place to get to and people really want to be here because it took so much work to get here [...] The scale of this place is small...All this leads to a certain intimacy people have with the resource and each other $[\ldots]$ In everyday life you typically don't talk to random people walking down the street but you do talk to people walking down the trail [...] Because of these circumstances, information gets passed. It's a very small town. ${ }^{87}$

Geographer, Denis Cosgrove articulates this sentiment in another way:

For the insider there is no clear separation of self from scene, subject from object. There is, rather, a fused, unsophisticated and social meaning embodied in the milieu. The insider does not enjoy the privilege of being able to walk away from the scene as we can walk away from a framed picture or from a tourist viewpoint. $^{88}$

My own experience demonstrates the veracity of this statement. When I visit Isle Royale, I typically stay at Daisy Farm_-right across Moskey Basin from the Bangsund cabin — at a campsite just off the Greenstone Ridge. I usually set up camp at Shelter \#1, a brown 15x7 foot,

\footnotetext{
${ }^{86}$ Isle Royal Park visitor. Personal Interview. 2013.

${ }^{87}$ Lucas Westcott. Personal Interview. 2013.

${ }^{88}$ Cosgrove, 19.
} 
screened-in, wooden shack with a slanted roof. Right outside this shelter, secluded by a wall of green thickets, is a classic A-frame picnic bench. This is where the Petersons and I talked during many evening hours. The blanket of mosquitoes typically hadn't come out yet, we drank hot tea, bathed in the remaining sunlight, and were entertained by Candy's superb birding abilities: “Ah, that's a white throat sparrow. ${ }^{, 89}$ One main theme that ran through these discussions was the park visitors' experience.

While park visitors come to Isle Royale for many reasons - to fish, to follow family tradition, to collect (every trail, every national park, etc.), to be in the Wolf/Moose Project, to paddle, to religiously retreat, or to wine and dine at the Rock Harbor Lodge (the $1 \%$ of nondesignated wilderness in the park) — the individuals that I spoke with on the trail system mainly come to the island to get away from technology and noise - to be seeped in solitude. The search for solitude is a component of the sublime, a concept that can be traced back to the cultural roots among the Biblical Desert Fathers. These Christian mystics were known to have given all their possessions to the poor and retreated to the desert. Still today, this search for solitude - to be in the "complete absence of $"$ "90 is a state of mind that many people seek. ${ }^{91}$ A component of solitude for many Isle Royale visitors is to be in the complete absence of familiar sounds. Candy confirms this: "If I were to ask people in an evening program what they value most about Isle Royale and miss the most when they go back to town, it's silence." 92 Within this silence, park visitors experience a noted switch from passive hearing to active listening ${ }^{93}$ :

- "Getting off the trail heightens my awareness and my listening becomes more acute."

\footnotetext{
${ }^{89}$ Candy Peterson. Personal Interview. 2013.

${ }^{90}$ OED Online, solitude (Oxford University Press, September 2015).

${ }^{91}$ Charles Hirschkind, The Ethical Soundscape: Cassette Sermons and Islamic Counterpublics (New York: Columbia University Press, 2006), 67-107.

${ }^{92}$ Candy Peterson. Personal Interview. 2013.

${ }^{93}$ Pauline Oliveros, Deep Listening: a Composer's Sound Practice (New York: iUniverse, Inc, 2005). Eric Clarke, Ways of Listening: an Ecological Approach to the Perception of Musical Meaning (Oxford: Oxford University Press, 2005).
} 
- "Lying in your tent at night and it's just the utter peace and quiet. No roads, no traffic, no television, it's quite the experience."

- "The most startling thing is to be able to stop on the trail in the middle of nowhere and hear nothing - the sound of silence. This was the biggest part of the trip for us."

- "Everything is simpler out here. Your job is walking. Everything is stripped away and it elevates sounds."

- "We notice every airplane that flies overhead. We don't normally notice this at home."

- "Juan heard the wings of a dragonfly."

- "It took me a day to realize how to close the privy door softly because I heard other people slamming them."

- "The soundscape slows you down, gives you time to reflect, and puts you in a meditative state."

- "Here on Isle Royale, the silence is nosier than noise." 94

From these responses we can understand that this citizen-science in sound is not just about collecting data - but about experiencing a place in sound. One visitor comment that I collected illustrates how this community listens beyond the notion of the soundscape: "Because of how silent it is I find myself not paying attention [...] thinking about things more than listening to the things around me." This sonic awareness is something that the Petersons nurture. Another example of this is that many visitors, as one Moosewatch volunteer noted, "are willing to stretch the truth of their hearing to suggest that they have heard a wolf." In fact, they are hearing the wails of loons, and the Petersons never correct them. Candy explains that, "The customer is always right. People hear, and think they hear amazing things. If they want to believe they heard wolves that's great, but we're not going to go running over looking for them. Even if you don't see them or hear them, you know they are there and that does something to you." "B5 "But somebody," Rolf replies, "is going to hear them."96

\footnotetext{
${ }^{94}$ From discussions conducted between the author and park visitors in 2013.

${ }^{95}$ Candy Peterson. Personal Interview. 2013.

${ }^{96}$ Rolf Peterson. Personal Interview. 2013.
} 
While Isle Royale park officials make no special effort to inform park visitors about this citizen-science in sound project, park visitors are already actively listening, and they hear—or think they hear-the wolves. ${ }^{97}$ When they do, most get excited and report their experiences back to park officials for validation. These observations of wolf howling make it to the Petersons through a variety of outlets: at Candy Peterson's bi-weekly evening presentation, at the Peterson's research cabin, or through wolf howling reports that can be filled out at ranger stations. ${ }^{98}$ These exchanges form an interactive, acoustic "imagined" community ${ }^{99}$ where the voice - the howl — creates an intimate sphere around it which includes all its hearers, limited in both time and space. ${ }^{100}$ Communities of many types — often united through one type of sound: of engines $^{101}$, of birds ${ }^{102}$, of bells ${ }^{103}$, or of amplified calls to prayer ${ }^{104}$ _form different contextually rich webs of meaning with competing interests and voices. In addition to this citizen-science in sound, Isle Royale stakeholders have expandingly politicized the howl because its density has declined along with wolf reproduction. Longtime park visitors ask Rolf, "Why aren't the wolves howling anymore?"105

\footnotetext{
${ }^{97}$ Most park visitors who make this sound based citizen-science successful are actively listening in the park but, for the most part—outside of Candy's cue to 'be listening out there and report back what you hear' - are unaware of their involvement in the Wolf/Moose Project prior to it being activated by the Petersons. Seth DePasqual—Isle Royale Cultural Resource Manager - makes the point that, 'If you ask park visitors up front to collect this data they might be less inclined to complete the task or more likely to overemphasize the thing they are observing.'

${ }^{98}$ Liz Valencia, Chief of Interpretation and Cultural Resources, explained to me that this visitor observation system was established because the Petersons requested it in the mid-2000s.

${ }^{99}$ Barry Truax, Acoustic Communication (Westport, Conn: Ablex, 2001) 65-92. Michelle Hilmes, Radio and the Imagined Community, The Sound Studies Reader Ed. Jonathan Sterne (New York: Routledge, 2012), 351- 361. ${ }^{100}$ Le Guin, 199.

${ }^{101}$ Stefan Krebs, Sobbing, Whining, Rumbling: Listening to Automobiles As Social Practice. The Oxford Handbook of Sound Studies Ed. Pinch Bijsterveld (New York: Oxford University Press, 2012), 79-101.

${ }^{102}$ Steven Feld, Sound and Sentiment: Birds, Weeping, Poetics, and Song in Kaluli Expression (Philadelphia: University of Pennsylvania Press, 1982).

${ }^{103}$ Alain Corbin, Village Bells: Sound and Meaning in the Nineteenth-Century French Countryside (New York: Columbia University Press, 1998).

${ }^{104}$ Tong Soon Lee, Technology and the Production of Islamic Space: The Call to Prayer in Singapore (Ethnomusicology 43.1 (1999): 86-100.

${ }^{105}$ Peterson (2007).
} 


\section{Interlude: The Harmony of Death}

If you could only see the stars in the sky once every hundred years, we'd all be out. But because we can see them every night, we don't even look up. ${ }^{106}$-Candy Peterson

Our natural self is to use these senses and when we are in town it's dulled. We are in a protected environment. Out here, all of a sudden, you gotta keep your ears open, your eyes open, you gotta watch the weather. You have to be aware of your world. Whereas when you are in town the world is just something that you go through. ${ }^{107}-$ Candy Peterson

The bell buoy at Middle Island Passage chimes and clangs with the current. The sun sets resulting in gradients of fluorescent earth tones. Candy places moose bones and a clinging brass wolf skull on the Lake Superior beach; Rolf jets across the basin to retrieve hand drawn sheets of music. The Peterson's set up for Candy's biweekly evening program — a time when people can share and cultivate knowledge. She quoted poet Antoine de Saint Exupéry one evening saying, "Love does not consist of gazing at each other but looking outward together in the same direction." ${ }^{\prime 108}$ Candy — a preacher of ecology—celebrates community through Rachel Carson-like paraphrases: "people experience the peace that passes all understanding-which Carson calls the sense of wonder that we are all born with." Drawing on this sense of wonder, Candy presents at each evening program her three entwined 'C's—complexity, change, and chance-with stories about the island:

Last year right about now some people who were doing a bird survey smelled something weird when they were hiking from Todd Harbor to Lake Harvey. They had the curiosity to follow their noses. They looked down into a water-filled old abandoned mine pit and knew something was dead at the bottom. Rolf and I went over, took one look, and knew it was three dead wolves. One of them had a radio collar that was still beeping. That was basically the end of the Chippewa Harbor Pack and their death helped reduce the wolf population to the lowest point ever observed. ${ }^{109}$

This one event — an artifact of 19th-century copper mining on the island - exemplified that complex things on Isle Royale trigger changes - sometimes expected, and sometimes by chance.

Candy preaches the importance of working together in harmony with each other. She preaches

\footnotetext{
${ }^{106}$ Candy Peterson. Transcript from personal sound recording. 2013.

${ }^{107}$ Candy Peterson. Transcript from personal sound recording. 2013.

${ }^{108}$ Candy Peterson. Transcript from personal sound recording. 2013.

${ }^{109}$ Candy Peterson. Transcript from personal sound recording. 2013.
} 
the importance of realizing that we-Isle Royale park visitors - are just as important as the spruce tree, blueberries, wolves, and moose on the island - which all live with term limits. Candy hopes that park visitors learn from their time on Isle Royale of the "reverence for the processes that contain us all...the processes that move us forward." ${ }^{110}$ Pointing to an array of gnarly moose bones scattered on the beach, Candy says,

The end is here. We all end up as bones... and death isn't such a bad thing. But we are required now to become the good creatures that we can be and that is going to involve some reverence, humility, and some cooperation with each other. ${ }^{111}$

At the end of all her talks Candy says gently that, "What I want you to consider tonight is the fact that we are all happier when we are in a group and getting along with each other." She instructs all the campers to get in a circle around the dead moose - a symbol for their own bones. As Candy passes out sheets of music she says, "This is an old girl scout round that celebrates death. It's important to keep the tempo." We sing:

Music Alone Shall Live (All Things Shall Perish)

All things shall perish from under the sky.

Music alone shall live,

Music alone shall live,

Music alone shall live,

Never to die.

${ }^{110}$ Candy Peterson. Transcript from personal sound recording. 2013.

${ }^{111}$ Candy Peterson. Transcript from personal sound recording. 2013. 


\section{The Politicized Howl}

Hope and nature - it's a peculiar combination. In nature, isn't goodness defined as whatever happens? If so, then what need is there to hope for anything? And isn't hoping nature to be a certain way route to crazed obsession for controlling nature to suit any old whimsical human proclivity? But isn't hope an unavoidable consequence of caring - caring about something for its own sake? How easily we tangle ourselves into such knots. We have so much to learn about how we ought to relate to nature. What happens next is just beyond the horizon. What happens next will teach us something that we need so desperately. It will teach us about our relationship with nature, but only if we are attentive and receptive. ${ }^{112}$-John Vucetich (Wolf Biologist)

During a conversation I had with Mark Romanski (Isle Royale National Park’s Biological

Science Technician) we discussed acoustic ecologist and composer Berry Truax's assertion that when a sound leaves a source it travels and interacts with the environment. When individuals pick up these sounds after they have traveled across the environment the sounds change and retain history. As articulated by science fiction author Ursula K. Le Guin, much like human communication where the message is a relationship between a speaker and a listener, the messages embedded in a wolf howl is a function of a society, and a culture in which the speaker, the sound, and the hearer are all in. ${ }^{113}$ This sound reflects time, place, and particular values, ebbing and flowing with fades and follies. ${ }^{114}$ One interpretive ranger on the island, nicknamed Tall Paul, explained to me that the wolf howl brings along with it important historical values. "Hearing a wolf," he says, "ties us to the wilderness. Its a reality check, a spiritual awakener.",115 Tall Paul, and so many park visitors, imagine the wolf howl on Isle Royale-because of the wilderness discourse — as a conduit to some elsewhere place, a utopia. But in fact, wolves on Isle Royale become someone to relate to, not as a human being but as another kind of being. In ecologist Gary Wockner’s dissertation “Policy Conundrums in the National Parks: Nature, Cultures, and the Wolves of Isle Royale," he sums this up nicely with a quote from one his informants, Tim Cochren:

\footnotetext{
${ }^{112}$ Vucetich, John. Winter Study 2013: Notes from the Field. CreateSpace Independent Publishing Platform, 2013.

${ }^{113}$ Le Guin, 187.

${ }^{114}$ Wockner, 82.

${ }^{115}$ Ranger Paul. Personal Interview. 2013.
} 
No one can deny that, even for Park Service employees and researchers, the wolves are significantly more than just a material animal. They are symbolic creatures, religious creatures, totems, and indicators. What they represent to people, what people have made them into, is far greater than their role as a predator in the food chain. One of the more cultural-theory-informed informants summed this up well: "Has there ever been such smoke and fire associated with a creature that $99.99 \%$ of Island users never see? WE want wolves, or are interested in wolves, because they are "the OTHER." They are not human, they are secretive, they are not like suburbia, not like sitting at a computer screen at work, not like wearing fashionable clothes. I think visitors and armchair enjoyers of Isle Royale largely want wolves at Isle Royale. In a sense they need them as intriguing, magnetic, and totem-like animals. Wolves give Isle Royale status."116

Just like the wolf howl has evolved in response to the environment, listening to the howl is a response to the history through which it has moved. The wolf howl has moved through our culture's construction of wilderness.

In 2013, the wolf population on Isle Royale, which typically comprises between eighteen and twenty-seven wolves, dwindled from sixteen wolves to just eight, the lowest number ever observed in this population. These wolves were the West-end Trio, which was comprised of the year prior's West-end Duo, plus a male_nicknamed Pip — that dispersed from the Chippewa Harbor Pack. The Chippewa Harbor Pack was now the Chippewa Harbor Trio. There were two lone wolves, one of which was nicknamed Isabelle. ${ }^{117}$ Much of what is learned about Isle Royale wolves and moose happens by observing from above, out of the small windows of the "flagship"— a small plane for a pilot and one researcher. These observations happen during Winter Study — seven weeks of fieldwork between January and February. John Vucetich—-the study's co-director-keeps a blog, recalling these events from the winter of 2013:

$1 \mathrm{Feb}$ : Any wolf that survives to age two or three at least dreams about dispersing from their natal pack. We know that dispersal is about one of the most dangerous times in a wolf's life. 2 Feb: By the time we saw her, she was running for her life, north along the beach of Rainbow Cove. She was being chased by Pip's two companions... By the time they reached the middle of Rainbow Cove, the smaller of the two tackled Isabelle. They both tumbled into Lake Superior. At $+5 \mathrm{~F}$, they rolled in chest-deep water...Isabelle got in a few good bites and dodged several others. Then the second wolf dove in. They both attacked Isabelle... These wolves lunged and sank their teeth into Isabelle with the same fury and power they use to bring down a nine hundred pound moose... Unable to take any more hits, she slipped loose and began swimming. She didn't stop until she was thirty meters offshore... After about ten minutes, she couldn't take

\footnotetext{
${ }^{116}$ Wockner, 223.

${ }^{117}$ Peterson, Rolf Olin, and John A. Vucetich, Ecological Studies of Wolves on Isle Royale Annual Report (Houghton, Mich: Michigan Technological University 2012-13).
} 
the cold water any longer. As Isabelle came to shore, her feet touched bottom, she curled her lips, bore her teeth, and waved her head back and forth, threatening counterattack to any advance...They attacked, retreated to dry ground for a moment or two, and attacked again... This cycle of attack-retreat-attack went on for the next twenty minutes...Pip never participated. He only watched...Pip and Isabelle are brother and sister. This spring they fed from the same carcasses in the Chippewa Harbor Territory, the pack to which they were born. Since that time, both dispersed from their natal territory, each hoping to find a mate...Thirty minutes after it all began, the wolves gave Isabelle a break. They backed off twenty yards, letting her alone at the water's edge. She stood on guard for a few moments, then sat, and once or twice lay down...Then the trio left the beach all together, heading in the general direction of their old kill site near Feldtmann Lake...The explanation for the violence, the motivation that drove Isabelle's assailant is simple: to eliminate a female who might steal a mate or raise pups that would later grow to become deadly competition. $4 \mathrm{Feb}$ : Late in the afternoon, Isabelle walked out on the ice of Grace Harbor. About a quarter mile from land, she lay down. She looked like a corpse... 16 Feb: Isabelle left the West-end Duo territory a few days ago. Now she's trying to kill a moose on her own in a portion of the Chippewa Harbor Territory that is not too often used by those wolves... Her determined motivation to find an unrelated wolf with whom to mate - a wolf that does not exist on Isle Royale — has made her unwelcomed by every other wolf that is on the island. ${ }^{118}$

This narrative reminds us that the wolf is one of the most romanticized, fabled, and controversial forms of wildlife on the planet, whose life is entangled in ecological, cultural, political, and economic contexts - as Vucetich notes - "no less than anything Shakespeare had ever penned.",119

A definitive example of wolf controversy unfolded after Yellowstone National Park was formed in 1872. The grey wolf-which roamed freely in Yellowstone before the park was established — was said to be "detrimental" to the landscape. ${ }^{120}$ The government ordered and assisted in the complete extirpation (human-caused extinction) of wolves in Yellowstone by 1926. When the wolves were killed off, the elk population multiplied, important tree species became overgrazed, and the biodiversity of the landscape changed. A decade later, while wildlife conservationists were advocating for the reintroduction of the grey wolf to Yellowstone, the ranchers that worked the land around the park opposed this reintroduction in fear of loss of livestock and, subsequently, their livelihood. However, in 1967, the gray wolf was one of the first species to be listed under the Endangered Species Preservation Act of 1966, eventually

\footnotetext{
${ }^{118}$ Vucetich (2013).

${ }^{119}$ Vucetich (2013).

${ }^{120}$ Chase, Alton, The Wolf Mystery: Playing God in Yellowstone-The Destruction of America's First National Park (Boston, MA: The Atlantic Monthly Press 2012-13) 120-125.
} 
leading to their reintroduction to Yellowstone. Between 1995 and 1996, 31 wolves were captured in Canada, transported to Yellowstone, and released. Rolf Peterson worked in Yellowstone in 1995 when the first batch of wolves was released using the Isle Royale Wolf/Moose Project as a comparative baseline. As the wolf population in Yellowstone grew to healthy numbers a trophic cascade unfolded: the elk population declined, tree species recovered, and other flora and fauna revitalized. Yellowstone Wolf Project Leader, Doug Smith—who worked with Rolf as a graduate student on Isle Royale in the late $70 \mathrm{~s}$ - said that this reintroduction was the greatest conservation achievement of the twentieth century. However, ranchers did not value this achievement and opposed it on the grounds that the wolves were eating their livestock; as one advocate for keeping wolves out of Yellowstone points out: "The real irony is that these same groups that promote and romanticize the wolf are blind — either by choice or ignorance - to the ecological tragedies playing out as their pet project tears limb from limb all those species that are smaller and/or less capable of resisting — not restoring balance in nature but rather destroying it." ${ }^{\prime 21}$ As Dave Mech explains, "Because of the strong feelings that both wolf haters and wolf advocates hold, it has been hard to sell the truth about the wolf-folks of each viewpoint resist accepting information they believe supports views opposite their own." ${ }^{122}$ Today, as park officials discuss the fate of wolves on Isle Royale, a similar debate is underway throughout the Upper Peninsula Region.

During a June $20^{\text {th }}, 2013$ meeting at the Cowles Auditorium at the University of Minnesota, the National Parks Conservation Association held a public forum entitled "The Disappearance of Isle Royale's Wolves: How Should We Respond?" On the panel was Peterson, Dave Mech (wolf biologist), Timothy Cochrane (environmental historian), and Kevin

\footnotetext{
${ }^{121}$ Ted B. Lyon and Will N. Graves, The Real Wolf: The Science, Politics and Economics of Co-Existing with Wolves in Modern Times (Ted B. Lyon, 2014).

${ }^{122}$ Mech, L. L. Boitani, xv.
} 
Proescholdt (Wilderness Watch Conservation Director). During the opening lecture Phyllis Green, Superintendent of Isle Royale remarked that the NPS is currently in "a fact-finding mode, a listening mode" and that they are going to look at the "problem, today very specific to Isle Royale, but a problem that is going to happen with iconic species all over the park service."123

One perspective on the issue attributes the decline of wolves on the island to climate change which, according to Peterson, is a "human-caused change"-similar to the extirpation of wolves in Yellowstone. Like the trophic cascade observed in that park, Peterson reminded the panel and audience that the wolves on Isle Royale, "are essential in maintaining the integrity of the forest." ${ }^{124}$ Peterson advised that the eight remaining wolves on Isle Royale should be genetically rescued with the introduction of one or two wolves from Canada to reinvigorate the pre-existing gene pool. Peterson stressed that this is an opportunity to creatively implement new standards for resource management, which will have significant value for the NPS down the road as the effects of global climate change emerge in other national parks.

Superintendent Green noted the long history of species going extinct on the island and pointed out that special policies are being considered today to accommodate wolves that first appeared on the island as recently as 50 years ago - a mere blip in time. In addition, Cochrane questioned what a "natural" animal is to Isle Royale. "Mammals come and go," he says, "that is the natural cycle for islands. Could the wolves leaving Isle Royale be a natural process of biogeography? Is winking out natural?" 125

\footnotetext{
${ }^{123}$ Phyllis Green. From transcript of "The Disappearance of Isle Royale's Wolves: How Should We Respond?” June 2013.

${ }^{124}$ Rolf Peterson. From transcript of “The Disappearance of Isle Royale's Wolves: How Should We Respond?” June 2013.

125 Tim Cochrane. From transcript of "The Disappearance of Isle Royale's Wolves: How Should We Respond?" June 2013.
} 
The most extreme among the three perspectives is wrapped in Kevin Proescholdt's wilderness ideology of "let nature take its course." ${ }^{126}$ Proescholdt warned the audience to be aware of the slippery slope of human manipulation, though he overlooked the fact that the designation of place as wilderness is not itself a form of manipulation. He told the audience in the auditorium, "Let Isle Royale choose its own course in its evolution into the future. With wilderness we should be guardians, not gardeners." ${ }^{127}$ Mech stepped in and said, "disagreements in science gets us closer to the truth," before stating his view that, "we've really been crying wolf about the wolves on Isle Royale since 1989." ${ }^{128}$ Mech thinks the best thing to do is to wait, probably because of how contested the situation is. Wockner, in his dissertation on this contested situation, summarized his informant surveys — which I think nicely summarizes the various views presented at this forum:

For some, it was important to preserve the dualism between nature and culture and therefore to enshrine Isle Royale as "wilderness." For another group, the wolf represented a healthy ecosystem that would be out of balance without them [wolves are needed to eat moose, or moose would eat the island to death]. For yet another group, wolves and wilderness were both, to some degree, social constructions that humans should manage as desired. Turn them both over to the best science, or to the American public to decide-let cultural values determine the fate of a cultural resource... Three distinct "ways of seeing" came out of that box at Isle Royale. Each tries to represent the truth about wolves and nature; all stand as three "multiple truths". Due to the "hybrid" status of wolves and nature, there is an "inherent instability of meaning" and a "crisis of representation." Which reading of the wolves and nature is correct? How should policy be changed? What should managers do? Whose ideology should they accept? ${ }^{129}$

Towards the end of the forum, an audience member asked Peterson if he had observed any wolf reproduction since April, to which he replied that no pups had yet been confirmed. ${ }^{130}$ This was not so surprising given that the previous summer (2012) was the first year in the WolfMoose Project's history during which they were unable to document any reproduction, and that

${ }^{126}$ Kevin Proescholdt. From transcript of "The Disappearance of Isle Royale's Wolves: How Should We Respond?" June 2013.

127 Kevin Proescholdt. From transcript of “The Disappearance of Isle Royale's Wolves: How Should We Respond?" June 2013.

${ }^{128}$ Dave Mech. From transcript of “The Disappearance of Isle Royale’s Wolves: How Should We Respond?” June 2013.

${ }^{129}$ Wockner, 226-7.

${ }^{130}$ Rolf Peterson. From transcript of “The Disappearance of Isle Royale's Wolves: How Should We Respond?” June 2013. 
the following Winter Study 2012-13 had found no evidence of courtship. ${ }^{131}$ The howl of the wolf on Isle Royale seemed to be an echo of the past. Surprisingly, right before I returned to the island in 2013 - a couple of weeks after Peterson had reported there had been no evidence of wolf reproduction-I received this message from him:

On July $3^{\text {rd }}$ (2013) Candy and I heard two (maybe three) pups and some adult wolves at Siskiwit Bay campground. Since that time they have been heard twice by other groups and one person showed us photos of pup tracks. ${ }^{132}$

${ }^{131}$ Peterson, R., J. Vucetich, 5.

${ }^{132}$ Rolf Peterson. Email correspondence. July 2013. 


\section{Interlude: The Sound of Reverence}

"By 1975, I actually became irritated with the howling that played havoc with our sleep."133 -Candy Peterson

Rolf and Candy had been on a canoe trip, stopped at Siskiwit Bay campground. Candy was doing laundry and laid her shirt down on the canoe to dry. Rolf was in the tent because of the mid-summer evening mosquito swarm. After Candy had finished the laundry, she walked from their tent down to the dock and suddenly heard a group of wolves howling. Among them were a couple of high-pitched yips. Rolf listened through the screen of the tent. "I wasn't convinced by the yips I heard. They could have been from yearlings. A little more robust, a little lower in pitch than pups should be howling at on the $3^{\text {rd }}$ of July, but there aren't any yearlings on the island," explained Rolf. Candy nodded, "It was one of those happy, everybody's together, group howls." The next morning their listening was validated by the discovery of 2.5 -inch tracks on the beach. This allowed them to confirm, against the odds, that 2 or 3 pups were birthed during the summer of 2013. The next day, the pups were heard again by visitors at Hay Bay and then a week later again at Siskiwit Bay.

At Daisy Farm in 2013, as we discussed the details of this news, sitting on the picnic table outside of Shelter \#1, the conversation quickly transitioned into very detailed wolf banter between Rolf and Candy_-in which, after about 30 seconds, I got lost and confused:

\footnotetext{
We didn't observe courtship... we did observe courtship from the Chippewa Harbor pack though.... the pack of three didn't have collars... The Chippewa Harbor pack seemed like the heart was taken out of it...the pair that mated in 2012 that didn't reproduce, we know who they were, it was a three year old male from Middle Pack and a two year old female from the Chippewa Harbor Pack...they were heavy into courtship... we didn't have a collar on this pack of three...Isabelle...no she wasn't in this pack...she's loose... ${ }^{134}$
}

As I sat there and listened to them discuss these wolves in such detail-wolves with whom they have been living side-by-side with for the past 50 or so years-I couldn't help but think that

\footnotetext{
${ }^{133}$ C. Peterson, 18 .

${ }^{134}$ Rolf and Candy Peterson. Personal Interview. 2013.
} 
these pup yips they heard on July $3^{\text {rd }}$, given their current situation, could be the last they ever hear on Isle Royale. Candy immediately interjects, "I have faith that we will hear wolves again. I wasn't that surprised to hear them this year. It's a sound we've heard so many times.... Oooooh there's that brown creeper [bird] I've been hearing." 135

Candy was thrilled to have heard those wolves on July $3^{\text {rd }}$ because the Petersons have resistance from the administration of Isle Royale National Park to proceed with their proposed solution: to introduce new wolves to the genetic mix of the few remaining wolves of Isle Royale. "If we just have a little more time here," says Candy, "because it seems like the park service is going to drag their feet forever in making this decision. We thought the decision would have been made this Fall (2013) but now we think the decision process will begin this Fall (2013). So if the wolves keep going for a little bit, that would be good." 136

\footnotetext{
${ }^{135}$ Candy Peterson. Personal Interview. 2013.

${ }^{136}$ Candy Peterson. Personal Interview. 2013.
} 


\section{Discussing Natural Sound in Law}

The dwindling wolf numbers on Isle Royale and their possible reintroduction/augmentation has little to do with soundscapes. With this kind of ecosystem discussion, soundscapes play a very small role in Park Service resource management at this time. ${ }^{137}$-Kurt Fristrup (acoustic ecologist)

In February 2016, Kurt Fristrup — the Senior Scientist of the Natural Sounds and Night Skies Division of the National Park Service — spoke with me over the phone. My main concern was to understand the degree to which the Natural Sounds Program understands the individual listening habits of park visitors in NPS resource management decisions. A transcription of the important components of this conversation can be found at Appendix A.

The Natural Sounds Program was established in response to the National Parks Air Tour Management Act of 2000. The program's initial objective was to collect background sound level measurements, a baseline condition, to estimate the natural ambience in the parks where air tours were in operation. ${ }^{138}$ The sound recording technology associated to this type of long-term data collection has evolved to allow for continuous audio recording. Fristrup explains that this longterm listening has, "helped us get a more complete picture of all the different kinds of sounds that take place in parks."139 Although, separate from the technological limitations of the programs' recording devices ${ }^{140}$, this "complete picture" is an objective one that is mainly interested in understanding noise intrusions in park lands. "We have not yet tried tackling," says Fristrup, "the much more complex issue of parsing all of the components of the soundscape and evaluating peoples' subjective responses to them. We are addressing the more universal

\footnotetext{
${ }^{137}$ Kurt Fristrup. Interview. 2016.

${ }^{138}$ According to the 2006 NPS Management Policies, section 8.2.3: The natural ambient sound level-that is, the environment of sound that exists in the absence of human-caused noise - is the baseline condition, and the standard against which current conditions in a soundscape will be measured and evaluated.

${ }^{139}$ Kurt Fristrup. Interview. 2016.

${ }^{140}$ The recording devices the program uses performs better below $1000 \mathrm{~Hz}$, which is in the range of frequencies that most transportation noise occurs. The recorders are not well equipped to record sounds that are above $1000 \mathrm{~Hz}$ because of the self-noise of the recording devices pre-amplifier and internal electronics.
} 
question: how does this background sound level effect the capacity of all organisms_-including humans - to hear any of the sounds that occur there?" 141

This universal question is essential to ask because the soundscape - the acoustic environment - affects all organisms in how they perceive each other and the environment. "If you allow noise to intrude a park," Fristrup says, "it not only affects the aesthetic evaluation of the park by visitors, but it also begins to break the sensory connections among visitors and the environment-among all organisms that are there." ${ }^{142}$ However, what about cultural sounds? Why then, is the soundscape — both "natural" and cultural—a component of NPS resource management? The 1988 NPS Management Policies was specific in stating that the Service will strive to preserve natural sounds like the "the howl of the wolf." The 2006 NPS Management Policies are clear in stating, "culturally appropriate sounds are important elements of the national park experience in many parks." They go on to say that, "the Service will preserve soundscape resources and values of the parks to the greatest extent possible to protect opportunities for appropriate transmission of cultural and historic sounds that are fundamental components of the purposes and values for which the parks were established.",143

In 2014, the Natural Sounds Program conducted a study on Isle Royale that concluded that the natural ambient sound level ranged between $40.1 \mathrm{dBA}$ during daytime and $22.8 \mathrm{dBA}$ at night with anthropogenic noise audible nearly $100 \%$ of the time. This study does not mention

\footnotetext{
${ }^{141}$ Kurt Fristrup. Interview. 2016.

${ }^{142}$ Kurt Fristrup. Interview. 2016.

143 Work by Psychologist Britt Mace [of Southern Utah University], Acoustic Ecologist Peter Newman [of Penn State], Acoustic Ecologist, Robert E. Manning [of University of Vermont] is looking at the affective dimension of how people respond to sounds - whether they judge them as appropriate in the context of whether they find them pleasing or annoying. One of the common exercises that those researchers have used has been an undirected listening exercise where visitors are asked to sit quietly and note the sounds they hear, identify them as best as they can, and then evaluate them along those two dimensions of appropriate/inappropriate and pleasing/annoying. Also see work on Dose-Response Relationships for Visitors to National Parks by Nicholas P. Miller, Grant S. Anderson, and Amanda Reposa.
} 
cultural soundscapes once. ${ }^{144}$ On Isle Royale, park visitors value the wolf howl as a component of the soundscape. The National Park Service acknowledges that this soundscape belongs to their resource management. If this baseline study determines the ways in which the soundscape is to be managed on Isle Royale, but does not include cultural soundscapes like the wolf howl, then the Park Service is overlooking an essential value that defines Isle Royale. Sound is a huge component of the park visitor experience, but it does not seem like the Park Service really focuses on that outside of limiting human-made noise. Ultimately, the question is: if the NPS holds a sound that people value in a park — like the howl — and that sound goes extinct, how does NPS resource management respond? While this question may seem irrational to some, I ask it because a dialogue about the importance of cultural sounds in parks as something to be managed is nonexistent to a large degree. When I posed this question to Fristrup, the Wilderness Act became of concern:

K: The Organic Act says that we are supposed to conserve resources unimpaired. Part of the determination [required for that] is to what epoch in time do we refer in identifying what the foundational resources of the park are. Wolves either are or are not part of that calculus as components of the ecosystem. If they are part of that calculus, as components of the ecosystem then I expect the Park Service will decide to reintroduce them, if they are not part of that and they are transient, the park will let nature take its course. But we can't manage things like it's a petting zoo. Our mandate doesn't say that we need to conserve the animals that are popular. Our mandate says that we need to conserve resources unimpaired. In terms of the Wilderness Act, it means that the natural processes must dominate. Under these criteria, I could imagine that this is why the soundscape on Isle Royale is really secondary. I think conserving the conditions, the natural processes, is important.

E: But human beings are a part of the natural processes. Right?

$\mathrm{K}$ : But the Wilderness Act is very specific. It's suppose to be untrammeled by man...

E: ...But that's contradictory because as soon as you designate something as "Wilderness," it becomes trammeled by man.

$\mathrm{K}$ : This is not entirely true. There are all sorts of things that are not allowed in wilderness. Often times, wilderness areas are managed to limit the number of recreationists who can visit. Labeling something "wilderness" doesn't necessarily protect it. And in fact one of the areas that our division [the Natural Sounds and Night Sky Division] is increasingly engaged in, is noise and light that doesn't respect boundaries. A lot of wilderness areas today are affected by noise and light far more then is consistent with the Wilderness Act management objectives. I don't think it's so clear.

${ }^{144}$ Isle Royale National Park. Acoustic Monitoring Report. Natural Resource Report NPS/NRSS/NRR—2014/886 
Given the fact that there are so many questions marks in the NPS's wilderness conundrum, the idea that reintroducing wolves based on the idea that Isle Royale park visitors value the wolf howl does not seem so absurd. Park policy is ambiguous. Scientist and park officials can describe policy options and advise on the likelihood of the repercussions of those options. But none of this analytical work based on collected data can make value decisions. What is natural, native, and diverse really hinges on values and its pretty clear to me that the NPS does not value cultural sounds. Accordingly, the NPS misrepresents their mission and their slogan, "parks are for people." If parks are for people, shouldn't people — the visitor-be essential in constructing the values and policy's of these places? Fristrup responded by stating that "popular values change rapidly, and if you were trying to manage parks in those ways there's no guarantee that that the park would stay environmentally and ecologically sustainable.” He goes onto say:

\begin{abstract}
Is the Park Service going to designate the wolf as some kind of keystone species for that island ecosystem? In my view, this decision doesn't get driven by the desirability of wolf sounds. This decision gets driven by whether or not, from an ecosystem management perspective, the judgment is that wolves belong there. This is an open question. You're right, this is one of the signature sounds for the island which very few people get to hear and which can transform a park experience. There is no question about that. When you look at the history - of not only Park Service regulations, but also the significant legal decisions - one of the principle findings has been that whenever there is any conflict between visitor use of parks and resource conservation, the courts have found that resource conservation must be given priority. Legal mandates tell us that we have to let the natural processes predominate. If park managers and scientists were to determine that restoring wolves was not conserving an authentic, intact ecosystem then the idea that visitors feel like wolf howls are the most important thing they experience on the island is not going to contribute to resource management. The Park Service makes decisions from a legislative and judicial perspective. This perspective does not pivot upon the subjective value that people place on certain sounds. It hinges on some sort of objective assessment of whether the ecosystem is intact, containing the species that are intrinsically critical to that ecosystem [...] National Parks are not amusement parks, nor are they are art galleries; they are not anything that has been constructed strictly for human enjoyment. They are places where we are trying to preserve something in the natural sense. We are trying to preserve a vignette of a time and a place for cultural and historic properties. ${ }^{145}$
\end{abstract}

Towards the end of my conversation with Fristrup, in which he responded to my position as an artist and composer, hypothetically asked: "Is the Natural Sounds Program at all interested in

\footnotetext{
${ }^{145}$ Kurt Fristrup. Interview. 2016.
} 
managing or crafting the composition of the soundscape through management actions?" Of

course he responded with a "most certainly no."

I cannot conceive of a time going forward when the Park Service would actually engage in a management action to manipulate natural soundscapes in someway that might prove more desirable. The Park Service will manage ecological systems so that natural processes predominate, and ensure that they are sustainable. Our part in that [process] is to make sure that the physical environment - these physical resources, both sound and photic - are such that animal and park visitor sensory systems can perform as they have evolved too, and we give the visitors and the wildlife the best chances to experience the most expansive and authentic acoustic environment as possible.

First off, on Isle Royale, the wolf howl does provide that "wild" and "authentic" experience for park visitors. But most importantly in regards to this comment, I disagree - not because the NPS focuses on the removal human-made machine noise as opposed to cultural sounds—but because the NPS, and wilderness advocates, have a blind eye to the fact that the NPS does in fact craft their composition of park soundscapes. When I brought this up, Fristrup transitioned:

$\mathrm{K}$ : Have you ever been in an improvisational acting class?

E: No.

$\mathrm{K}$ : One little technique that I've picked up from improv classes is that when you're in a conversation with somebody and you say, "Yes, but..." effectively you're saying "Yes. Now I'm going to dismiss everything you've just said, and tell you what I want to say." In these improv classes, they have you go through exercises where you say "Yes, and...." where you're constructing a dialogue by adding to things, not dismissing them.

E: My goal here is to understand as many perspectives on this matter.

Fristrup is absolutely right, the "Yes, and..." response in a dialogue is a good option when talking about "wilderness" and "nature" because an individuals definition of natures hinges on their values and beliefs. Unfortunately, individuals do not always observe that their own perspective is just one of many, and when people say "Yes, but..."—like we both did—one is not acknowledging this fact. The questions posed in this section about whether or not we listen to people in parks as possibly contributing to resource management is trying to add an additional perspective to the mix that is not present. Fristrup concludes: 
Part of what you're interested in is the diversity of perspectives and the diversity of values. How do we have conversations about this issue without spiraling into an escalating denial of another person's perspective? How do we have conversations that actually allow us to more fully appreciate the breadth of perspectives and try to identify themes that are common to all? Even if we do decide not to reintroduce wolves on Isle Royale based on the value of wolf howls, it still is a conversation that the Park Service and all public stakeholders needs to have. If nothing else, your work here will help clarify for all of us what the foundations of park management are all about. ${ }^{146}$

${ }^{146}$ Kurt Fristrup. Interview. 2016. 


\section{Echo of the Past}

"And then there are the times when the wolves are silent and the moon is howling." ${ }^{147}$ — George Carlin

The wolf pups heard by the Petersons and visitors on July $3^{\text {rd, }} 2013$ were in fact the last wolf pups heard on Isle Royale. These three pups brought the West Pack up to a population of six. The other social group on the island, the Chippewa Harbor Pack, brought the total wolves on the island up to nine. ${ }^{148}$ During the 2014 Winter Study, John Vucetich reported that skim ice had formed between Isle Royale and the mainland - a sign that a solid ice bridge will form at some point — which would be the second ice bridge in the past 17 years. Ice bridges are important because they represent the possibility that a wolf can migrate from Canada and infuse the population with new genetic material. An ice bridge did eventually form - and instead of wolves migrating from Canada to the island, one walked off. Isabelle - the resilient lone wolf in search of a suitable mate-left her home the first day of her life in which there was an ice bridge. Two weeks later, she was found — shot dead with a pellet gun by an eleven-year-old girl—near the frozen mainland beach inside the reservation boundaries of the Grand Portage Band of Lake Superior Chippewa Indians. ${ }^{149}$ At the end of that summer (2014) Rolf posted this message and poem on the Wolf/Moose Facebook page:

I had really hoped to see a live moose and hear a wolf howl while I was on the island. Neither came true. One of my last days, sitting in the morning sun at Daisy Farm, I felt part of the emotion of wilderness I think a lot of Isle Royale visitors share.

"ISLE ROYALE DAWNING"

Morning shed her dew before me.

The sun revealed her graces

and warmed to the touch

every fiber of the day,

but where was the night sound,... the howl of wilderness?

-Ron Porritt, Isle Royale visitor

\footnotetext{
${ }^{147}$ George Carlin quoted in the opening of the 2014-15 Wolf/Moose Study Annual Report.

${ }_{148}$ Rolf Peterson, and John Vucetich, Ecological Studies of Wolves on Isle Royale Annual Report, (Houghton, Mich: Michigan Technological University), 2014.

149 John Vucetich, Winter Study 2014: Notes from the Field (CreateSpace Independent Publishing Platform, 2014).
} 
Soon after, Candy sent me this in an email:

It doesn't seem that the island's wolves reproduced this year. Very few people have heard howling or seen wolves, and nobody has heard a group howl with high-pitched voices, so we are thinking the end may come soon for these wolves.

Wilderness for me, it's a place with all its significant components - in the case of Isle Royale, where moose are the dominant herbivore, that includes a predator that maintains the health of the entire ecosystem. One of the directives of the Organic Act, upon which the National Parks depend, is to maintain and pass on these special places UNIMPAIRED for future generations. Isle Royale without wolves would be an impaired park.

I've been thinking about the ways people pursue happiness and run from sadness. Isle Royale is a place where people can sit still long enough to feel the blessing, the goodness, truth and beauty of nature, overtake them. No need to pursue or to run, just open your heart.

A recent visitor said this very thing to us- - he said he'd been paddling on Moskey Basin and, all of a sudden, he had the sensation that life is good, that it's all beautiful. "Great," I said. "Now you can go home because you've had 'the Isle Royale experience'. "No," he replied, "You see, I'm a playwright, and I need to find some conflict, something dark." I had a similar encounter with an artist in residence a few years ago. It seems to me we bring the darkness with us, and we like to project it.

For me, it has been hard not to see the dark side of the NPS decision to do an EIS on the various wolf management options. [Superintendent] Phyllis Green and [Chief of Natural Resources] Paul Brown know that the wolves may not last long enough for the study to be completed. The entire staff seems to have bought into this policy. I recall the Hans Christian Anderson story "The Nightingale"— the Chinese courtiers echo the opinions of the emperor. A little bird speaks truth to power and saves the day. So, I soldier on, trying to see the good in these two people who seem unable to see anything good in the wolfmoose project.

The wolves are completely dependent on humans at this point. We may be having lovely numinous experiences (a term I just learned from my "Christian Century" magazine) here on Isle Royale, but they are trapped in a pristine prison. For them, pursuit of happiness and running from sadness is possible only when there's an ice bridge to the mainland. Isabelle made the escape in January and was promptly shot. The NPS may be willing to stand by and wait for the demise of the wolves here, but I am not. I will speak out to anyone who wants to listen!

On into the day! Best of luck to you with your projects!!!

Thanks for listening!

Candy

By January 2015, the wolf population on the island had decreased from nine wolves to just three - organized into a single social group called the Group of Three. According to the 2014/15 Ecological Studies of Wolves on Isle Royale Annual Report, another ice bridge formed and two mainland wolves walked from Canada to the island. A few days later they left. Whatever the intent of these two wolves, they never became aware of the three native Isle Royale wolves 
and even if they had, it is far from certain that genetic rescue — mating between an immigrant and a native that would mitigate inbreeding - would have occurred. It may, for all practical purposes, be too late for genetic rescue to occur on Isle Royale. ${ }^{150}$ On the last day of Winter Study 2014-

15, Rolf made this observation from the air in the flagship:

The Group of Three were heading for the shore....I thought it ironic that as the wolves reached shore, they were framed by the long shadows of the tall fir trees, trees that existed now only because of previous generations of wolves that had reduced moose density in the 1970s. This scientific finding is 20 years old, but it hasn't penetrated the thinking of everyone. Finally, the wolves disappeared in the trees and we were on approach to land. Without saying it, I thought, "Thank you, wolves, for all you've taught us...I'm sorry, very sorry, that it wasn't quite enough." I was quiet and left Donnee [the pilot] without a response as he briefed me on his landing plans and where he would drop me off. Before the engine was quiet, I had dried my eyes...knowing this was the last time anyone would see wolves on Isle Royale this winter, and perhaps for a very long time to come. ${ }^{151}$

The Petersons are eagerly listening for any clues of wolf reproduction because they feel

responsible for the wolves and hope for more time before complete extinction. Today, the long-

feared extirpation of wolves on Isle Royale is almost, if not already, complete.

${ }^{150}$ Rolf Peterson, and John Vucetich, Ecological Studies of Wolves on Isle Royale Annual Report, (Houghton, Mich: Michigan Technological University), 2015.

${ }^{151}$ John Vucetich, Winter Study 2015: Notes from the Field, (CreateSpace Independent Publishing Platform), 2015. 


\title{
Interlude: The Yawn/Wolves as People
}

The following quotes - from the Candy Peterson and John Vucetich—are reflections that

illustrate the human's relationship with another being — the wolf. This interlude is a stepping-

stone to the section, "Transition: From Wilderness to Music."

\begin{abstract}
When it was the 50th anniversary of this study, we [The Wolf/Moose Project] had a big celebration out here [Isle Royale]. Two days before the celebration we got a call on the radio that wolves had killed a moose at the Moskey Basin campground. We went down and stayed in Shelter \#8 right by the carcass. I lay awake all night thinking about what I needed to do in preparation for this big celebration- 60 people were coming to the cabin and I needed to bake-while listening to the wolves crunch the bones and rip the flesh off this moose cow. As soon as it was light the next morning, I rolled over in my sleeping bag in the shelter and looked out at this rock ridge. The wolves were all there. The big male wolf-as soon as I rustled my sleeping bag - was looking right at me with his ears up. He yawned. That yawn was like, "chill out lady, this weekend is about us — not you guys. Get your perspective right." That weekend went very well—even though the oven died-because I kept remembering that yawn. ${ }^{152}$
\end{abstract}

Understanding the life of a wolf — how it is the same and how it is different than ours - helps us understand ourselves and our humanity. The most remarkable lesson to learn from stories of individual wolves is also the simplest: The most important similarity between you and a wolf is that you both experience a life. That lesson is so simple and easy to overlook it merits being repeated - wolves are experiencers of life.

Understanding the life of an organism from its perspective should generate not so much respect, but empathy. Empathy is vivid, knowledge-based imagination about another's circumstances, situation, or perspective. Empathy tends to generate care... Is a wolf a person? The etymological root of person is a Greek word that means "mask," referring to the mask an actor would wear on stage. A person is an actor in the world. And so Shakespeare wrote, "All the world's a stage, and all the men and women merely players." Possessing [the traits that wolves do] - sensory consciousness, memory, dreams, intentions, personality, emotions - certainly qualifies as being an actor in the world, as the experiencer of a life. It is perfectly right to treat our dogs as people. Native Americans were certain that wolves and many other creatures were people. $^{153}$

${ }^{152}$ Candy Peterson. Personal Interview. 2015.

${ }^{153}$ R. Peterson, J. Vucetich, (2014). 


\section{The Value of Listening to People Listen}

"Parks are for people. And we need to consider that in our decision-making." 154

- Isle Royale National Park Interpretive Ranger

"Superintendent Green said we crossed the line. She said, "you are supposed to be scientists, you're not supposed to be advocates..."155 —Candy Peterson

In the Bangsund cabin, Candy's baking timer was clicking with the loons wailing on the lake, the smells from her pumpkin and chocolate pecan pies filled the musty wooden room. I was overly energetic because Candy kept filling my cup up with hot coffee and my plate with sugary oat bars. Candy bragged about the beautiful aurora she and Rolf saw the previous night — the one I missed. They were excited to show me an elaborate song that a Moosewatch volunteer recorded that season. Candy said, "Things like this help us cope with the bureaucracy of this place." The implications of this simple statement are that Rolf and Candy have serious resentment toward some of the main park officials of Isle Royale.

Many Isle Royale park officials were surprised that a permit for my project was approved by the NPS because soundscape research on Isle Royale had been nonexistent; the NPS, as discussed above, has only conducted a handful of qualitative studies with park visitors, dealing only with noise mitigation. ${ }^{156}$ As Rolf said, "I think its fair to say that the park service isn’t really listening to the public...they are just not set up to. ${ }^{.157}$ One possible reason why Isle Royale park officials have such a limited understanding — if any at all—of visitor perception of the soundscape is because all NPS researchers are constrained through strict Office of Management and Budget (OMB) approval, which takes months to process. Jeffery Olsen (NPS Chief of Public

\footnotetext{
154 Isle Royale National Park Interpretive Ranger. Personal Interview. 2013.

${ }^{155}$ Candy Peterson. Personal Interview. 2015.

${ }^{156}$ Pilcher, Ericka J., Peter Newman, and Robert E. Manning. 2009. "Understanding and Managing Experiential Aspects of Soundscapes at Muir Woods National Monument". Environmental Management. 43, no. 3: $425-435$. Stack DW, N Peter, RE Manning, and KM Fristrup. 2011. "Reducing Visitor Noise Levels at Muir Woods National Monument Using Experimental Management". The Journal of the Acoustical Society of America. 129, no. 3: 137580 .

${ }^{157}$ Rolf Peterson. Personal Interview. 2013.
} 
Affairs) explained to me in an email that NPS researchers can solicit visitor responses on a numbers of issues, including the soundscape, if they get OMB (Office of Management and Budget) approval. ${ }^{158}$ This tedious approval process has been set into place to reduce the burden of government paperwork on the public. However, based on my experience communicating with the public on Isle Royale, most are thrilled to share their experiences through face-to-face dialogue. Rolf is right, given constraints like OMB approval, the NPS is just not set-up to listen to the public. Accordingly, if Isle Royale National Park officials do not understand the ways in which this generation listens through the soundscape on the island, how can Isle Royale National Park abide by the NPS' mission to conserve their soundscape "resource for the enjoyment, education, and inspiration of this and future generations"? ${ }^{159}$ This guiding principle, reflected in the common saying in NPS literature that "The national parks belong to you," ${ }^{160}$ are why the voices of national park visitors - our voices—should be heard in policymaking. If the voices of park visitors who valued the wolf were being heard, park officials would know that the howl of the wolf is an essential value of the soundscape for park visitors on Isle Royale. Articulated in another way: If the howl — an icon and emblem of the soundscape in the National Parks—is on the brink of vanishing due to "unacceptable impacts," what responsibility does the NPS have in preserving and protecting this feature of the "resource"? ${ }^{161}$

When I posed this question to Isle Royale National Park's Cultural Research Manager, Seth DePasqual, he quickly deflected the question, saying, "This is irrelevant. Science is going to

\footnotetext{
${ }^{158}$ OMB approval is a requirement of the Paperwork Reduction Act (PRA) of 1980.

${ }^{159}$ National Park Service, “What We Do," http://www.nps.gov/aboutus/index.htm (January 2016).

${ }^{160}$ National Park Service, “Do Your Part,” http://www.nps.gov/getinvolved/doyourpart.htm (January 2016).

${ }^{161}$ The Visitor Experience and Resource Protection Handbook (VERP) - a National Park Service resource that provides a framework for management planners to better understand the resources visitors desire and their social conditions - does not mention the soundscape once. In passing, the handbook briefly mentions that park visitor's value the absence of other people's sounds.
} 
make the decisions." ${ }^{162}$ DePasqual's response brought to mind a conversation I had with a park visitor on the trail earlier that day. This visitor told me,

One thing people say is that we shouldn't intervene because if we introduce fresh genes into the gene pool of wolves here, we would be sticking our hands in it - except we are already sticking our hands in it because of global warming. Part of this is my own sentimentality too; I want there to be wolves here. ${ }^{163}$

This park visitor's reflexive observation—acknowledging his own sentimentality—is influenced not only by science, but also by his emotional connection to that scientific understanding. Unlike DePasqual, this park visitor is mindful of his suppositions not only about science but also about everyday life. ${ }^{164}$ "Science,” as Bateson wrote, "is just one more method of perception. Science probes; it does not prove." 165

Researchers can analyze all the different policy options, and scientists can advise as to the likelihood of the repercussions that result from following those various policy options based on their data. However, as articulated by Science and Technology Studies (STS), neither can make decisions for anyone; values determine decisions. This valorization of science as a way of managing nature has unfortunately led to the adoption of certain unexamined values-like the paradox of "letting nature take its course." DePasqual said,

I think the beauty of all this is that the matter is out of our hands. We as people are always trying to organize and make things ideal. What I love about this situation is that it is out of our control. The lake is in control of what happens here. Should we continue to tinker? And try to make things the way we want them to be? If we put new genes into the pool we'll be turning this place into a lab? ${ }^{166}$

Individuals like DePasqual believe in a world made visible through the lens of scientific inquiry, but the focus on empirical science overlooks what they actually feel through their body in the world. In other words, if DePasqual believes — at the same time - that the world is a collection of disembodied, empirical objects to be categorized, counted, understood, and managed, but also

\footnotetext{
${ }^{162}$ Seth DePasqual. Personal Interview. 2013.

${ }^{163}$ Isle Royale National park visitor. Personal Interview. 2013.

164 Bateson, 26.

${ }^{165}$ Bateson, 30.

${ }^{166}$ Seth DePasqual. Personal Interview. 2013.
} 
gets ecstatic when talking about his love for the embodied, relational experience of hearing and seeing wolves, he commits a categorical error and contradicts himself. This type of contradiction — a Cartesian dualism—plagues national park management and ultimately rules out intersubjective experience when constructing policy. To a certain degree, NPS perspectives have cultivated a deafness to any perspective that might contradict their unexamined assumptions. ${ }^{167}$

If scientific data determines decisions regarding how to approach the management of the dwindling wolf population on Isle Royale, then how is it that the experts on this science-Rolf Peterson and John Vucetich — are no longer being listened to by Isle Royale National Park officials? Candy makes light of this, "They all get around the coffee pot and talk, but they sure don't include us. We don't have a Superintendent who is very good at communicating."168 When I pushed Candy on what she meant, I was shocked to learn that Superintendent Green-who ultimately makes all of the decisions on Isle Royale — has not attended one of Candy's evening programs at Daisy Farm in the six years she has been giving the presentations. These evening presentations are entirely unique; there, I have witnessed a common ground where park officials, scientists, and park visitors respectfully communicate their points of view. How can the leader of this national park - the individual who makes all final decisions — not be a part of this dialogue? In fact, Candy reported that Superintendent Green recently told her that park visitors need to be "re-programmed" after they experience the viewpoints shared in Candy's presentations. In other words, by stating this, it is clear that Superintendent Green does not value the perspectives other then her own.

\footnotetext{
${ }^{167}$ Bateson, 27.

${ }^{168}$ Candy Peterson. Personal Interview. 2013.
} 
While DePasqual and I have different views on the issue, we at least both accept, are intrigued by, and listen to each other's perspectives. We both believe that, as environmental activist, Gary Wockner articulated,

That many different people, groups, and institutions could look at national parks over a 100 year history and interpret them differently, and could claim that the parks represented a host of different values and ideas that changed over time and place speaks to the postmodern concepts of "difference," "pastiche," "polyvocality," and the "relativism of meaning.,"169

DePasqual and I agree that the situation of the wolves of Isle Royale is bringing some people

together through the illumination of history. DePasqual said,

A number of different scientists have weighed in on this thing. A number of different scientists have different opinions on the matter. What we are benefiting from now is an expanded look at the issue. We are learning more about how we got to this point. A year ago we weren't really thinking about how the moose got to the island. For awhile I thought that there was this one story and this is how it is...but actually there are all these possibilities about how we got to where we are today... ${ }^{170}$

Whether or not the confluence of perspectives that has emerged will contribute to important decisions that not only affect Isle Royale National Park, but also policies across the NPShinges on Superintendent Green. All we can do is hope that she takes into consideration all the other voices that care about the future of Isle Royale and in addition, acknowledges the fact that the wolf has "cultural weight." As Wockner states in the conclusion to his dissertation:

If the last beaver on Isle Royale were about to die, would headlines about a 'death watch' appear? How about for a plant species or a species of bird? Not likely. Given this cultural weight heaped upon wolves by Park Service employees and researchers, and given the similar weight implied from the American public, it cannot be denied that wolves are cultural resources as well as natural resources. That the policies of the Park Service do not deal with this fact, and that this omission causes policy failure and tension, is one of the major conclusions of the case study. ${ }^{171}$

Isle Royale officials are considering how to proceed, and their process reveals some oldworld views regarding "nature" distilled to this basic dilemma: to intervene or to "let nature take its course" and in so doing continue the strict "hands-off" policy for managing wildlife that has ruled the NPS for its 100-year history. Their decision in this case, as articulated by the Isle

\footnotetext{
${ }^{169}$ Wockner, 73.

${ }^{170}$ Seth DePasqual. Personal Interview. 2013.

${ }^{171}$ Wockner, 224.
} 
Royale Park Superintendent and others, will more broadly set precedent in NPS mandates as they inevitably begin to adapt to global climate change. The situation on Isle Royale is the biggest and most controversial issue facing the NPS today, and the document that will determine the fate of wolves on the island is the NPS's Moose-Wolf-Vegetation Management Plan and Environmental Impact Statement (plan/EIS). When I left the island in 2013, Isle Royale National Park officials said they were in the pre-scoping phase of the plan/EIS; however, the Petersons informed me that NPS seemed to be "dragging their feet"172 on a decision about whether or not to reintroduce wolves or augment the existing wolf population.

Responding to an April 2014 news release by Superintendent Phyllis Green, four U.S. Senators led by Gary Peters (D-MI) sent the director of the National Park Service, Jonathan Jarvis a letter. In it he urges the National Park Service to accelerate the plan/EIS review process on Isle Royale and to complete its planning in a year or less, instead of the two to three year timeline estimated by the National Park Service:

It is our understanding that the National Park Service has already made the decision to not bring new wolves to Isle Royale in the immediate term. Bringing new wolves to Isle Royale, also known as species augmentation, should be preserved as an option to prevent losing this unique wolf population. Valuable time has been lost because a review process has not yet started. National Park Service is expected to start an initial scoping process in the coming month with a broader review expected to be completed in two to three years. This timeline simply does not align with the reality of Isle Royale's current wolf population. National Park Service should reach a management decision while all options, including species augmentation, remain available. We urge the National Park Service accelerate the completion of a National Environmental Policy Act planning process and conclude this process by June 1, $2016 .{ }^{173}$

During July 2015 Isle Royale National Park filed a Notice of Intent to prepare the plan/EIS, one which ignored the Senators' plea to expedite the process. In a detailed NPS newsletter published shortly after the Notice of Intent was filed, the public was asked to submit responses to an online survey of the proposed alternatives for managing the moose population: let nature take its course;

\footnotetext{
${ }^{172}$ Rolf Peterson. Personal Interview. 2013.

${ }^{173}$ Gary Peters, United States Senate Letter, http://www.peters.senate.gov/imo/media/doc/150529_Letter_Wolves_IsleRoyale.pdf (May 2015).
} 
wolf augmentation (add wolves to the preexisting population); wolf reintroduction (add wolves after extirpation); manage moose by translocation of live moose or culling. The Public Scoping Comment Period ended in August 2015. When I submitted my comments, I found that I was confused about how the plan defined "nature"-in fact, the plan does not define it at all. Also, when the plan discusses possible solutions for keeping moose numbers down in the future, they bring up climate change as a possible solution. In the plan, it becomes clear that the NPS acknowledges the effects of human beings on the island, a statement which clearly contradicts any type of "let nature take its course" language. In addition, there has been much discussion about whether or not these public comments will actually contribute to the plan. In a piece in the Detroit News (August, 2015) Nancy Warren (director of the National Wolf Watcher Coalition) was quoted saying that the 1,100 comments she received — which $75 \%$ call for genetic rescueare being disregarded by the National Park Service. Candy Peterson also voiced her concern about the park service being required to solicit comments but not required to "pay attention to them." Candy explained to me,

For two and a half years the park has been receiving email responses- 1,000 people wrote in (including myself)...I read them all. 85\% of those responses want wolves on Isle Royale... she [Superintendent Green] has said that those responses will not be part of the plan/EIS. She has ignored those comments because they don't affirm her position. ${ }^{174}$

According to the official plan/EIS timeline-after refinement of the alternatives, the production of a draft plan, and the distribution of a final plan — a Record of Decisions will finally be made during the Fall/Winter of 2017. According to Rolf, however, the remaining two or three Isle Royale wolves will die in that period of time.

At the 2013 forum entitled “The Disappearance of Isle Royale's Wolves: How Should We Respond?," a member of the public asked Superintendent Green, "What is the vision of Isle

\footnotetext{
${ }^{174}$ Candy Peterson. Personal Interview. 2015.
} 
Royale National Park?" ${ }^{175}$ Green responded, "For Isle Royale we are in the process of defining what that vision is." ${ }^{176}$ I asked Rolf about how a park- which is managed based on values, or visions_ could not already have these visions firm and articulated. He replied, "They are trying to remove wolves from the mission of the park." ${ }^{177}$ I understand that when circumstances change, values shift. Based on my understanding, however, most visitors want wolves on the island. Both Rolf and I agree that — if this is true — the Superintendant's refusal to articulate an intention to mold policy toward removing wolves from the island is absolutely undemocratic. ${ }^{178}$ My response to a question about management alternatives in the Scoping questionnaire was concise:

I'd like to suggest that new management tools be established that are innovative; management tools that were not established in accordance with the 1964 Wilderness Act; management tools that reflect today-in the year $2015 .^{179}$

As we move past the $50^{\text {th }}$ Anniversary of the Wilderness Act, NPS decision-making needs to start immediately considering other narratives and how they comingle. In addition, this plan/EIS document is full of contested words like, "natural," "ecosystem integrity," and "healthy ecosystem" that reinforce the assumed strict line between culture and nature, and between - as Wockner explained, "European colonization and that which came before."180 In a 2009 statement, the National Park Service Director Jonathan Jarvis admitted that the NPS needs to start confronting the fact that the world we live in today is different than when park policy—and the Wilderness Act - was first established. ${ }^{181}$ He said that NPS policies need to change with the

\footnotetext{
${ }^{175}$ Member of public. From transcript of “The Disappearance of Isle Royale's Wolves: How Should We Respond?” June 2013.

${ }^{176}$ Phyllis Green. From transcript of “The Disappearance of Isle Royale’s Wolves: How Should We Respond?" June 2013.

${ }^{177}$ Rolf Peterson. Personal Interview. 2015.

${ }^{178}$ I tried to contact Superintendent Green to get her perspective but did not receive a response.

${ }^{179}$ Erik DeLuca. Plan/EIS Public Scoping Submission. 2015.

${ }^{180}$ Wockner, 226.

${ }^{181}$ Jonathan Jarvis, Climate Change and National Parks, https://www.doi.gov/ocl/hearings/111/ClimateChangeOnNatlParks_040709 (April 2009).
} 
climate. But I would add that we need not only consider the narratives of policy makers, capitalists, park service employees, and scientists, but the narratives of park visitors - their narratives that emerge from listening for wolf howls. In government law, the NPS includes sound as a constituent part in their "resource management" and each park individually identifies the "resources" that they value. ${ }^{182}$ If the wolf howl—an icon and emblem of the soundscape in the NPS — is on the brink of vanishing, what responsibility does the NPS have for preserving and protecting this feature of the "resource"? It became clear to me that park visitors value the wolf howl, but whether or not this will be considered in the plan/EIS is at the heart of the complexand, ultimately, contradictory_relationship the NPS has with nature. In an April 2014 interview with Science, Superintendent Phyllis Green reported that, "the decision is not to intervene as long as there is a breeding population." 183

When I left the Bangsund cabin in late September 2015, Rolf and Candy were clear about their feelings. With the lack of communication coming from Isle Royale officials they feel helpless about the future of the Isle Royale wolves. As Candy ran out of the cabin-visibly sad, she said, "And so we keep going and hope we are forgiven at some point." The door slammed shut, I signed the guestbook, gobbled down another cranberry oat bar, and hugged the Petersons goodbye.

\footnotetext{
${ }^{182}$ United States, Management Policies (Washington, D.C.: U.S. Government Printing Office, 2006).

${ }^{183}$ Science, "U.S. Park Service Nixes Immediate Genetic Rescue of Isle Royale Wolves." Accessed December 2015 from: http://www.sciencemag.org/news/2014/04/us-park-service-nixes-immediate-genetic-rescue-isle-royale-wolves
} 


\section{Transition: From Wilderness to Music}

...one could view everyday life itself as theatre. ${ }^{184}$-John Cage (Composer)

Twilight is my favorite time to be on Isle Royale. The sounds of change - the dusk

chorus - the deep blue water, the dark green tree line, and the sky all blur together with a purple tint-like experiencing three horizontal lines of a Rothko painting in a large reverberant space. I value this moment on the island because I can exist in the differences of time-fleeting. From Gregory Bateson:

All receipt of information is necessarily the receipt of news of difference, and all perception of differences is limited by threshold. Differences that are too slight or too slowly presented are not perceivable...Knowledge at any given moment will be a function of the thresholds of our available means of perception. Not only can we not predict into the next instant of the future, but more profoundly, we cannot predict into the next dimension of the microscopic, the astronomically distant, or the geologically ancient. As a method of perception - and that is all science can claim to be - science, like all other methods of perception, is limited in its ability to collect the outward and visible sign of whatever may be the truth. ${ }^{185}$

In this speck of time - today - the wolves of Isle Royale allow us to understand, by listening in, the changing threshold of our relationship with nature. What if the National Park Service considered the relational dynamism of nature? What if, ideologically and discursively, they focused less on paradoxical objects called wilderness and more on our direct experience of that wild object down to wild plant growth in the cracks of the sidewalk? Should the National Park Service be responsible for understanding how to manage and interpret parklands by entwining emotion, reasoning, art and science? The Isle Royale acoustemologies that emerge from Rolf and Candy's citizen-science in sound lifetime initiative is an example of that entwinement.

Unlike certain communicative mediums — written words, printed words, reproduced speech, filmed speech, the telephone, e-mail—which form physically detached communities, Isle Royale acoustemologies link minds together physically. ${ }^{186}$ Listening for the howl—both

\footnotetext{
${ }^{184}$ Cage, John, Michael Kirby, and Richard Schechner. 1966. "An Interview with John Cage". The Tulane Drama Review. 10: 50-72.

${ }^{185}$ Bateson, 29-30.

${ }^{186}$ Le Guin, 194.
} 
foundationally and effectively - is an embodied human experience which is an emergent

property of a listening relationship between wolves and humans. This relationship moves beyond interactivity to intersubjectivity which results in a specific kind of community. ${ }^{187}$ Relationships are always about aesthetics - awareness and responsiveness to connecting patterns. ${ }^{188}$ Social anthropologist Katja Neves-Graça writes about the aesthetics of an ex-whale hunter turned whale-watch skipper of the Azores who describes what it was like when he was a hunter acting in unison and communion with his prey:

Now with both hands on his knees, breathing with some difficulty, the harpooner is invaded by an overwhelmingly intense range of emotions - happiness, fear, pain, exhilaration. The whale's throe is the whaler's agony. Each painful movement of the giant's body is felt by the whaler's aching bones. Every time the whale's tail crushes into the water the whaler's heart shatters and sinks. When finally the whale's small flipper comes to rest, the whaler chinches his jaw and looks fixedly at the star of the whale's last wish. The whale is dead, the whaler is mortified. And yet, it is at this very moment where life and death meet, that the whaler glimpses the sublime and senses it with all his being. He becomes aware that he feels the living unity of self-whale-surrounding, and suddenly, if for a fleeting instant, he realizes that all the pain and suffering he has ever endured in his life, all the good and happy moments he has lived, whence his entire existence, is justified in the beauty of a mortal whale. Whalers are not addicted to slaughtering whales. They long for the transformed understanding they gain from responding to the pattern that connects them to the whales, to each other, to the Ocean, to the people of Lajes, and to the island of Pico. For a whaler of Lajes, it is a fundamental truth that 'nobody loved a whale more than a whale hunter'. For them, this truth is sacred. ${ }^{189}$

When Neves-Graça was learning about the aesthetics of whale hunting, she realized that she needed to combat an important pitfall of eco-tourism as she watched for whales: to stop trying to locate the beauty — the sublimity — of the whale as an object out there waiting to be found and instead focus on the whole experience. Instead of fixating his gaze on the brief photographic moments, the ex-whale hunter turned whale-watch skipper directs people's attention to auditory details, like the sounds that whales make. Neves-Graça says that the skipper makes people aware of distinct patterns of breathing and explains which ones meant the whale was "relaxed, nervous,

\footnotetext{
${ }^{187}$ Le Guin, 188.

${ }^{188}$ Neves-Graca, Katja. "Chasing Whales with Bateson and Daniel." Australian Humanities Review, Issue 35 (2005).

${ }^{189}$ Neves-Graca, 1(2005).
} 
tired, or simply resting."

Similarly, Rolf and Candy Peterson nurture these Isle Royale acoustemologies - acquired through awareness and responsiveness - that are founded on understanding relationships with wolf and environment. With the backdrop of the island's circadian rhythms and heart beats these acoustemological synchronicities belong to a music of everyday life:

If you mount two clock pendulums side by side on the wall, they will gradually begin to swing together. They synchronise with each other by picking up tiny vibrations they each transmit through the wall. Any two things that oscillate at about the same interval, if they're physically near each other, will gradually tend to lock in and pulse at exactly the same interval...Physicists call this beautiful, economical laziness mutual phase locking, or entrainment...All living beings are oscillators. We vibrate...we pulse, move rhythmically, change rhythmically; we keep time. ${ }^{191}$

Like yoik song-chants of the indigenous Nordic Arctic Sami, this connection through "tiny vibrations" - sound, is developed through an aesthetics of entrainment - the aesthetics of listening in music of everyday life. In this music, as renowned Sami joiker and professor Ande Somby says, "It is not easy for the trained ear to hear the difference between an animal's yoik, a landscape's yoik or a person's yoik." Instead, unlike most conceptions of human/nature relationships, the yoiker, the yoiked, and the yoik are one thing. For both Sami and Isle Royale acoustemologies — the sonic way of knowing a place-human communication with the nonhuman is not achieved by means of dualistic Cartesian thinking but rather through an appreciation for their place within nature, premised on an "epistemology of holism."192 Like a metaphor, this type of "intra-species and cross-species communication" 193 is about identifying the differences and similarities between humans and non-humans-leading to a critical, politicized awareness of environmental issues that is not "external to the human agent."194 As Neves-Graça observes with Bateson in mind, the meaning of the communicated

\footnotetext{
${ }^{190}$ Neves-Graca, 1(2005).

${ }^{191}$ Le Guin, 195.

${ }^{192}$ Neves-Graca, 1(2005).

${ }^{193}$ Neves-Graca, 1(2005).

${ }^{194}$ Neves-Graca, 1(2005).
} 
message is intrinsic to the interaction which can not entirely be reducible to a written narrative:

Ecological aesthetics in particular can never be about the detached appreciation of arbitrarily dissected and located aspects of part-whole relations (as in whale watching and its effort to 'see' how beautiful whales are). As the Azorean material shows, it is through interaction-comparison that a whaler recognizes himself in that with which he interacts, while at the same time he recognizes the differences that make him a part of a whole. It is by means of this process that the whaler becomes aware of patterns that links him to other whalers and humans, to sperm whales, to the environments of Lajes.

Because Isle Royale acoustemologies are immanent in the interaction, as Ingold explains, what does it mean to reduce and reproduce it to some type of objectification-like an art object?

...my aim is to replace the stale dichotomy of nature and culture with the dynamic synergy of organism and environment, in order to regain a genuine ecology of life. This ecology, however, will look very different from the kind that has become familiar to us from scientific textbooks. For it comprises a kind of knowledge that is fundamentally resistant to transmission in an authorized textual form, independently of the contexts of its instantiating in the world. ${ }^{195}$

It would be reductionist to express this socioaesthetic world through any type of objectification

like a composed musical narrative or an analytical deconstruction.

\begin{abstract}
When "nature" becomes an object of visual consumption, to be appreciated by the connoisseur's eye sweeping over an expanse of landscape, there is a good chance it has already left the realm of firsthand experience and entered the category of constructed experience that we can appropriately call simulation. Ironically, then, many of the experiences that contemporary Americans most readily identify with naturemountain views seen from conveniently located lookouts, graded trails traversed along gurgling streams, great national parks like Yosemite visited with reservations made months in advance-could equally well be considered simulation. Thus the distinction between simulation and nature with which we began is a crumbling dike, springing leaks everywhere we press upon it. ${ }^{196}$
\end{abstract}

This is why one needs to be in the perpetually, rhythmically changing material reality of Isle Royale - listening in with Rolf and Candy, themselves, with the gestalt_learning about human, about wolf, and all the different relationships between in, as Ingold writes, the "ecology of life" or "sentient ecology." ${ }^{\prime 197}$ This relational process is a form of discovery of music in everyday life. Like the hybridity of wolves and their howls - material objects which also carry socially

\footnotetext{
195 Ingold, 16.

${ }^{196}$ Katherine, Hayles, "Simulated Nature and Natural Simulations: Rethinking the Relation between the Beholder and the World." in Uncommon Ground: Toward Reinventing Nature, William Cronon, ed. (New York: W.W. Norton Company) 89.

${ }^{197}$ Ingold, 25.
} 
constructed symbolism in American culture - this example of music in everyday life exists somewhere in-between nature and culture. ${ }^{198}$

The ecological metaphor that emerged from the environmental movement of the $60 \mathrm{~s}$ has since been adopted by the discourse of music. Instead of using the ecological metaphor to investigate the preservation of musical diversity, scholars are rapidly asking what music can tell us about the natural environment and what the natural environment can tell us about music (Allen 2011) (Feld 1994) (Glahn 2003) (Guy 2009) (Pedelty 2012) (Rehding 2002) (Titon 2009). ${ }^{199}$ Listening with and through Isle Royale has taught me that we need to think about environmental music differently_acknowledging that the "nature" which people seek to understand and protect is always encountered through the lens of a culture's own conceptions. What if environmental music resounded with more historical and cultural elements, including narratives about the meaning and moral imperatives that contribute to the engagements with nature that have inspired it? ${ }^{200}$ What if environmental music proclaimed that all the different natures flow from human values? What would a self-critical environmental music sound like? Instead of thinking about environmental music — the cultural experience of nature — as either occupying one pole of the nature/culture dualism, "as either autonomous natural actors or absolute social productions, ${ }^{201}$ what if we approached environmental music with metaphors like philosopher Bruno Latour's “quasi-object” and feminist scholar Donna Haraway's “cyborg” that allow for a part-nature/part-culture object to be both ideal and material, "one that is a part of the story and also tells its own story" ${ }^{202}$ ? How does an artist do this?

\footnotetext{
${ }^{198}$ Wockner, 219.

${ }^{199}$ Perlman, Marc. 2014. 'Ecology and Ethno/musicology: The Metaphorical, the Representational, and the Literal'. http://ethnomusicologyreview.ucla.edu/content/ecology-and-ethnomusicologymetaphorical-representational-andliteral (accessed 1 January 2015).

${ }^{200}$ Cronon, "Introduction," (1995), 26.

${ }^{201}$ Demeritt, 163.

${ }^{202}$ Wockner, 93.
} 


\section{The Last Boat Out: to Empathy in the Art of Nature}

The living tongue that tells the word, the living ear that hears it, bind and bond us in the communion we long for in the silence of our inner solitude. ${ }^{203}$-Ursula K. Le Guin

I’ve spent many hours sitting atop the old Mt. Ojibway fire tower lookout. Looking down on a good portion of this 210-square-mile island I see a place that amplifies the most important issues that will determine not only the future of the National Park Service-whose Centennial is in 2016 - but also come to define the greater American environmental movement in all its incarnations. To the north, I can make out the shore where Isabelle's body was found and to the south I can see Ransom Hill, Angleworm Lake, and Lake Benson. Somewhere-out there, roaming - are two or three wolves but their dynamic past is right here entangled in the popular misconceptions of the "natural balance." Environmental historians like William Cronon have articulately demonstrated that human beings have been manipulating ecosystems since the record of time. Cronon asks, "What would a more historically and culturally minded way of understanding nature look like, which would take seriously not just the natural world but the human cultures that lend meaning and moral imperatives to that world?"204 Sitting seven stories above the Greenstone Ridge, with the fire tower droning in sympathetic vibration with the wind, I recall Cronon's seven cultural constructions of nature - none of which are natural: nature as a naive reality, nature as moral imperative, nature as Eden, nature as artifice, nature as virtual reality, nature as commodity, nature as demonic other (nature as avenging angel), and nature as contested terrain. These conceptions of nature are essential to understand because they not only tell us about ourselves, but also about the context of the things we label with the term.

\footnotetext{
${ }^{203}$ Le Guin, 205.

${ }^{204}$ Cronon, "Introduction," (1995), 26.
} 
I reiterate that the materiality of environmental music is not my concern; rather, my concern is the metaphor imposed by the authors of this form of environmental art. Wockner Writes:
A landscape is a cultural image, a pictoral way of representing, structuring or symbolizing surroundings. This is not to say that landscapes are immaterial. They may be represented in a variety of materials and on many surfaces - in paint or on canvas, in writing on paper, in earth, stone, water, and vegetation on the ground. A landscape park is more palpable but no more real, no less imaginary, than a landscape painting or poem. Indeed the meanings of verbal, visual and built landscape have a complex interwoven history. To understand a built landscape, say an eighteenth-century English park, it is usually necessary to understand written and verbal representations of it, not as 'illustrations', images standing outside it, but as constituent images of its meaning or meanings. And of course, every study of a landscape further transforms its meaning, depositing yet another layer of cultural representation. ${ }^{205}$

American composer John Luther Adams (JLA) counters this metaphor when he said, "The truth is, I'm no longer interested in making music about anything." ${ }^{206}$ In the shadow of his Pulitzer Prize in Music and the Grammy for his orchestral work Become Ocean, JLA was honored with the 2015 William Schuman Award. On the last night of JLA's Schuman Award concerts, I sat in the Miller Theater at Columbia University and listened to one of my favorite pieces of music: In a White Silence for celesta, harp, string quartet, two vibraphones, and string orchestra. Three years earlier, during the winter solstice in Denali National Park, I ironically listened to this same work on my iPod in the very "white silence"—still, absence-of-sound—by which the piece was inspired. Living in a small cabin outside Fairbanks, JLA has grounded his career on the idea of Alaska. This music, and, in general, the way JLA represented it seduced me into visiting Alaska many times to experience his nature.

Right before JLA's cascade of successes, The Boston Globe published an article in July 2015 called "The Portable Wilderness of John Luther Adams," which speaks to the ways in which JLA's music resonates within the broader wilderness ideology. JLA thinks his music can

\footnotetext{
${ }^{205}$ Wockner, 1.

${ }^{206}$ John Luther Adams, Making Music in the Anthropocene (Slate.com 2015).
} 
become a "place" where the listener becomes "the protagonist." 207 JLA denies any type of musical narrative and wants to leave "the story behind to get to this primary experience of listening, where it is no longer about what the composer is telling you: you are in the musical wilderness and need to find your way own way out." ${ }^{, 208}$ This classic avant garde viewpoint— that music can somehow be autonomous and separate from the composer who authored it — is similar to the wilderness ideology that insists that nature is separate from the human. Humans have been manipulating nature since the beginning time and there is no way to let the music JLA composes to be "itself." JLA's music is like the landscape in that we remember it through an engagement that is "itself pregnant with the past." 209

JLA, who values nature as the groundwork of morality, represents his music through discussions of "nature as demonic other"—where the nonhuman world, despite the human beings best efforts, will never be fully controlled. JLA consistently predicts ecological doom by offering narratives of disaster occurring because of our "misdeeds against earth.",210

Life on this earth first emerged from the sea. As the polar ice melts and sea level rises, we humans find ourselves facing the prospect that once again we may quite literally become ocean. ${ }^{211}$

During a presentation at the Banff Cantre, while a recording plays of his romantically dramatic, prize-winning work Become Ocean, JLA poetically described his listening to Pacific Ocean waves and then swiftly transitions:

A strong gust of wind reminds me of the increasingly capricious weather and the storms that lash this and other shores with growing voracity. The burning sunlight reminds me of melting tundra and expanding desserts, of diminishing polar ice and rising seas all over the earth. What does this mean for music? Or for any artist working in any medium today? These looming threats to the biosphere compels me to write music that is more than mere entertainment, more then a personal narrative, or a celebration of the heroic struggle of the individual. But can music be engaged with current events and at the same time detached from them? Can music resonate with the world around us and yet still create a world of its own? ${ }^{212}$

\footnotetext{
207 John Luther Adams Schuman Award Concert Program Note 2015.

208 John Luther Adams, Making Music in the Anthropocene (Slate.com 2015).

${ }^{209}$ Ingold, 189.

${ }^{210}$ Cronon, "Introduction," (1995), 48.

${ }^{211}$ John Luther Adams, Become Ocean: for orchestra, musical score (2015)

${ }^{212}$ John Luther Adams: Music in the Anthropocene: https://www.youtube.com/watch?v=wWG0zpPOGcQ
} 
These questions_ - perhaps one could even consider them justifications - are inherently contradictory. In search for the fulfillment of his desires, JLA fled to Alaska in the 70s to work for the Wilderness Society, the Alaska Coalition, and the Northern Alaska Environmental Center. Returning to simpler, more primitive living; moving out of the confinements of civilization; finding that truer world that would allow one to rejuvenate one's sense of self, are all sentiments that reflect the American frontier myth - the wild West. This myth that was brought to life through the imagination of easterners via western novels written about the American frontier. "To protect wilderness," says Cronon, "was in a very real sense to protect the nation's most sacred myth of origin" and where the "last bastion of rugged individualism" could be accessed. $^{213}$ In Alaska, the nature that JLA believes in- the nature he represents through his music — is the kind of nature that human beings belong out of - not in. Has JLA ever stopped to wonder what effects his contribution to the Alaska National Interest Lands Conservation Act (the largest land preservation law in U.S. history) had on aboriginal hunting and fishing rights? Did he consider the removal of natives from their land? Although the musical sounds alone- the impulses that move little particles of air and travel through materials that vibrate- are beautiful to listen too, how can I separate them from the way JLA represents these sounds?

JLA's award winning orchestral work Become Ocean draws people into nature as a “demonic other," while also reflecting the "nature as Eden" narrative where the "perfect landscape, a place so benign and beautiful and good that the imperative to preserve or restore it could be questioned only by those who ally themselves with evil." ${ }^{214}$ Become Ocean is a catalyst that perpetuates the idea that humans are responsible for destroying pristine nature-resulting in “environmental degradation and moral jeopardy." Become Ocean reinforces the idea that the

${ }^{213}$ Cronon, "The Trouble with Wilderness," (1995) 77.

${ }^{214}$ Cronon, "Introduction," (1995) 37. 
nature to which we need to return is a place that is some version of the "original garden, the paradise that would have been ours if only we hadn't lost our way."215 JLA can't think about nature as being entwined with his own cultural pursuits — nature as right here — and he feels the need to choose between "life as an environmental activist or life as an environmental artist":

Someone else could take my place in politics and no one else can make the music that I imagined but me...music and art can matter every bit as has much as activism and politics...music has the power to inspire the renewal of human consciousness, culture, and yes - even politics... and yet I refuse to make political art...political art fails as politics and as art... art must be itself... When I let the music be whatever it wants to be then everything else including any social or political meaning will follow...I'm not interested in sending messages or telling stories with music...I'm no longer interested in making music about anything...the last thing I want to do is limit the listeners imagination. ${ }^{216}$

JLA's music - a one-way communication that deflects dialogue - is political through his environmentalism, which is ultimately defined entirely by his conceptualizations of nature.

To be clear, politics do not need to be embedded in the materiality of a work for it to be political. Even if he aspires to make music separate from his beliefs, listeners-like the Boston Globe writer of "The Portable Wilderness of John Luther Adams" and a number of new composer networks like Landscape Music — are going to experience the music through the lens of his environmental politics conveyed through his composition titles, program notes, his op-eds in popular media outlets, his books, and the many speeches he gives. As Cronon writes, When we look closely at ideas of nature, we almost always find competing notions of the good, the true, and the beautiful disguised as singular, monolithic nature. If nature is partly in the eyes of the beholder, whose eyes should we trust to see it clearly? ${ }^{217}$

But why does JLA so actively try to distance himself as an environmental activist while simultaneously grounding his life's work on that very identity? How much does JLA's political stance contribute to the way listeners experience his music? Are these politics the stimulant for his success? These questions are important to ask because as Cronon points out, "all of this calls into question the familiar modern habit of appealing to nonhuman nature as the objective

\footnotetext{
${ }^{215}$ Cronon, "Introduction," (1995) 39.

${ }^{216}$ Adams, (2015).

${ }^{217}$ Cronon, "Trouble with Wilderness," (1995) 82.
} 
measure against which human uses of nature should be judged." ${ }^{218}$ In this case, JLA's music is, for many individuals, the idealized representation of what nature should be-_nature as artifice." JLA knows what nature should look like: his clear vision of it "becomes a moral or cultural imperative" and remakes it so completely that he - and the supporters that buy his music and his message — become indifferent toward other perspectives and histories. JLA's musical landscapes and the messages that he attaches to them, despite their apparent symbolic opposition, become indistinguishable and merge into one another. ${ }^{219}$ This music becomes a form of "nature as virtual reality" where-like Sea World — individuals are confronted with situations where the natural and the virtual coexist.

Why does JLA go so far in justifying what his music is not? One possible reason for this is that JLA does not want to sell his music as "nature as commodity." But he does. Like the objects sold by the Nature Company, his music is framed through an environmentalist discourse. Continuing the comparison to Sea World, JLA's music contains a particular idea of authentic nature that is bought and sold as a consumable experience. He sells the idea that if you buy his music — a recording of it or a live experience in a concert hall—it will raise your awareness of his particular vision of what nature should be:

For modern consumers, spectacular images of nature appear as compelling visual evidence that their individual purchases, and their lifestyle in general, are connected to positive environmental effects at locations that are usually distant and exotic (from the perspective of the consumer). The push of a virtual button, or the swipe of a virtual card appears to initiate a chain of events ending in the protection of a family of artic polar bears or an acre of tropical rainforest. ${ }^{220}$

JLA's music — a mode of environmental fixing which "sells nature to save it" —interacts much like carbon offsetting, where, as cultural anthropologist James Igoe says,

\footnotetext{
${ }^{218}$ Cronon, "Introduction," (1995) 25.

${ }^{219}$ Cronon, "Introduction," (1995) 40.

${ }^{220}$ Igoe, 13.
} 
nature that can be made exchangeable for the purposes of investment... by channeling exchange value for ecological and social good. The price tag is still imagined as determining the fate of nature, but now that fate will be a positive one. ${ }^{221}$

One possible reason why people have bought into JLA's ideas of nature, through his music, is that, as noted by Igoe, the socio-ecological effects of our activities and relationships - at multiple scales and locales — are, like sound, both far-reaching and impossible to see. "We are thus," Igoe says, "exceedingly dependent on abstract models of reality, with few practical means of verifying them."222 I'm not arguing that environmental music — nature — as a commodity is "bad" but rather want to illuminate Igoe's point that "modern culture and capitalist value making are the source of [abstract, universal,] awe-inspiring nature" that often detaches the history from which it sprang. ${ }^{223}$ JLA's music_- presented as a virtual reality, a simulated environment, "exchangeable nature for contemplation",224_presents a cultural construction so "comfortable that it seems utterly commonsensical, universal, and natural to those who inhabit it — no matter how problematic its consequences may be. ${ }^{225}$ Paradoxically, JLA offers advice for listeners on how to remove his politics — politics he clearly denies making — from the music: "if a listener feels constrained by any words that I may offer along with the music then I encourage her to ignore them..."226 Despite simultaneously inviting people to ignore this message, JLA has consistently represented his music as being able to bring awareness to the environment and global climate change:

As a composer it's my belief that music can contribute to the awakening of our ecological understanding. By deepening our awareness of our connections to the earth, music can provide a sounding model for the renewal of human consciousness and culture. ${ }^{227}$

\footnotetext{
${ }^{221}$ James Igoe, A Genealogy of Exchangeable Nature, in S. Paladino and S. Fiske The Carbon Fix: Forest Carbon, Social Justice, and Environmental Governance (California: Left Coast Press, 2016) 1-2.

222 Igoe, 4.

223 Igoe, 10.

224 Igoe, 12.

${ }^{225}$ Cronon, "Introduction," (1995) 46.

${ }^{226}$ Adams, (2015).

227 John L. Adams, The Place Where You Go to Listen: In Search of an Ecology of Music (Middletown, Conn: Wesleyan University Press, 2009), 1.
} 
This dance helps to naturalize the idea that one can observe problems with the environment, but is not personally responsible for acting differently_turning the environment into something that has nothing to do with our own actions, a "nature as naive reality."

All of JLA's beliefs of nature "want us to see nature as if it had no cultural context, as if it were everywhere and always the same." ${ }^{228}$ But anything having to do with the phenomenon of nature always belongs to culture, and this should never be ignored. ${ }^{229}$ Much like the Cartesian dualisms at play in the National Parks because of the fundamental wilderness ideology that lies at their foundation, JLA's music, and the way it is represented, contradicts itself. He said the following in a popular Slate op-ed:

There are moments when it sounds like the waves will come crashing through the open windows and carry us away. And then it falls to a whisper and it startles me awake. In these sudden still moments I am filled with an exquisite mixture of tranquility and dread. In the morning I rise and do the best to write down the music that I heard in my dreams. My thoughts return often to the melting of the polar ice and rising of the seas. I remember that all life on this earth first emerged from the sea and I wonder if we humans as a species may once again return to the sea sooner than we imagine. Yet if you ask me if I'm composing a piece about climate change, I'll tell you no, not really. Then is this music about the sea? Yes, well...in a way $[\ldots]$ We can no longer deny the reality that human impacts on our earth are unprecedented in our history [...] Even if it is too late to avert disaster we have both an ethical and biological imperative to try $[\ldots]$ the changes we humans have set into motion potentially catastrophic... are we really so dead set on doing ourselves in? Our survival as a species depends on a fundamental change of our way of being in the world...My work is not activism, it is art... Its impossible to separate my life as a composer and a thinking human being of the citizen of the earth...If my music can inspire people to listen more deeply to this miraculous world we inhabit then I will have done what I can as a composer to help us navigate this perilous era of our own creation.

While it may seem like JLA is scaring listeners into buying his music, I believe this is not his intention. While JLA seeks to control and manipulate my experience of his world I think his ultimate goal is to make beautiful musical objects - a goal at which I think he succeeds. But, even in the moments I listen to JLA's beautiful musical objects and attempt to separate the way they are represented, I can't help but think that even the act of listening to this style of romantic

${ }^{228}$ Cronon, "Introduction," (1995), 35.

${ }^{229}$ Cronon, "Introdcution," (1995), 35 
music is also itself a culturally-constructed act that I have learned from a long lineage of

romantic poets like John Muir. ${ }^{230}$

JLA justifies making these sounds by framing them as if they needed some "practical"

use. ${ }^{231}$ These musical framings are summarized by JLA nicely in a passage that describes his

intentions of migrating to Alaska, and eventually leaving Alaska for New York City:

There was this feeling not only that we could save the wilderness and preserve entire ecosystems intact, but that we could also create a kind of ecotopian society, and show the rest of the country, and the rest of the world, how to do it...That didn't work out. Alaska has devolved into a colony of big oil, and its politics have become so closed, hard-bitten, and strident. But despite it all, I still cling to that romantic, idealistic, impossible vision of how the world really is, or how it might be, and how we might be in the world...It [Alaska] embodies that sense of openness, of edge, of possibility, of excitement, of extreme beauty and danger, that I found so intoxicating when I was 21, and I still do...I still cling to that Alaska, even if it no longer exists in some way. Maybe it never existed, except in my imagination, and in the imaginations of a few of us who went there with those ideals... Maybe in a way, part of the reason I needed to leave home was to assert for myself that the music is its own Alaska - that the music has become a geography of its own. ${ }^{232}$

Environmental music — and nature — becomes something that the authors created to mimic a "landscape" that may have never existed. 233

With the loons calling against the clatter of the Middle Island Passage bell buoy, I walked along the Superior shoreline on the familiar trail from Daisy Farm back to Rock Harbor — headed to catch the last boat off the island for the season. I passed through Siskiwit mine, a place where for the past four years I've contemplated my path in life. Just before Rock Harbor, I glanced over at the spot where a plume of bees attacked me three years earlier-sending my body into anaphylactic shock. In a few weeks, snow will start to accumulate and like my changing memories of being in this place, this archipelago will undergo its seasonal switch to winter. This perpetually changing island changed me in many ways; most importantly, it reconstructed me, I

\footnotetext{
${ }^{230}$ Cronon, "Introduction," (1995), 55.

231 Tom Service, John Luther Adams: a force of nature. July 2015. Accessed from: http://www.theguardian.com/music/musicblog/2015/jul/02/john-luther-adams-music-across-the-distancesouthbank?utm_content=buffer3fb24\&utm_medium=social\&utm_source=twitter.com\&utm_campaign=buffer

232 Jeremy Eicher, The Portable Wilderness of John Luther Adams. July 2015. Accessed from: https://www.bostonglobe.com/arts/music/2015/07/13/the-portable-wilderness-john-lutheradams/zYsE1vfxB76vBVTpvjmunI/story.html

${ }^{233}$ Wockner, 83.
} 
hope, to be a responsible, empathetic, critically aware individual—one among many who walk this island. 


\section{Coda: Rethinking Environmentalism through Music}

"All that you touch you change. All that you change changes you. The only lasting truth is change."234 -Octavia Butler

Much of environmental music - from its emergence in $15^{\text {th }}$-century landscape paintings to poems by the Transcendentalists, and 1960s land art-falls within the tradition of "wilderness" as a construction. It presents art objects as the best antidote to our human selves-a refuge from which to understand how to save the planet. ${ }^{235}$ But as Cronon counters, this art "quietly expresses and reproduces the very values its devotees seek to reject." ${ }^{, 236}$ Like "virtual reality," 237 environmental art acts as an illusion where individuals get the sense that nature can be manipulated and controlled, separate from the history in which it emerged. Existing within "realist assumptions and primitivist fantasies," 238 environmental art tends to lack the critical reflexivity it seeks out, and ends up as a "commodity"239 — a product that can be bought, sold, and capitalized upon.

Environmental music can bring attention to things; it can be read as questions about perception, or it can even be an assertion of authorship. In this regard, this dissertation extends R. Murray Schafer's ideas about authorial control: that we can hear the acoustic environment as a musical composition, while also owning responsibility for its composition. As a "rethinking" 240 of environmental aesthetics as art in the anthropocene, ${ }^{241}$ I propose that Isle Royal acoustemologies - a politicized, socioesthetic, citizen-science in sound - is a nuanced form of

\footnotetext{
${ }^{234}$ Octavia Butler. Parable of the sower. (New York: Four Walls Eight Windows, 1993) 1.

${ }^{235}$ Cronon, "Trouble with Wilderness," (1995), 69.

${ }^{236}$ Cronon, "Trouble with Wilderness," (1995), 80.

${ }^{237}$ Cronon, "Introduction," (1995), 46.

${ }^{238}$ Foster, 302-307.

${ }^{239}$ Cronon, "Introduction," (1995), 46.

${ }^{240}$ Katharine Norman, Sound, Listening and Place: Editorial (Organised Sound, 16.3, 2011), 03-205.

${ }^{241}$ H. Davis and E. Turpin, Art in the Anthropocene: Encounters Among Aesthetics,Ppolitics, Environments and Epistemologies (London: Open Humanities Press, 2015). Timothy Morton, Ecology Without Nature: Rethinking Environmental Aesthetics (Cambridge, Mass: Harvard University Press, 2007).
} 
participatory, situational $^{242}$ environmental music playing out in everyday life; a

(de)composition - where the nature/culture dialectic (as opposed to a dualism) is critically

engaged. Unequivocally, we need to listen for and connect with the nature (environmental

music) in our backyard-like the "howl." One goal of this dissertation is to provide a critical

reflection of my own artistic practices to illuminate far-reaching cultural webs found in

environmental music. I am not taking the responsibility in this dissertation to provide a solution

to the problems I outline in the previous section on JLA. Although, composer David Dunn's

work, The Sound of Light in Trees ${ }^{243}$ treats many of the problems discussed in that section with

delicacy. $^{244}$

The moment I returned home from Isle Royale in 2015, I got this report from the

Petersons:

${ }^{242}$ Doherty, (2009).

${ }^{243}$ David Dunn, The Sound of Light in Trees (Santa Fe, N.M.: EarthEar, 2006).

${ }^{244}$ Climate change has recently ignited a massive infestation of bark beetles in New Mexico. Sound artist, David

Dunn has used the sounds of these beetles, in The Sound of Light in Trees, to make a composition in which $100 \%$ of album sales goes to the Acoustic Ecology Institute. Over two years, Dunn listened to one tree in his backyard using custom-built microphones to hone a spectrum of sounds in our world that are outside of our normal human experience. In this project, Dunn very literally, started by listening to the nature in the cracks of his backyard. While the work offers a compelling, aesthetically pleasing listening experience, it is also an expression of how art and science can fruitfully be in dialogue. This sound art project led to an academic paper by Dunn and James Crutchfield in Science called, "Insects, Trees, and Climate: The Bioacoustic Ecology of Deforestation and Entomogenic Climate Change." This paper included a discussion about how forest biologists could implement Dunn's monitoring methods to find areas of increased beetle activity. Dunn's critical awareness of this environmental music is most clear in the extended liner notes to the album: "My intention in the composing of this collage was to convince the listener of the surprising complexity of sound occurring within one species of tree as emblematic of the interior sound worlds of trees in general. It is also intended to demonstrate the rich acoustical behavior of a single species of small insect and to suggest how sound is a much more important aspect of how it organizes its world, and interacts with its surrounding ecosystem, than previously suspected [...] One of my underlying intentions has been to create a true synthesis of art and science where my field studies of these insects and tree interiors through sound monitoring could not only yield fascinating sound art sources but some novel scientific insights along the way [...] I readily admit just how fanciful my flights of hypothetical imagination might be, not to mention my lack of scientific credentials, but I also happen to think that this is one of the most important roles for artists in forging a new collaborative relationship with science: science fiction that might lead to science fact [...] One of the delightful aspects of this kind of synthesis between art and science is that even if my speculations and research prove to be misguided, the sounds that I have recorded remain intrinsically interesting. You don't need to know what all of these sonic machinations might mean to find them aesthetically engaging. Perhaps of equal importance to the pure revelation of this phenomenon is its generative working method and the possibility that the strategies employed by sound artists, for creating a compelling sonic experience out of the sounds of the natural world, might have a deeper application within science itself." 
At least two wolves are still alive on Isle Royale. I just heard them howling, 9PM on 29 September. One was just west of Daisy Farm, the other one much farther away, maybe on the Greenstone above Angleworm. The wolves had just ceased howling when a saw-whet owl commenced its repetitive call. After the free-form of a wolf howl, the saw-whet sounds almost electronic. ${ }^{245}$

Like this symbolic description of sound, this dissertation narrative describes a location-a

"common middle ground" ${ }^{246}$ where nature can be art and art can be nature. It hopes to create a place where music as environmental activism is not only an objectification of the very nature it seeks to protect, but also an act of listening through an ongoing dialogue with humans and their relationship with "nature" through sound.

${ }^{245}$ Rolf Peterson. Personal correspondence. 2015.

${ }^{246}$ Cronon, "Trouble with Wilderness," (1995), 89. 


\section{Appendix A: Conversation with Kurt Fristrup (Senior Scientist, Natural Sounds Program)}

Kurt (K): The Natural Sounds Program was established because of the National Parks Air Tour Management Act of 2000. The first five years of work here [Natural Sounds and Night Skies Division] were driven by making background sound level measurements to estimate the natural ambience in the parks where air tours were in operation. The thing that has driven our instrumentation package is the need to make sound level measurements compatible with the highest standards that the Department of Transportation uses when measuring aircraft and road noise. As recorders have gotten better, we have increased the amount of audio data we collect with our typical sound level measurements. In the beginning there were ten-second clips collected every two minutes. We did this mainly to allow people to listen, then try and identify what noise sources-like aircraft, helicopter, or fixed wing sounds - were present in the data. Over the last seven years we've migrated to continuous audio recording. This has helped us get a more complete picture of all the different kinds of sounds that take place in parks. We use a pretty good microphone and preamp - [worth] about $\$ 1500$ - and these do better then the human ear below about a $1000 \mathrm{~Hz}$, which is in the range of frequencies that most transportation noise occurs. However, the recorders don't do so well in capturing higher frequencies. Our data collection has done a great job measuring soundscapes and quantifying conditions below a couple thousand $\mathrm{Hz}$ but at higher frequencies we are often limited by the noise of the microphone.

Erik (E): Does the Natural Sounds Program understand how park visitors perceive sounds in parks?

$\mathrm{K}$ : Our main priority is to collect data to identify what is the background against which all sounds are heard and to what extent that background or residual level is affected by noise. We have not yet tried tackling the much more complex issue of parsing all of the components of the soundscape and evaluating peoples' subjective responses to them. We are addressing the more universal question: how does this background sound level effect the capacity of all organismsincluding humans - to hear any of the sounds that occur there? What's nice about that is there is a reasonably consistent framework for interpreting impacts. Working with the masked hearing threshold regime rather then an absolute or intrinsically limited hearing threshold regime allows us to understand how the increase in background sound level will cause a corresponding decrease in how animals - all organisms - can detect certain signals. This is why we have focused on a listening area alerting distance approach [the distance at which sounds can be heard] to interpreting changes in the soundscape. Again, we do not focus on the transients that occur. We focus on long-term, slowly varying background sound level against which all sounds are heard.

E: On Isle Royale, people value the wolf and their howl as a component of the soundscape. The National Park Service acknowledges that this soundscape belongs to their resource management. If the NPS has a sound that people value in a park - like the howl — and that sound goes extinct, do they consider this in possible reintroduction?

$\mathrm{K}$ : The dwindling wolf numbers on Isle Royale and their possible reintroduction/augmentationwhich has been discussed for years - has little to do with soundscapes. With this kind of 
ecosystem discussion, soundscapes play a very small role in Park Service resource management at this time.

E: Why then, is the soundscape — both "natural" and cultural—a component of NPS resource management? The 1988 NPS Management Policies was specific in stating that the Service will strive to preserve natural sounds like the "the howl of the wolf." The 2006 NPS Management Policies are clear in stating, "culturally appropriate sounds are important elements of the national park experience in many parks." They go on to say that, "the Service will preserve soundscape resources and values of the parks to the greatest extent possible to protect opportunities for appropriate transmission of cultural and historic sounds that are fundamental components of the purposes and values for which the parks were established."

$\mathrm{K}$ : The acoustical environment is a critical physical resource because it affects the way all organisms are able to perceive each other and the environment. If you allow noise to intrude a park, it not only affects the aesthetic evaluation of the park by visitors, but it also begins to break the sensory connections among visitors and the environment-among all organisms that are there. We are invested in trying to defend the natural sound levels in a park.

\title{
E: I think this is fantastic. Does the Park Service define what noise is?
}

K: If you look at the 2006 NPS Management Policies, section 8.2.3 [Use of Motorized Equipment] it says that the Park Service will measure all impacts to the soundscape, measured against the natural sound levels that existed prior to any human noise intrusions:

\begin{abstract}
The variety of motorized equipment - including visitor vehicles, concessioner equipment, and NPS administrative or staff vehicles and equipment - that operates in national parks could adversely impact park resources, including the park's natural soundscape and the flow of natural chemical information and odors that are important to many living organisms. In addition to their natural value, natural sounds (such as waves breaking on the shore, the roar of a river, and the call of a loon), form a valued part of the visitor experience. Conversely, the sounds of motor vehicle traffic, an electric generator, or loud music can greatly diminish the solemnity of a visit to a national memorial, the effectiveness of a park interpretive program, or the ability of a visitor to hear a bird singing its territorial song. Many parks that appear as they did in historical context no longer sound the way they once did. The Service will strive to preserve or restore the natural quiet and natural sounds associated with the physical and biological resources of parks. To do this, superintendents will carefully evaluate and manage how, when, and where motorized equipment is used by all who operate equipment in the parks, including park staff. Uses and impacts associated with the use of motorized equipment will be addressed in park planning processes. Where such use is necessary and appropriate, the least impacting equipment, vehicles, and transportation systems should be used, consistent with public and employee safety. The natural ambient sound level-that is, the environment of sound that exists in the absence of human-caused noise - is the baseline condition, and the standard against which current conditions in a soundscape will be measured and evaluated. ${ }^{247}$
\end{abstract}

This statement is significant because other forms of environmental impact analyses that the NPS considers are considered in relation to the "no option" alternative. So there's this potential for an accumulation of impacts over time as different actions take place and without any evaluation of their cumulative effects. The Park Service states in these management policies that all noise impacts are judged relative to the natural ambient background, meaning that even though there

\footnotetext{
${ }^{247}$ United States. 2006. National Park Service management policies draft. [Washington, D.C.]: U.S. National Park Service. http://purl.access.gpo.gov/GPO/LPS64788.
} 
may be other noise producing objects near by, you don't get to discount your impact because those are there. You have to judge your impacts - every noise source - relative to the natural ambient background.

E: Right, I understand that the NPS soundscape is managed from acoustic monitoring and baseline reports. Your division very recently conducted a study on Isle Royale in 2014. The study concluded that the natural ambient sound level ranged between $40.1 \mathrm{dBA}$ during daytime and $22.8 \mathrm{dBA}$ at night with anthropogenic noise audible nearly $100 \%$ of the time. This study does not mention "cultural soundscapes" once. ${ }^{248}$ I understand that each park is defined by their specific values. If this baseline study determines the ways in which the soundscape is to be managed on Isle Royale, but does not include "cultural soundscapes" like the wolf howl, then the Park Service is overlooking an essential value that defines Isle Royale. As you know, sound is a huge component of the park visitor experience, but it doesn't seem like the Park Service really focuses on that outside of limiting human-made noise. Is anybody working on understanding visitor perception of the soundscape in National Parks?

K: This work by Psychologist Britt Mace [of Southern Utah University], Acoustic Ecologist Peter Newman [of Penn State], Acoustic Ecologist, Robert E. Manning [of University of Vermont] is looking at the affective dimension of how people respond to sounds - whether they judge them as appropriate in the context of whether they find them pleasing or annoying. One of the common exercises that those researchers have used has been an undirected listening exercise where visitors are asked to sit quietly and note the sounds they hear, identify them as best as they can, and then evaluate them along those two dimensions of appropriate/inappropriate and pleasing/annoying. There has also been some work on how intrusions degrade the restorative effect of natural sound environments; [these demonstrate] not so much on how people judge the sounds, but more how the physiological benefits of being in natural areas are degraded by noise intrusions.

E: Has this type of subjective listening research made its way into NPS resource management?

$\mathrm{K}$ : The Park Service and the FAA have jointly funded research that looks at noise exposure in park settings and some quantitative relationships from that that have emerged. Look at the work on Dose-Response Relationships for Visitors to National Parks by Nicholas P. Miller, Grant S. Anderson, and Amanda Reposa. So yes, this research has been turned into quantitative relationships that have played a role in park management. The idea that Isle Royale would make a policy that reflects an element of the soundscape only sounds irrational because there are so many other resource factors that would play into wolf reintroduction/augmentation. I'm not saying soundscapes wouldn't play a role at all, but I suspect that the impact of the trophic cascading effect of top-level predators over the entire ecosystem would probably dominate the conversation.

E: I understand this, and I also think this question could start a dialogue about the importance of "cultural" sounds in parks as something to be managed.

${ }^{248}$ Isle Royale National Park. Acoustic Monitoring Report. Natural Resource Report NPS/NRSS/NRR—2014/886 
K: The Organic Act says that we are supposed to conserve resources unimpaired. Part of the determination [required for that] is to what epoch in time do we refer in identifying what the foundational resources of the park are. Wolves either are or are not part of that calculus as components of the ecosystem. If they are part of that calculus, as components of the ecosystem then I expect the Park Service will decide to reintroduce them, if they are not part of that and they are transient, the park will let nature take its course. But we can't manage things like it's a petting zoo. Our mandate doesn't say that we need to conserve the animals that are popular. Our mandate says that we need to conserve resources unimpaired. In terms of the Wilderness Act, it means that the natural processes must dominate. Under these criteria, I could imagine that this is why the soundscape on Isle Royale is really secondary. I think conserving the conditions, the natural processes, is important.

\section{E: But human beings are a part of the natural processes. Right?}

$\mathrm{K}$ : But the Wilderness Act is very specific. It's suppose to be untrammeled by man...

E: ...But that's contradictory because as soon as you designate something as "Wilderness," it becomes trammeled by man.

$\mathrm{K}$ : This is not entirely true. There are all sorts of things that are not allowed in wilderness. Often times, wilderness areas are managed to limit the number of recreationists who can visit. Labeling something "wilderness" doesn't necessarily protect it. And in fact one of the areas that our division [the Natural Sounds and Night Sky Division] is increasingly engaged in, is noise and light that doesn't respect boundaries. A lot of wilderness areas today are affected by noise and light far more then is consistent with the Wilderness Act management objectives. I don't think it's so clear.

E: Given the fact that there are so many questions marks and gray areas in this wilderness conundrum, the idea that reintroducing wolves based on the idea that Isle Royale park visitors value the wolf howl doesn't seem so absurd. Park policy is ambiguous. Scientist and park officials can describe policy options and advise on the likelihood of the repercussions of those options. But none of this analytical work based on collected data can make value decisions. What is natural, native, and diverse really hinges on values and its pretty clear that the NPS just doesn't value "cultural” sounds.

$\mathrm{K}$ : Is the Park Service going to designate the wolf as some kind of keystone species for that island ecosystem? In my view, this decision doesn't get driven by the desirability of wolf sounds. This decision gets driven by whether or not, from an ecosystem management perspective, the judgment is that wolves belong there. This is an open question. You're right, this is one of the signature sounds for the island which very few people get to hear and which can transform a park experience. There is no question about that. When you look at the history - of not only Park Service regulations, but also the significant legal decisions - one of the principle findings has been that whenever there is any conflict between visitor use of parks and resource conservation, the courts have found that resource conservation must be giving priority. Legal mandates tell us that we have to let the natural processes predominate. If park managers and scientists were to determine that restoring wolves was not conserving an authentic, intact ecosystem then the idea 
that visitors feel like wolf howls are the most important thing they experience on the island is not going to contribute to resource management.

E: I understand, but this makes me feel like the soundscape-cultural sounds, specifically - is not a resource for the National Park Service. This makes me feel like the NPS slogan "parks are for people" isn't true. If parks are for people, shouldn't people — the visitor-be essential in constructing the values and policy's of these places?

$\mathrm{K}$ : This is an interesting approach and it's an approach that Congress in Western states [of America] push for all the time. I think that court decisions have gone the directions they have because popular values change rapidly, and if you were trying to manage parks in those ways there's no guarantee that that the park would stay environmentally and ecologically sustainable. Parks were designated in the first place for the resources and for the value that those resources have for future generations. First and foremost, these resources have to be managed and preserved, and then, after that, the task of the Park Service is to find the most sustainable ways for visitors to experience those resources. Our tiny division here is the only federal agency in the entire federal government that is concerned with the quality of the acoustical environment. Every other agency that does anything in this area is concerned only with managing noise to acceptable levels of annoyance. Every other agency - the Department of Transportation and the Department of Defense, for example - they all manage soundscapes or acoustical environments such that there is no unacceptably adverse impacts either in terms of annoyed populations or health impacts. I would say the Park Service is actually notable because they have invested in the creation of this little division to actually work on what constitutes high quality acoustical environments, and how to help parks mitigate the effects of noise both inside and outside boundaries.

E: Right, but it still seems to only be about noise. I think about how the aesthetic qualities of listening impact our lives. Both this position and my role as an artist leads me to ask questions like: is the Natural Sounds Program interested in understanding visitor perception of the soundscape that moves beyond "noise"? Does it move beyond merely classifying soundscapes as just good or bad soundscapes that trigger annoyances or pleasures?

K: That's absolutely true, yes. But the work that has been conducted on this will still never make it into resource management outside of understanding noise impacts. We've funded a fair amount of work in this area. If you're asking, "Is the Natural Sounds Program at all interested in managing or crafting the composition of the soundscape through management actions?" I would say that the answer is most certainly no. I cannot conceive of a time going forward when the Park Service would actually engage in a management action to manipulate natural soundscapes in someway that might prove more desirable. The Park Service will manage ecological systems so that natural processes predominate, and ensure that they are sustainable. Our part in that [process] is to make sure that the physical environment — these physical resources, both sound and photic - are such that animal and park visitor sensory systems can perform as they have evolved too, and we give the visitors and the wildlife the best chances to experience the most expansive and authentic acoustic environment as possible. 
E: I understand, but the NPS does craft their composition of the soundscape - to remove humanmade machine noise from air tours, for example. I agree with this [decision]. But, on Isle Royale, the wolf howl does provide that "wild" and "authentic" experience for park visitors. These sounds [of the wolf howl] are almost gone.

K: I'll say two things. Have you ever been in an improvisational acting class?

E: No.

$\mathrm{K}$ : One little technique that I've picked up from improv classes is that when you're in a conversation with somebody and you say, "Yes, but..." effectively you're saying "Yes. Now I'm going to dismiss everything you've just said, and tell you what I want to say." In these improv classes, they have you go through exercises where you say "Yes, and...." where you're constructing a dialogue by adding to things, not dismissing them. I'm just noting that there have been many times in this conversation where you have said to me: "I get that, but..."

E: Sorry about that. My goal here is to understand as many perspectives on this matter.

K: We've come back to this Isle Royale situation two or three times and I've given you - as far as I am able - a view on how the Park Service makes decisions from a legislative and judicial perspective. This perspective does not pivot upon the subjective value that people place on certain sounds. It hinges on some sort of objective assessment of whether the ecosystem is intact, containing the species that are intrinsically critical to that ecosystem. Even though it's not my area, I would defend the park managers whose decisions about wolves on Isle Royale holds true to protecting the integrity of natural processes. National Parks are not amusement parks, nor are they are art galleries; they are not anything that has been constructed strictly for human enjoyment. They are places where we are trying to preserve something in the natural sense. We are trying to preserve a vignette of a time and a place for cultural and historic properties. Our legislation is really clear on these points. If it turns out that wolves go extinct on Isle Royale and, in fact, that is the way the island's ecosystems are suppose to work, then people will just need to find other reasons to visit the park or go to Voyagers or Pictured Rocks [National Parks] where there are wolves howling - and where wolves are a sustainable feature of the environment.

E: The "Yes, and..." response in a dialogue is a good option when talking about wilderness and nature because, as we know, people approach these things based on what they value. A lot of times, people don't realize that their own perspective is just one of many, and when people say "Yes, but..."- - like we both did-you're not acknowledging this fact.

$\mathrm{K}$ : Part of what you're interested in is the diversity of perspectives and the diversity of values. How do we have conversations about this issue without spiraling into an escalating denial of another person's perspective? How do we have conversations that actually allow us to more fully appreciate the breadth of perspectives and try to identify themes that are common to all?

E: The question about whether or not we listen to people in parks as possibly contributing to resource management is trying to add an additional perspective to the mix that I don't think is present. 
$\mathrm{K}$ : This is certainly worth talking about. Even if we do decide not to reintroduce wolves on Isle Royale based on the value of wolf howls, it still is a conversation that the Park Service and all public stakeholders needs to have. If nothing else, your work here will help clarify for all of us what the foundations of park management are all about. 


\title{
Appendix B: Discussing Fieldworks and Representation
}

\begin{abstract}
A fieldwork engages with the geographic site but then warps one's perception of the space comparable to a mathematical "strange attractor." Sharing, on one hand, the history of art installation (which can modulate the encompassing architecture and the viewer's phenomenological perception) and on the other hand, the history of "site-specific" or earthwork art (which amplifies the place's story or materiality), a fieldwork creates its own temporary-architecture within a space or in a landscape. However, such a landscape need not be natural and the architecture may not always be a traditional shelter or sculpture, but can be composed of sonic material, electromagnetic fields, light fluctuations, or relationships. At its core, a fieldwork is dynamic and geospatial. ${ }^{249}$-Charles Stankievech
\end{abstract}

The following is an edited conversation I conducted with fieldwork artist, Charles Stankievech. Stankievech is an artist whose research has explored the notion of "fieldwork" in the embedded landscape, the military industrial complex, and the history of technology. He is currently the Director of Visual Studies in the Faculty of Architecture, Landscape and Design at the University of Toronto.

E (Erik) - Why did you select a label for your artistic methodology that has such a deep political resonance?

C (Charles) - I needed to find a banal everyday life word that was neutral - like "installation." I needed something generic, not a neologism. I wanted to select something that people felt was familiar. Fieldwork as an artistic term has been used a lot and has exploded since the Fieldwork: Marfa ${ }^{250}$ research program was established in Texas and the Documenta(13)'s 100 Notes - 100 Thoughts ${ }^{251}$ series - the first of which was written by Michael Taussig called Fieldwork Notebooks. ${ }^{252}$ I do want to carefully articulate that my fieldwork is not the kind of fieldwork that Taussig is talking about. There is this tradition of the artist as ethnographer....

E - Right, Hal Foster wrote the chapter The Artist as Ethnographer in his book, The Return of the Real ${ }^{253}$ where he critiqued the artist who longed for the "other" and occupied this "quasianthropological paradigm" at the ethnographic turn of 1960s. Foster makes a great point that the intentionality of the artists who occupy this space is affected by "realist assumptions" and "primitivist fantasies" who lack a certain critical reflexivity.

C - If you grab a popular book like Situation, ${ }^{254}$ published by Whitechapel Gallery, they have a whole chapter on fieldwork. The chapter focuses on this kind of artist as ethnographer fieldwork with Miwon Kwon's One Place after Another and The Center for Land Use Interpretation. I would have a certain affiliation with this work, but I am really interested in ambiguity. The whole idea [originally] of using fieldwork was that it fractures, and we can talk about it in so many different ways. Is it a descriptor of the process, the research, or the work? It is not that I am an artist going to do fieldwork: which means I go out, research and come back to my university

\footnotetext{
${ }^{249}$ Charles Stankevitch, Magnetic North Exhibition Catalogue (2010)

${ }^{250} \mathrm{http}: / / \mathrm{www}$. fieldworkmarfa.org/

$251 \mathrm{http}: / / \mathrm{d} 13$.documenta.de/\#/publications/100-notes-100-thoughts/

${ }^{252}$ Taussig, Michael T. Fieldwork notebooks = Feldforschungsnotizbücher. Ostfildern: Hatje Cantz, 2011.

${ }^{253}$ Foster, Hal. The Return of the Real: The Avant-Garde at the End of the Century. Cambridge, Mass: MIT Press, 1996.

${ }^{254}$ Doherty, Claire. Situation. Cambridge, MA: MIT Press, 2009.
} 
office or laboratory - this scientific, ethnographic thing — and then I write my book. It [my work] was the inversion of that in the sense that the artwork itself is the fieldwork, its work as in the noun object.

E - I want to read you something from Taussig's Fieldwork Notebooks. He says, "The notebooks become ends in themselves and thus actively encourage contributions from the field, the field being of course at once observer and observed, and observer observed." This makes me think that maybe your fieldwork interacts much like Taussig's notebooks.

C - I would disagree. I was thinking about energy fields. I was thinking about interdisciplinarity. When I went to [the residency] Fieldwork: Marfa I was asked to give a lecture. In preparation, I thought about how I was defining my methodology as a studio-based practice. I never wrote down my method. I wrote the definition and I've been doing it. But there is a whole discourse on fieldwork and the arts [which I was not a part of].

E - Yes, there are several classic books out there: Between Art and Anthropology, ${ }^{255}$ Contemporary Art and Anthropology, ${ }^{256}$ and The Traffic in Culture. ${ }^{257}$

C - Anna-Sophie Springer and I published a book called The Subjective Object in 2011/12 on K. Verlag Press that engages with the controversial site of the ethnographic museum and the role of the archive. This is to say, I am interested in anthropology and issues of colonialism, but it was never intended to be part of my fieldwork methodology. At first I tried to contrast myself from this work but I think what I want to fundamentally say is that my work just doesn't deal with people.

E - What about your work on sound and surveillance? You're essentially dealing with the cultural underpinnings of how humans - specifically within the context of military-have communicated with sound.

C - Right, it does deal with culture. It doesn't deal with the rules of surveillance and politics; it deals with technology, landscape, and culture at large. The work doesn't deal with a particular community, which I think [is what] separates it from anthropology. People are not in my works, not even actors, and there are a couple reasons for this. The very first fieldwork that I made was Distant Early Warning in 2008, where I positioned radio stations housed in geodesic domes in the Arctic and the stations transmitted underwater sound recordings of the Yukon River. For this project, I worked with the official historian for [National] Parks Canada and the Arctic. He talked about the oral history of the indigenous people in the region and their influence. On the Distant Early Warning website there is a re-publication of an archive of images. A lot of these images were a part of this story and included all this indigenous participation. The park historian also gave presentations of the work. In this case, I had someone dealing with the oral history, doing anthropological work. He's working directly with these peoples' stories. I'm not in the

\footnotetext{
${ }^{255}$ Schneider, Arnd, and Christopher Wright. Between Art and Anthropology: Contemporary Ethnographic Practice. Oxford: Berg Publishers, 2010.

${ }^{256}$ Schneider, Arnd, and Christopher Wright. Contemporary Art and Anthropology. Oxford: Berg, 2006.

${ }^{257}$ Marcus, George E., and Fred R. Myers. The Traffic in Culture: Refiguring Art and Anthropology. Berkeley: University of California Press, 1995.
} 
position to do that. My work is a military history. Living up in the Arctic I've always been aware of issues of colonialism. Anthropology has a huge problem with colonization and this idea of the intellectual academic conducting fieldwork on a community from a privileged position. This is why I have always had a problem with the anthropological take on art.

E - The objectification of culture.

C - Exactly, so when I went to Fieldwork: Marfa I told them that I didn't actually know what I was going to make until I got there. I told them that I couldn't propose a research project before I go. That would be disingenuous from my perspective. I didn't want to be a tourist in that community. I didn't want to come in with my preconceived notions, drop into the environment and see out a plan. It was really about understanding landscape - not telling other peoples' stories. Other people can tell those stories just fine. I don't try to engage in the anthropological discourse, and I don't position my work in that field. The point wasn't to go to a place and observe, make my notebooks, and go back to the studio, museum, or gallery. The ideal fieldworks activate the space. Field recordists like Alan Lomax or the The World Soundscape Project crew are more tied to anthropology in that they go into a field and make documents, records, and notebooks. It becomes interesting when you become observed in it and you can play with these ideas of subjectivity and observation. But, what I am interested in is actually spatially activating something. Like the bug zapper piece in $\mathrm{Marfa}^{258}$ or the radio work in the Arctic. These works often exist in the landscape itself.

E - While some of your work is site-specific, the majority of it is positioned in the gallery that allows you to interact with it just like a book or a record. What is the difference between installing your modular fieldworks in a gallery versus producing a manuscript? Your fieldworks are the objectification of your fieldwork; the installations are your notebooks.

C - My practice is multivalent and I wouldn't say that everything I make should be categorized as fieldwork. The Distant Early Warning project is a strong example of a fieldwork. This work now travels as a museum installation. However, like you said, it is now a document of a fieldwork. The Ghost Rocket World Tour series interacts in the same way. In the gallery we have various artifacts, sculptures, and videos of "performances" of the fieldwork in the landscape. In a traditional field recording practice one goes to a site and documents it. For me, this means that I normally take some photographs, do some sound recording, maybe take a sample of some sort, and bring some objects back. But with The Ghost Rocket World Tour, I am actually announcing a performance in it. I'm launching a rocket in the landscape and this becomes a marked event. I'm really trying to break down the difference between being a passive observer and this idea of performing in the landscape as a way to activate the landscape. But then we go back to the gallery, we install the document like an anthropologist would install their exhibit at the natural history museum; however, there is still that part back at the original site. To break this down a bit farther, I should say that my sites do not always need to be a landscape.

\footnotetext{
${ }^{258}$ Homeland Security: It's Hard to Find a Good Lamp for "36 electrifying fluorescent bug zappers suspended in a grid above a public space."
} 
E - Ethnomusicologist and performance studies scholar Michelle Kisliuk introduced me to Writing Culture: The Poetic and Politics of Ethnography. ${ }^{259}$ It discusses a lot of the issues we've been talking about here: representation, interdisciplinarity, active/passive participation, the subjective, the objectivity, and poetics. After the publication of that book a trend began where individuals researching cultures started to become more of an active participant in the work. While you say that your not dealing directly with communities of people, your work - and my own-does follow suite with ethnographers who take on a more active role in their research. Michelle, just like us, became interested in the poetics of a place and how participation might teach her about different sensibilities. When she was studying at Tufts University she heard a field recording made by Simha Arom of the music of the BaAka people of the Central African Republic. She says that that recording overwhelmed her so much with its beauty that if she could learn enough about it to join in she would die happy. This moment led her to a life of learning about the life of this music. Michelle's process ${ }^{260}$ is similar to the way we work in the field. This is to say, the word fieldwork, for me, is inextricably tied to the ethnographic process.

C - I find fundamental systemic problems with the field of anthropology. Obviously there are contemporary anthropologists who have thought through these ideas, but I find it to be a very problematic discipline. I'm not going to throw it out the window, I am just going to keep moving forward and think about the way I use it.

E - The key point of this discussion is that because we work across disciplines we have a responsibility to understand the history of each and how they comingle. While, yes, you could go back and call your work something else based on the politics we've been discussing, that would be a disservice to the process of discovery. Art is about growing, building, and walking down a path. It's important to understand where you start and where you end, to observe change and observe how you moved through that change - this growth should be present in the work. But what gives artists the right to use sensitive terms and materials - without a certain critical awareness - for their own artistic purposes? I think this is something that you, of course, take head on.

$\mathrm{C}$ - I ask myself if fieldwork is the best word to use to describe my work. I ask myself if I should let someone else label my work - should I even be defining it as conceptual? This is the reason why we don't use the word "site-specific." With "site-specific" there tends to be one specific point that is examined. What we are interested in is this field that goes out, this field that connects, this field that has depth, froth, and breadth. It's not about one specific site or place"fields" include the lay of the land.

E - The history, the dirt, the current political underpinnings, invisible sounds, and the people listening to them. "Fields" include all the layers that make up a place and "fieldworks" themselves tend to reflect this. You have a composer like Morton Feldman who wanted the sounds he presented to exist on their own terms. He wanted to free sounds from "compositional rhetoric". He wanted his musical "frames" to be ambiguous. His music is not about patterns of

\footnotetext{
${ }^{259}$ Clifford, James, and George E. Marcus. Writing Culture: The Poetics and Politics of Ethnography. Berkeley: University of California Press, 1986.

${ }^{260}$ Kisliuk, (1998).
} 
rain or his Jewish heritage-it's about the physicality of sound. I am pointing this out because I think that fieldworks can also be framed in this way.

C - It's always easy to just think about things and not open your mouth; there is always a danger in fossilizing your work and practice. But with fieldwork it is a slippery enough term that we'll continue trying to figure out what it is exactly in this context. When one is very articulate about their work, people are scared away from engaging with it. Some people think it shuts things down. Some people think that artwork should be open enough so that the viewer can read it the way they want. Lots of people make empty artwork. Empty work allows a certain screen to project ones fantasies upon it and this does very well in the art world because curators and collectors can write there own thoughts into it.

E - Right. I'll end by saying that our students have grown up using technology to access knowledge far and wide. I think this is manifesting in students who have to work across many disciplines and fields. They get confused because our society tells them to just pick one discipline to work within. A methodology like fieldwork is saying that you don't have to pick one thing. 


\section{Appendix C: Wolf Listeners: An Adventure Through Sound}

This sound recording is a composition that weaves together field recordings that I made on Isle Royale and musical works that were inspired by my time working on the island. This "sonic ethnography" is a representation of the materials that I worked through to write Wolf Listeners: through Isle Royale National Park Acoustemologies. This sound recording, a very specific mnemonic object that triggers memories of my experiences, is not a representation of the written portion of this dissertation but a version, or a simulation of it that will hopefully be accessible to all different types of people. 


\section{Appendix D: Portfolio of Musical Works}

I. Each of the electroacoustic musical works in this portfolio were commissioned by, and donated to the National Park Service under their Artist-in-Residence program. The annotations below provide some insight into each work.

Winter (2013): orchestra, voice, and recordings of silence. 25:00

Commissioned by Denali National Park. Premiered by the Fairbanks Summer Arts Festival Orchestra, conductor Robert Franz. Denali Visitor Center, AK. July 2013.

The text for Winter was synthesized from my field notes into a straightforward text that deals with notions of confinement.

White Blanket (2013): large chamber ensemble, optional soprano voice, and electronics. 8:00 Commissioned by Denali National Park. Performed by fellows of the Bang on a Can Summer Music Festival. MASS MoCA. North Adams, MA. July 2013.

During my time in the confinements of the Savage River cabin due to the extreme temperatures and lack of light, I reflected on my musical past, the politics of musical borrowing, genre blurring, and issues of framing.

\section{For Cowboy Randy Erwinn (2012): electric guitar quartet. 9:00}

Commissioned by Grand Canyon National Park. Performed by Dither. Christ Episcopal Church. Charlottesville, VA. February 2013.

During my residency in the Grand Canyon I found a cigar box guitar in a crevice of the trail crew bunkhouse. Amid field recording trips and listening workshops I wrote little riffs with this instrument on the porch under the hot summer, cicada filled air.

At the Edge of the Sea (2012): saxophone quartet and pre-recorded sounds. 10:00 Commissioned by Acadia National Park. Performed by POD Sax Quartet. LSU School of Music Recital Hall. Baton Rouge, LA. March 2012.

The form of The Edge of the Sea outlines tidal rhythms around Schoodic Point during my residency in Acadia.

Lake (2011): string quartet and film. 12:00

In collaboration with filmmaker Philip Gale. Commissioned by Isle Royale National Park. Performed by Friction Quartet. First Universalist Church. San Francisco, CA. November 2013.

Lake features musical material that slowly "grows" over time informed by a belief circulating amongst park rangers and guests of Isle Royale National Park that the subtle environment there slowly comes into "focus" over time. This music is presented with an $8 \mathrm{~mm}$ silent film that was made on the island in 1956 by life lessee Philip R. Gale. 
Cascades (2011): large percussion ensemble and pre-recorded sounds. 7:00

Commissioned by North Cascades National Park. Performed by the Hamiruge Percussion Ensemble. LSU School of Music Recital Hall. Baton Rouge, LA. March 2012.

Cascades was composed algorithmically from time-lapse sounds gathered from an autonomous sound recorder that I positioned under the Boston Glacier in North Cascades.

Six Days (2010): bass flute, bass clarinet, percussion, piano, violin, cello, and 6.1 channels of pre-recorded sound. 10:00

Commissioned by Wrangell-St. Elias National Park and Preserve. Performed by the InnoVox Ensemble. Shapeshifter Lab, Brooklyn, NY. December 2013.

The sonic fabric for Six Days of Summer counterpoints musical renderings of diurnal rhythms with hydrophonic and air field recordings that I made of glacial environments in Wrangell-St. Elias, Alaska.

Four Days of Winter (2010): accordion(s), violin(s), tuba(s), bass clarinet(s), and 1 channel of pre-recorded sound. 8:00

Commissioned by Crater Lake National Park. Performed by the Little William Theater

musicians. Hammer Museum. Los Angles, CA. August 2010.

II. Each of these electroacoustic musical works was made independently from the National Park Service Artist-in-Residence program but inspired by visits to specific National Parks.

3 songs, 3 interludes (2014): Reed quintet and 5 tape players 13:00.

Isle Royale National Park. Performed by Splinter Reeds. Berkely Art Museum. Berkely, CA. October 2014.

Dry Run (2011): percussion, voice, organ, and 1-channel of pre-recorded sound. 7:00 Shenandoah National Park. The Sanctuary at The Haven, Charlottesville, VA. April 2011.

Within a Sand Dune (2010): amplified percussion quartet. 7:00

Great Sand Dunes National Park. Performed by Talujan Percussion Ensemble. Old Cabell Concert Hall, University of Virginia. Charlottesville, VA. February 2010.

Within a Sand Dune explores the subtle frequency, time, and power fluctuations of a magnified bit of sound that I recorded inside the Great Sand Dunes. 


\section{Bibliography}

Adams, John Luther. The Place Where You Go to Listen: In Search of an Ecology of Music.

Middletown, Conn: Wesleyan University Press, 2009.

Making Music in the Anthropocene. Slate.com.

$<$ http://www.slate.com/articles/arts/culturebox/2015/02/john luther_adams grammy winner for _become_ocean_discusses_politics_and.html $>24$ Feb 2015.

_ Schuman Award Concert Program Note. 2015.

_ Become Ocean: for orchestra. Musical score. 2015.

Allen, Aaron S, "Prospects and Problems for Ecomusicology in Confronting a Crisis of Culture." Journal of the American Musicological Society 64(2) (2001): 414-424.

Baldwin, Amalia. Becoming Wilderness: Nature, History, and the Making of Isle Royale National Park. Houghton, Mich: Isle Royale \& Keweenaw Parks Association, 2011.

Bateson, Gregory. Mind and Nature: A Necessary Unity. New York: Dutton, 1979.

Butler, Octavia. Parable of the Sower. New York: Four Walls Eight Windows, 1993.

Cage, John, Michael Kirby, and Richard Schechner. “An Interview with John Cage." The Tulane Drama Review 10 (1966): 50-72.

Carlyle, Angus. Autumn Leaves: Sound and the Environment in Artistic Practice. Paris, France: Association Double-Entendre in association with CRISAP, 2007.

Chase, Alton. The Wolf Mystery: Playing God in Yellowstone-The Destruction of America's First National Park. Boston, MA: The Atlantic Monthly Press. 2012-13.

Clarke, Eric. Ways of Listening: an Ecological Approach to the Perception of Musical Meaning Oxford: Oxford University Press, 2005.

Clifford, James, and George E. Marcus. Writing Culture: The Poetics and Politics of Ethnography. Berkeley: University of California Press, 1986.

Cloke, Paul, Chris Philo, and David Sadler. Approaching Human Geography: An Introduction to Contemporary Theoretical Debates. New York: Guilford Press, 1991.

Corbin, Alain. Village Bells: Sound and Meaning in the Nineteenth-Century French Countryside. New York: Columbia University Press, 1998.

Cosgrove, Denis. Social Formation and Symbolic Landscape. Madison: University of Wisconsin Press, 1998. 
Cosgrove, Denis and Stephen Daniels. The Iconography of Landscape: Essays on the Symbolic Representation, Design, and Use of Past Environments. Cambridge, England: Cambridge University Press, 1988.

Cronon, William. "Introduction: In Search of Nature.” Uncommon Ground: Toward Reinventing Nature. Edited by William Cronon. New York: W.W. Norton \& Co, 1995. 23-68.

— Nature's Metropolis: Chicago and the Great West. New York: W.W. Norton, 1991.

—The Trouble with Wilderness; or, Getting Back to the Wrong Nature." Uncommon Ground: Toward Reinventing Nature. Edited by William Cronon. New York: W.W. Norton \& Co, 1995. 69-90.

Davis, H and E. Turpin. Art in the Anthropocene: Encounters Among Aesthetics, Politics, Environments and Epistemologies. London: Open Humanities Press, 2015.

Demeritt, Davis. The Nature of Metaphors in Cultural Geography and Environmental History. Progress in Human Geography 20.1 (1994): 22-37.

DeNora ,Tia. Music in Everyday Life. Cambridge: Cambridge University Press, 2000.

Doherty, Claire. Situation. Cambridge, MA: MIT Press, 2009.

Dunn, David. The Sound of Light in Trees. Santa Fe, N.M.: EarthEar, 2006.

Feld, Steven. Sound and Sentiment: Birds, Weeping, Poetics, and Song in Kaluli Expression. Philadelphia: University of Pennsylvania Press, 1982.

—_ "From Ethnomusicology to Echo-muse-ecology: Reading R. Murray Schafer in the Papua New Guinea Rainforest.” Soundscape Newsletter 8 (1994): 9-13.

Foster, Hal. The Return of the Real: The Avant-Garde at the End of the Century. Cambridge, Mass: MIT Press, 1996.

Gale, Thomas P., and Kendra L. Gale. Isle Royale: A Photographic History. Houghton, Mich: Isle Royale Natural History Association, 1995.

Glacken, Clarence J. Traces on the Rhodian Shore: Nature and Culture in Western Thought from Ancient Times to the End of the Eighteenth Century. Berkeley: University of California Press, 1967.

Glahn, Denise Von. The Sounds of Place: Music and the American Cultural Landscape. Boston: Northeastern University Press, 2003. 
Gramann, J. H. "The Effect of Mechanical Noise and Natural Sound on Visitor Experiences in Units of the National Park Service. ”Social Science Research Review 1.1 (1999): 1-16.

Guy, Nancy."Flowing down Taiwan's Tamsui River: Towards an Ecomusicology of the Environmental Imagination." Ethnomusicology 53(2) (2009): 218-48.

Harrison, R. T., Clark, R. N., \& Stankey, G. H. Predicting Impact of Noise on Recreationists San Dimas Forest Service. U.S. Department of Agriculture. 1980.

Harvey, David. The Condition of Postmodernity: An Enquiry into the Origins of Cultural Change. Oxford England: Blackwell, 1990.

Hayles, Katherine. "Simulated Nature and Natural Simulations: Rethinking the Relation between the Beholder and the World." in Uncommon Ground: Toward Reinventing Nature. Edited by William Cronon, New York: W.W. Norton Company, 1995. 409-425.

Helmreich, Stefan. “Listening Against Soundscapes.” Anthropology News. 51.9 (2010):1-2.

Hirschkind, Charles. The Ethical Soundscape: Cassette Sermons and Islamic Counterpublics. New York: Columbia University Press, 2006.

Hilmes, Michelle, Ed. Jonathan Sterne. The Sound Studies Reader: Radio and the Imagined Community. New York: Routledge, 2012.

Igoe, James. A Genealogy of Exchangeable Nature, in S. Paladino and S. Fiske The Carbon Fix: Forest Carbon, Social Justice, and Environmental Governance. California: Left Coast Press, 2016.

Jensen, M., \& Thompson, H. "Natural Sounds: An Endangered Species." The George Wright Forum 21.1 (2004): 10-13.

Kisliuk, Michelle. Seize the dance!: BaAka Musical Life and the Ethnography of Performance. New York: Oxford University Press 1998.

Peterson, Carolyn. A View from the Wolf's Eye. Houghton, Mich: Isle Royale Natural History Association, 2008.

Krebs, Stefan. "Sobbing, Whining, Rumbling: Listening to Automobiles As Social Practice." The Oxford Handbook of Sound Studies. Edited by Pinch Bijsterveld. New York: Oxford University Press, 2012.

Lee, Tong Soon. "Technology and the Production of Islamic Space: The Call to Prayer in Singapore." Ethnomusicology 43.1 (1999): 86-100.

Le Guin, Ursula K. The Wave in the Mind: Talks and Essays on the Writer, the Reader, and the Imagination. Boston: Shambhala, 2004. 
Lyon, Ted and Will Graves. The Real Wolf: The Science, Politics and Economics of Co-Existing with Wolves in Modern Times. Ted Lyon, 2014.

Andrews, Malcolm. Landscape and Western Art. Oxford: Oxford University Press, 1999.

Marcus, George E., and Fred R. Myers. The Traffic in Culture: Refiguring Art and Anthropology. Berkeley: University of California Press, 1995.

McCain , John and Jon Kyl, "Statement by Senators McCain and Kyl on Passage of Grand Canyon Overflights Provision," <http://www.mccain.senate.gov/public/index.cfm/pressreleases?ID=397d18be-9be2-2453-2549-ca956ee5f758> Published on June 2012. Accessed on 15 December 2015.

Mech, L. David., and Luigi Boitani. Wolves: Behavior, Ecology, and Conservation. Chicago. Chicago: University of Chicago Press, 2003.

Miller, Nicholas. "US National Parks and Management of Park Soundscapes: A Review." Applied Acoustics. 69.2 (2007): 77-92.

Morton, Timothy. Ecology Without Nature: Rethinking Environmental Aesthetics. Cambridge, Mass: Harvard University Press, 2007.

Neumann, Roderick. "Ways of Seeing Africa: Colonial Recasting of African Society and Landscape in Serengeti National Park." Cultural Geographies 2.2 (1995): 149-169.

Neves-Graca, Katja. Chasing Whales with Bateson and Daniel. 2005.

Norman, Katharine. "Sound, Listening and Place: Editorial." Organised Sound 16.3 (2011): 1-8.

Oliveros, Pauline. Deep Listening: a Composer's Sound Practice. New York, iUniverse, Inc, 2005.

Olwig, Kenneth. "Reinventing Common Nature: Yosemite and Mount Rushmore-A Meanduring Tale of a Double Nature." In Uncommon Ground: Toward Reinventing Nature. Edited by Willian Cronon. New York: W.W. Norton and Company,1995. 379408.

Pedelty, Mark. Ecomusicology: Rock, Folk, and the Environment. Philadelphia, Pa: Temple University Press, 2012.

Peterson, Rolf. The Wolves of Isle Royale: A Broken Balance. Ann Arbor: University of Michigan Press, 2007.

Peterson, Rolf, and John Vucetich. Ecological Studies of Wolves on Isle Royale Annual Report. Houghton, Mich: Michigan Technological University, 2014. 
_Ecological Studies of Wolves on Isle Royale Annual Report. Houghton, Mich: Michigan Technological University, 2012-13.

_Ecological Studies of Wolves on Isle Royale Annual Report. Houghton, Mich: Michigan Technological University, 2015.

Perlman, Marc. "Ecology and Ethno/musicology: The Metaphorical, the Representational, and the Literal." <http://ethnomusicologyreview.ucla.edu/content/ecology-andethnomusicologymetaphorical-representational-and-literal> Accessed 1 January 2015.

Pilcher, E. J., Newman, P., \& Manning, R. E. "Understanding and Managing Experiential Aspects of Soundscapes at Muir Woods National Monument." Environmental Management 43.3 (2008): 425-435.

Proctor P. Reid, and Steve Olson. Protecting National Park Soundscapes. Washington, DC: The National Academies Press, 2013.

Schafer, R. Murray. The Soundscape: Our Sonic Environment and the Tuning of the World. Rochester, VT: Destiny Books, 1994.

Schneider, Arnd, and Christopher Wright. Between Art and Anthropology: Contemporary Ethnographic Practice. Oxford: Berg Publishers, 2010.

Schneider, Arnd, and Christopher Wright. Contemporary Art and Anthropology. Oxford: Berg, 2006.

Smith, Neil. Uneven Development: Nature, Capital, and the Production of Space. New York, NY: Blackwell, 1984.

Rehding, Alexander. "Eco-Musicology." Journal of the Royal Musical Association 127(2) (2002): 305-320.

Taussig, Michael. Fieldwork Notebooks. Feldforschungsnotizbücher. Ostfildern: Hatje Cantz, 2011.

Titon, Jeff Todd. "Music and Sustainability," Special Edition of The World of Music, Vol. 51, no. 1 (2009)

Truax, Barry. Acoustic Communication. Westport, Conn: Ablex, 2001.

United States. The National Park Service Organic Act (16 U.S.C. 12 3, and 4)

United States. Wilderness Act. United States Statutes at Large. 1964.

United States. Management Policies.1988. 
United States. Management Policies 2006. Washington, D.C.: U.S. Government Printing Office, 2006.

Vucetich, John. Winter Study 2013: Notes from the Field. CreateSpace Independent Publishing Platform, 2013.

- Winter Study 2014: Notes from the Field. CreateSpace Independent Publishing Platform, 2014.

Winter Study 2015: Notes from the Field. CreateSpace Independent Publishing Platform, 2015.

Wockner, Gary L. Policy Conundrums in the National Parks: Nature, Culture, and the Wolves of Isle Royale. Dissertation. 1997. 